San Jose State University

SJSU ScholarWorks

Master's Theses

Master's Theses and Graduate Research

1998

\title{
Evaluation of airflow prediction methods in compact electronic enclosures
}

Rebecca Biswas

San Jose State University

Follow this and additional works at: https://scholarworks.sjsu.edu/etd_theses

\section{Recommended Citation}

Biswas, Rebecca, "Evaluation of airflow prediction methods in compact electronic enclosures" (1998).

Master's Theses. 1732.

DOI: https://doi.org/10.31979/etd.gatj-sa46

https://scholarworks.sjsu.edu/etd_theses/1732

This Thesis is brought to you for free and open access by the Master's Theses and Graduate Research at SJSU ScholarWorks. It has been accepted for inclusion in Master's Theses by an authorized administrator of SJSU ScholarWorks. For more information, please contact scholarworks@sjsu.edu. 


\section{INFORMATION TO USERS}

This manuscript has been reproduced from the microfilm master. UMI films the text directly from the original or copy submitted. Thus, some thesis and dissertation copies are in typewriter face, while others may be from any type of computer printer.

The quality of this reproduction is dependent upon the quality of the copy submitted. Broken or indistinct print, colored or poor quality illustrations and photographs, print bleedthrough, substandard margins, and improper alignment can adversely affect reproduction.

In the unlikely event that the author did not send UMI a complete manuscript and there are missing pages, these will be noted. Also, if unauthorized copyright material had to be removed, a note will indicate the deletion.

Oversize materials (e.g., maps, drawings, charts) are reproduced by sectioning the original, beginning at the upper left-hand corner and continuing from left to right in equal sections with small overlaps. Each original is also photographed in one exposure and is included in reduced form at the back of the book.

Photographs included in the original manuscript have been reproduced xerographically in this copy. Higher quality 6" $\times 9$ " black and white photographic prints are available for any photographs or illustrations appearing in this copy for an additional charge. Contact UMI directly to order.

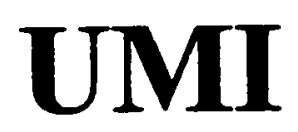

A Bell \& Howell Information Company 300 North Zeeb Road, Ann Arbor MI 48106-1346 USA 



\title{
EVALUATION OF AIRFLOW PREDICTION METHODS IN COMPACT ELECTRONIC ENCLOSURES
}

\begin{abstract}
A thesis
Presented to
\end{abstract}

The Faculty of the Department of Mechanical and Aerospace Engineering San Jose State University

\author{
In Partial Fulfillment \\ of the Requirements for the Degree \\ Master of Science
}

by

Rebecca Biswas

December 1998 
UMI Number: 1392797

Copyright 1999 by

Biswas, Rebecca

All rights reserved.

UMI Microform 1392797

Copyright 1999, by UMI Company. All rights reserved.

This microform edition is protected against unauthorized copying under Title 17, United States Code.

\section{UMI}

300 North Zeeb Road

Ann Arbor, MI 48103 
(ㄷ) 1999

Rebecca Biswas

ALL RIGHTS RESERVED 
APPROVED FOR THE DEPARTMENT OF MECHANICAL AND AEROSPACE ENGINEERING MSME PROGRAM

Dr. Raghu B. Agarwa

Project Advisor

Mechanical and Aerospace Engineering, SJSU

$\frac{\text { Aeny Permats }}{\text { Dr. Henry Jernicka }}$

Graduate Advisor

Mechanical and Aerospace Engineering, SJSU

Avijit Goswami

Dr. Avift Goswami

Consulting Engineer

Applied Thermal Technologies, Inc.

Vive Joe C

Executive Vice President and General Manager

Applied Thermal Technologies, Inc.

APPROVED FOR THE UNIVERSITY

Willian tiob 


\title{
ABSTRACT \\ EVALUATION OF AIRFLOW PREDICTION METHODS IN COMPACT ELECTRONIC ENCLOSURES
}

\author{
by Rebecca Biswas
}

As electronic systems continue to dissipate more power and become more compact, cooling is becoming more critical in the design process. Although there are many new cooling technologies on the horizon, air-cooling continues to be the most widely used method. Fan curves provided by the fan manufacturer are often used to predict the airflow in electronic enclosures. These fan curves are usually generated with no obstructions close to the fan. Most modern electronic systems contain densely packaged components including airflow obstructions such as inlet and outlet grills in close proximity to the fan. It is therefore possible that methods that use fan curves can often be inaccurate for predicting the airflow. Fan curves are used in computational fluid dynamics packages as well as with system impedance curves. The main objective of this study is to understand the accuracy of different methods of airflow prediction that rely on pressure loss and fan curve data when compared to experimental results obtained in a wind tunnel. The results obtained from different approaches are compared and validated in order to justify their use. 


\section{ACKNOWLEDGEMENTS}

I express my deep sense of gratitude to all those people, from both Applied Thermal Technologies, Inc. and San Jose State University who contributed to the completion of my thesis work. In particular, I wish to express my appreciation to Dr. Vivek Mansingh and Dr. Avijit Goswami for suggesting the problem for my MS thesis and clearing my doubts as well as supervising the work with invaluable suggestions. I would also like to express my appreciation to Prof. Raghu B. Agarwal for his consistent feedback and encouragement. I am particularly indebted to them for the countless inspiration and informative hours they have spent with me, which has helped me in developing a broad perspective.

My special thanks to friends in the Applied Thermal Technologies, personal friends and to my family for their kind help, encouragement and company throughout my project work. At last I would like to thank my husband for his love, care, patience and immense support throughout. 


\section{Table of Contents}

CHAPTER 1 INTRODUCTION .........................................................................1

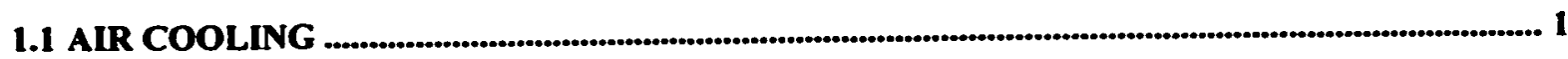

1.2 RELATED STUDIES.

1.3 PRESENT APPROACH

CHAPTER 2 AIRFLOW PREDICTION METHODS ........................................10

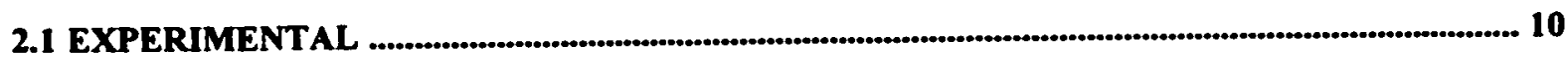

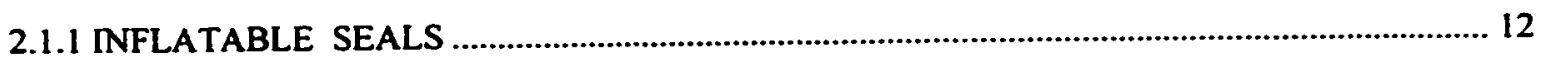

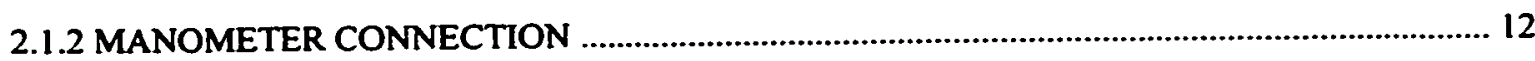

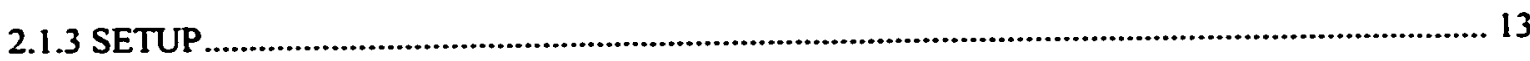

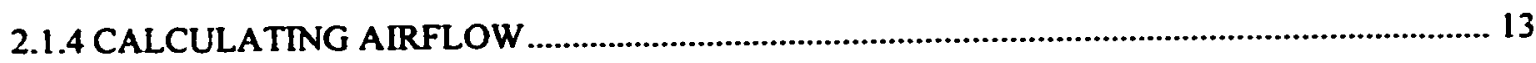

2.2 MATCHING FAN TO SYSTEM

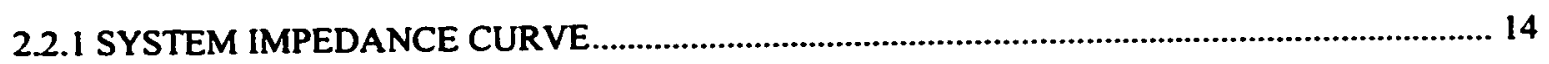

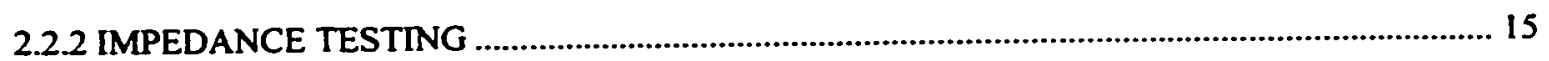

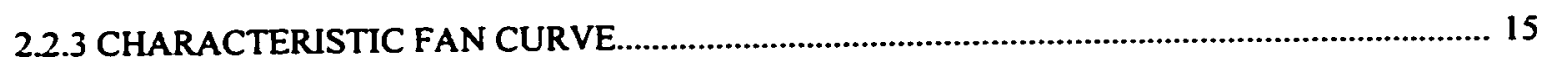

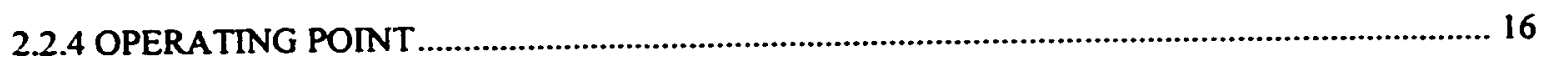

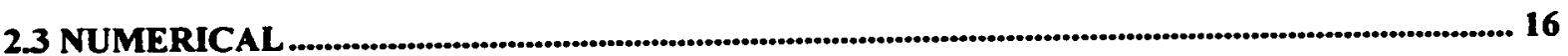

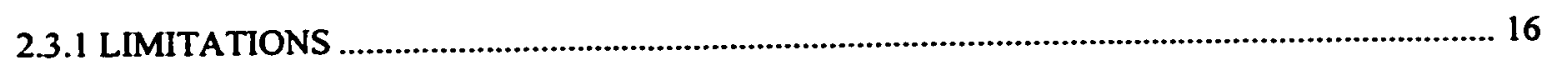

2.3.2 COMPUTATIONAL MODELING WITH ICEPAK ................................................................... 17

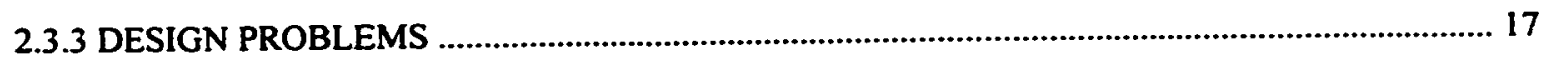

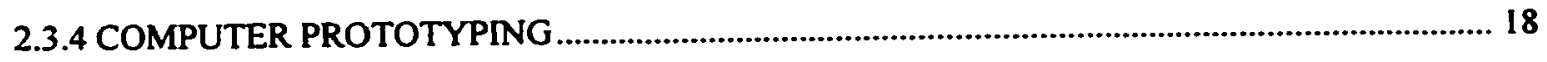

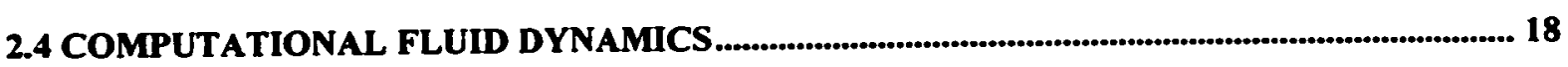

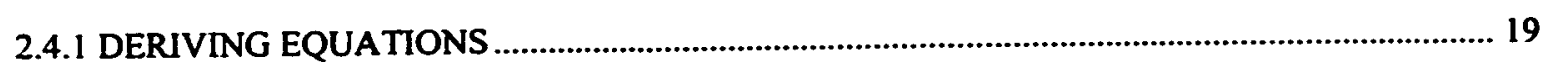

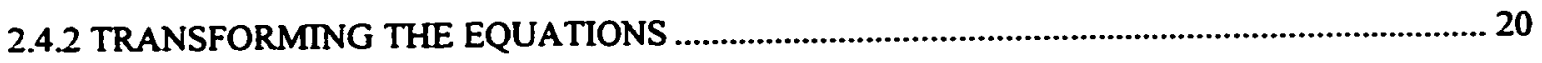

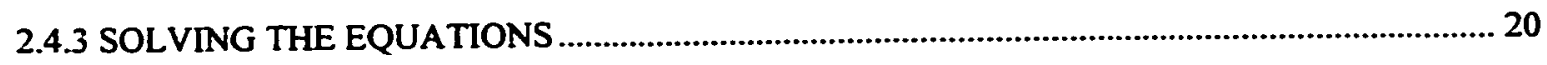

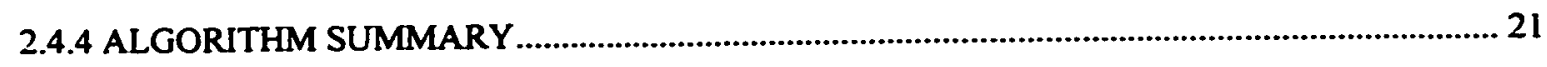

CHAPTER 3 MODELING AND SIMULATION ..............................................23 
3.1 PHYSICAL MODEL

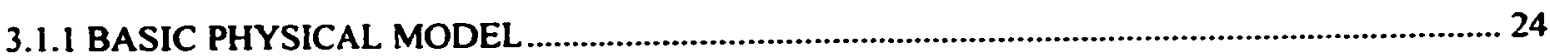

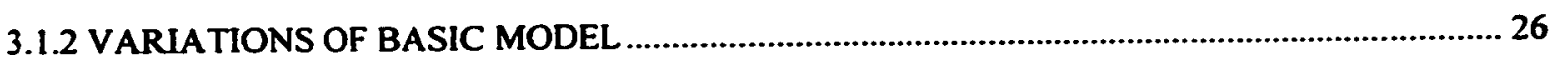

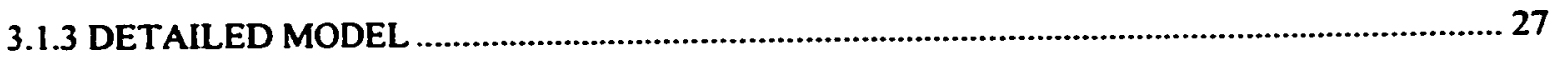

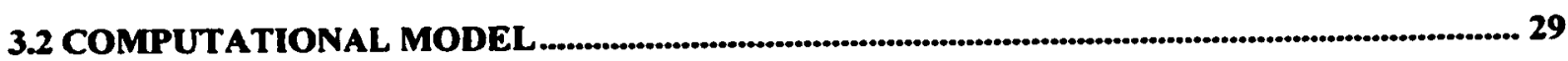

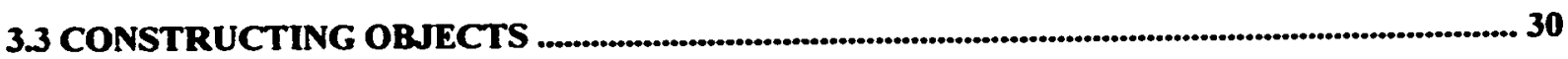

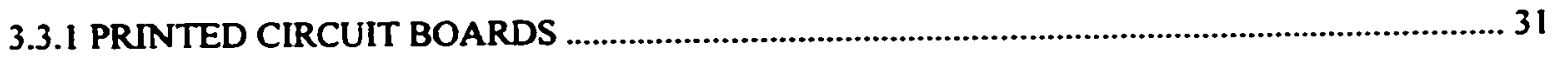

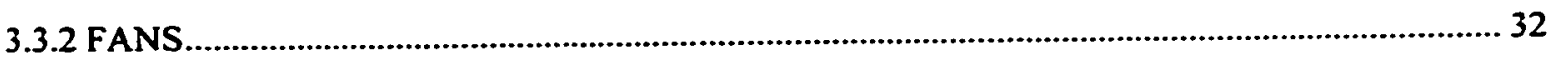

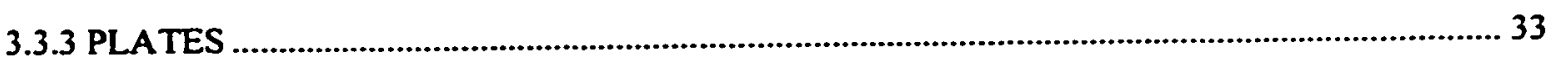

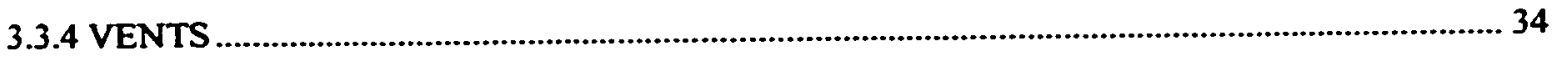

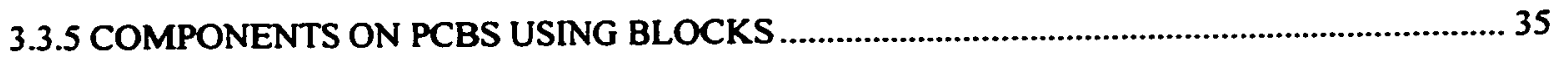

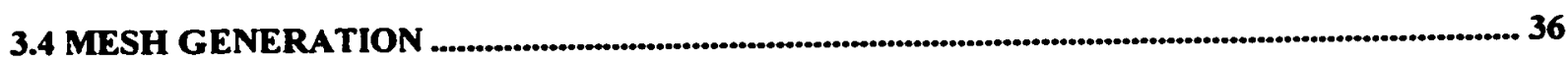

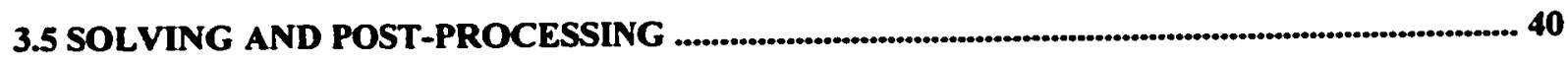

3.6 CALCULATING PRESSURE LOSS COEFFICIENT .............................................................. 41

3.7 PROBLEMS ENCOUNTERED DURING SIMULATION ........................................................ 42

CHAPTER 4 COMPARISON OF DIFFERENT TECHNIQUES ......................44

4.1 BASIC MODEL WITH 60MM FAN AND 33\% OPEN AREA GRILLS ..................................... 44

4.2 BASIC MODEL WITH 60MM FAN AND 23\% OPEN AREA GRILLS ...................................... 45

4.3 BASIC MODEL WITH 60MM FAN AND 40\% OPEN AREA GRILLS ..................................... 47

4.4 BASIC MODEL WITH 80MM FAN ........................................................................................... 49

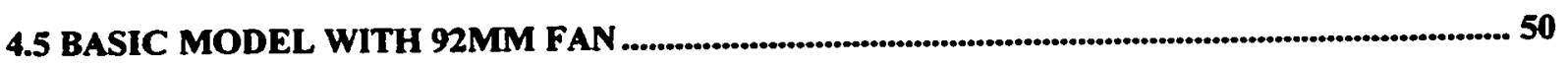

4.6 BASIC MODEL WITH 60MM FANS IN SERIES ..................................................................... 52

4.7 BASIC MODEL WITH 6OMM FANS IN PARALLEL .............................................................. 53

4.8 DETAILED MODEL WITH 60MM FAN .................................................................................... 54 


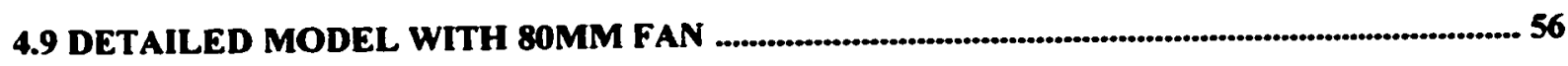

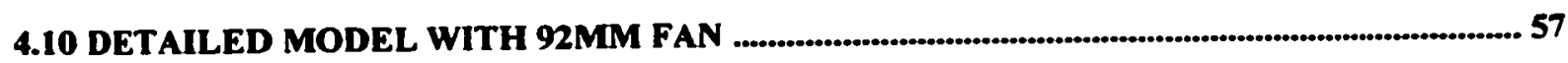

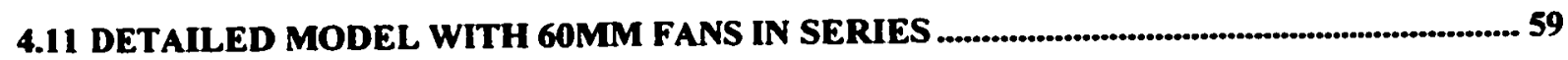

4.12 DETAILED MODEL WITH 60MM FANS IN PARALLEL .................................................. 60

4.13 RESULTS AND DISCUSSION

CHAPTER 5 CONCLUSIONS ....................................................................68

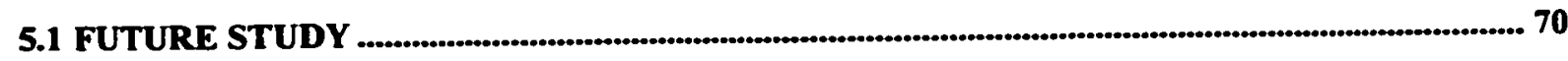

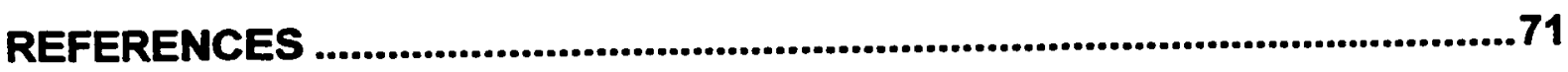

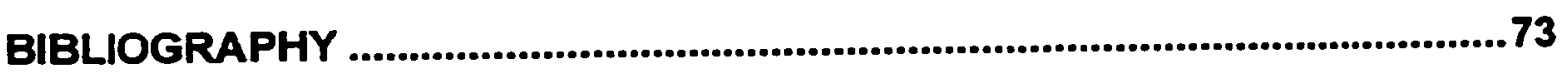




\section{List of Figures}

FIGURE 2.1: WIND TUNNEL

FIGURE 3.1: PHYSICAL MODEL OF THE ENCLOSURE FROM OUTSIDE

FIGURE 3.2: INSIDE THE BASIC MODEL

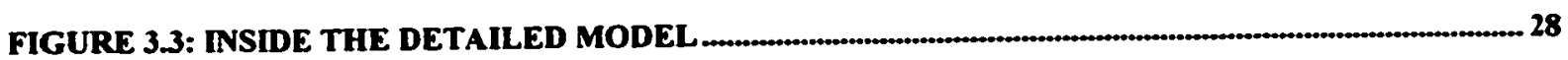

FIGURE 3.4: BASIC MODEL CONSTRUCTED USING ICEPAK WITH 6OMM FAN .................................... 30

FIGURE 3.5: BASIC MODEL WITH FANS IN PARALLEL .

FIGURE 3.6: BASIC MODEL WITH FANS IN SERIES.

FIGURE 3.7: DETAILED MODEL USING ICEPAK WITH 60MM FAN

FIGURE 3.8: DETAILED MODEL USING ICEPAK WITH 6OMM FANS IN PARALLEL ......................... 34

FIGURE 3.9: DETAILED MODEL USING ICEPAK WITH 6OMM FANS IN SERIES ....................................... 35

FIGURE 3.10: MESH GENERATION FOR THE BASIC MODEL (+Y DIRECTION) ..............................

FIGURE 3.11: MESH GENERATION FOR THE BASIC MODEL (+X DIRECTION) ................................. 38

FIGURE 3.12: MESH GENERATION FOR THE DETAILED MODEL (+Y DIRECTION) .............................. 39

FIGURE 4.1: FAN-SYSTEM PERFORMANCE CURVES OF BASIC MODEL (33\% OPENING) .....................44

FIGURE 4.2: VELOCITY PROFILES OF THE BASIC MODEL (33\% OPENING) .

FIGURE 4.3: FAN-SYSTEM PERFORMANCE CURVES OF BASIC MODEL (23\% OPENING) .................... 46

FIGURE 4.4: VELOCITY PROFILES OF THE BASIC MODEL (23\% OPENING; + Y AXIS) ............................ 47

FIGURE 4.5: FAN-SYSTEM PERFORMANCE CURVES OF BASIC MODEL (40\% OPENING) ...................48

FIGURE 4.6: VELOCITY PROFILES OF THE BASIC MODEL (40\% OPENING; + Y AXIS) ........................... 48

FIGURE 4.7: FAN-SYSTEM PERFORMANCE CURVES WITH 8OMM FAN (BASIC MODEL) ....................... 49

FIGURE 4.8: VELOCITY PROFILES OF THE BASIC MODEL WITH 80MM FAN ........................................ 50

FIGURE 4.9: FAN-SYSTEM PERFORMANCE CURVES WITH 92MM FAN (BASIC MODEL) ......................51

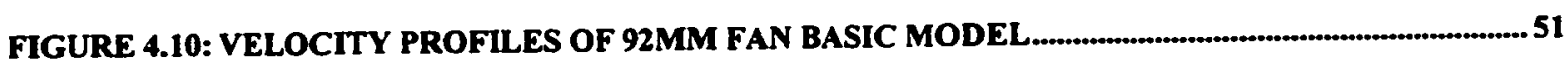

FIGURE 4.11: FAN-SYSTEM PERFORMANCE CURVES WITH FANS IN SERIES (BASIC MODEL) .........52

FIGURE 4.12: VELOCITY PROFILES OF THE BASIC MODEL WITH FANS IN SERIES (+Y AXIS) ..........53

FIGURE 4.13: FAN-SYSTEM PERFORMANCE CURVES WITH FANS IN PARALLEL (BM) ........................54 
FIGURE 4.14: FAN-SYSTEM PERFORMANCE CURVES OF GOMM FAN (DETAILED MODEL) 55

FTGURE 4.15: VELOCITY PROFILES OF DETAILED MODEL (60MM FAN)

FIGURE 4.16: FAN_SYSTEM PERFORMANCE CURVES OF 80MM FAN (DETAILED MODEL) ............56

FIGURE 4.17: VELOCITY PROFILES OF DETAILED MODEL WITH 8OMM FAN ..................................5 57

FIGURE 4.18: FAN-SYSTEM PERFORMANCE CURVES OF 92MM FAN (DETAILED MODEL) ............58

FIGURE 4.19: VELOCITY PROFILES OF 92MM FAN (DETAILED MODEL) $\ldots \ldots \ldots \ldots$

FIGURE 4.20: FAN-SYSTEM PERFORMANCE CURVES WITH FANS IN SERIES (D. MODEL) .............59

FIGURE 4.21: VELOCITY PROFILES OF FANS IN SERIES (DETAILED MODEL) ..................................... 60

FIGURE 4.22: FAN-SYSTEM PERFORMANCE CURVES WITH FANS IN PARALLEL (D. MODEL)........ 61

FIGURE 4.23: COMPARISON OF AIRFLOW WITH PERCENT OPEN AREA OF GRILL...................... 62

FIGURE 4.24: PERCENTAGE ERROR IN AIRFLOW VERSUS PERCENT OPEN AREA OF GRILL......... 62

FIGURE 4.25: COMPARISON OF AIRFLOW WITH CHANGE IN FAN SIZE (BASIC MODEL)................ 63

FIGURE 4.26: PERCENTAGE ERROR IN AIRFLOW VERSUS FAN SIZE (BASIC MODEL)

FIGURE 4.27: COMPARISON OF AIRFLOW WITH CHANGE IN FAN SIZE (DETAILED MODEL) ........ 64

FIGURE 4.28: PERCENTAGE ERROR IN AIRFLOW VERSUS FAN SIZE (DETAILED MODEL)

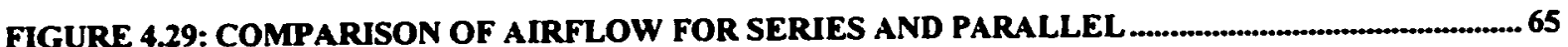

FIGURE 4.30: PERCENTAGE ERROR IN AIRFLOW WITH FANS IN SERIES AND PARALLEL ........... 66

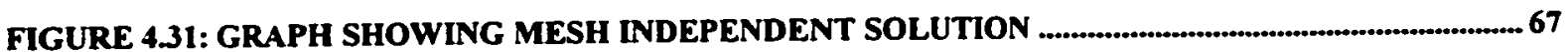




\section{Nomenclature}

\section{Letter symbols}

V/O input / output

W/in ${ }^{2} \quad$ unit of power density - watt per square inch

2-D two dimensional

3-D three dimensional

psi unit of pressure - pounds per square inch

$\mathrm{CFM} / \mathrm{cfm}$ unit of air flow - cubic feet per minute

$\mathrm{kg} / \mathrm{sec} \quad$ unit of mass flow - kilogram/sec

$\mathrm{x}, \mathrm{y}, \mathrm{z} \quad$ three axis in $\mathrm{x}, \mathrm{y}$ and $\mathrm{z}$ direction

T temperature

p pressure

u velocity in $\mathrm{x}$-direction

$v \quad$ velocity in $y$-direction

w velocity in $\mathrm{z}$-direction

mm sq. unit of area - square millimeter

in. sq. unit of area - square inch

cm. sq. unit of area - square centimeter

$\operatorname{Re} \quad$ Reynolds number

$\mathrm{Pe} \quad$ Peclet number

$\mathrm{Ra} \quad$ Rayleigh number

Pr Prandtl number

$\zeta \quad$ pressure loss coefficient 
static pressure (Pascal)

$\rho$ density of fluid $\left(\mathrm{kg} / \mathrm{m}^{3}\right)$

$\omega_{\mathrm{o}}$

velocity $(\mathrm{m} / \mathrm{s})$ 


\section{Chapter 1}

\section{Introduction}

In order to achieve improved performance in data processing equipment, trends in electronic package designs have moved towards larger circuit chips, higher $\mathrm{L} / \mathrm{O}$, increased circuit density, and improved reliability. Increasing chip size, I/O and current density can improve performance because it reduces the electrical line lengths thereby reducing the signal flow times. Greater circuit density means more power density $\left(W / \mathrm{in}^{2}\right)$. Power density has increased exponentially with time over the past 15 years and it is assumed that it will continue to increase in the near future. With microelectronic technology steadily packing more chip power into smaller packages, cooling issues are becoming the bottleneck to further size reductions or power enhancement. Time to market with new products has also become an important issue. Reliability at all levels of packaging is directly related to operating temperature. Higher operating temperatures accelerate various failure mechanisms such as creep, corrosion, and electromigration. It is increasingly important to be able to predict the cooling performance of electronic enclosure layouts early in the design cycle, when modifications to improve heat transfer are relatively fast and implementations are inexpensive.

\subsection{Air Cooling}

Although there are many new cooling technologies on the horizon, air-cooling continues to be the most widely used method. The abundance of air in the atmosphere makes it the prime coolant for electronic equipment. It is easily available, and has heat transfer 
properties that permit its use in a variety of applications. Air-cooling is the most widely used approach in the thermal management of electronic equipment. Air-cooling is cost effective, causes very little environmental impact, and imposes very little or no special requirements upon the user of the equipment as compared to liquid cooling.

In the event, that thermal requirements cannot be met using the preferred natural convection technique, forced convection with air is often the choice. Most modern electronic systems containing densely packaged components use fans or blowers for forced air-cooling. Designing forced convection electronic systems requires one or more reliable ways to predict the airflow and pressure drop characteristics of the system. Obstructions in the airflow path, such as PC Boards, inlet and outlet grills, etc. cause pressure losses thereby reducing the total airflow in the enclosure. Determining the airflow produced by a fan using analytical methods is usually very difficult and inaccurate. Traditionally, this has been done using wind tunnel tests, which although very accurate, can be costly, time consuming and cumbersome. New computational fluid dynamics (CFD) tools are becoming increasingly popular due to their ease of use. These tools are being increasingly used to thermally analyze and optimize the system during the design process.

\subsection{Related Studies}

Linton and Agonafar [1] (1989) used a CFD program to model the flow through a Personal computer. The model yielded qualitatively accurate flow paths. However, the investigators had to adjust the value of air viscosity away from the actual to arrive at an accurate pressure drop through the enclosures. They suggest a method of iteration using a 
fan manufacturer's performance curve (flow versus static pressure) to determine the operating point of the enclosure under study.

Mansingh and Misegades [2] (1990) used an iterative technique with another CFD program to determine the operating flow and pressure drop through a computer system processing unit. Numerically stimulated particle traces were recorded using video equipment. The particle traces showed some extremely interesting flow characteristics. Although they reported good agreement between measured and calculated pressures, the process required twelve iterations to reach a flow value within $\pm 10 \%$ of actual. This requires ten hours of run time on a Cray Y-MP supercomputer. Additionally, 1.5 manmonths were invested in creating the computer model. The authors indicated that qualitatively accurate flow paths were calculated.

Since the fan performance curves are determined without any significant inlet and outlet flow disturbances, in most cases dependence on a fan manufacturer's performance curves will yield calculated flows higher than actual flows and thus a serious problem is inherent in these approaches to modeling enclosure flow. Most real fan applications have some type of disturbance such as filters or bulkheads in close proximity to the fan. Hill and Hill [3] (1990) studied the effect of reduced plenum size on small, axial flow fan performance. Significant performance effects were noted with plenum depths as large as one-half the fan diameter.

Deiters and Hill [4] (1991) attempted a comparison of test versus analysis using FloTHERM and a typical electronic enclosure used in industry. This particular study did not yield a satisfactory agreement because measurements were made and related to 
analytic predictions close to the exhaust of the fan where airflow is very turbulent and simplified axial flow assumptions were not valid. However, Deiters and Hill did demonstrate the critical need to have an accurate measurement of the volume flow rate to be used as an input condition to the analytic method.

Gopalakrihna [5] (1991) studied the use of FloTHERM to predict the component temperature of the finned heat sinks. Very good agreement between model predictions and test data was achieved. However, the velocities for the problem were well defined and fully developed, but no fan effects were at issue in this analysis. Agonafer and Moffat [6] (1990) used the CFD tool PHOENICS to model fully developed flow between two flat plates with block simulating electronic components obstructing the flow along one plate. Comparisons were made between published experimental data and analytical results, and an agreement within $8 \%$ on the film coefficient was achieved. The authors found that the solution accuracy was improved to a point by refining the grid but that refinement beyond a particular point produced poorer results. It was discovered that when the grid cells became small enough near the wall the predicted flow regime erroneously switched from turbulent to laminar.

Attempts to establish guidelines for making efficient and accurate CFD models for aircooled electronic enclosures were studied by Deiter and Hill [7] (1992). They found the correlation of static pressures was better in the pressurized case than in the evacuated case. However the agreement to either the pressurizing or evacuating cases could be improved with adjustment of the loss coefficient. Velocity agreement was much better between test and analysis when the blocking effect of the fan hub was included. 
The field of computational fluid dynamics is well described in the literature and several researchers have applied these techniques to electronics cooling applications. Most of these studies are models of laminar flow and don't present extensive comparisons to experimental data. Among these studies, Schmidt and Patankar [8] (1986) presented results of their study of laminar forced convection cooling of arrays of heated rectangular blocks. Davalath and Bayazitoglu [9] (1987) presented conjugate heat transfer results for 2D laminar flow over an array of rectangular blocks, and Oosthuizien [10] (1988) presented computational results for $2 \mathrm{D}$ laminar forced convection over two identical heated blocks.

Asako and Faghri [11] (1988), [12] (1989) and [13] (1991) presented numerical results for fully three dimensional flow over an array of rectangular blocks. They investigated laminar flow with a constant temperature boundary condition [11] (1988), laminar flow with a constant heat flux boundary condition [12] (1989) and turbulent flow [13] (1991). Their computational models are developed for periodic fully developed flow and heat transfer.

Anderson [14] (1993) presents comparisons between computational and experimental results for heat transfer and fluid flow from an array of heated blocks. Data for the adiabatic heat transfer coefficient, the superposition kernel function, and the channel pressure drop are compared. Although computational results for heat transfer coefficient almost matched with the experimental data, the superposition kernel function shifted up as much as $50 \%$ which indicates that the computational model under-predicts the amount of cross channel mixing and computational results for pressure drop matched within $20 \%$ on average. 
The resistance to heat flow from finned LSI packages to the cooling airflow has been studied by Ashiwake, Nakayama, Kobayashi, and Daikoku [15] (1983) date by combining the physical models with the results of heat transfer experiments, flow visualization experiments and pressure drop experiments. Although crude assumptions were employed in analytical modeling, the proposed method of heat transfer and pressure drop was proved to serve the task of cooling system designers.

Sriskanda and Morehouse [16] (1993) utilized the flow resistance model to determine the flow inside an air-cooled business size computer. The development of the model was approached in three steps. First they determined the flow directions and flow elements of the computer as best possible. Then the individual flow element resistance was determined analytically or experimentally and finally the resistive network model is constructed and then modified to examine flow situations. This study does not claim to have developed something new with flow resistance modeling, but several lessons were learned, which might be of use to other practitioners.

Ma and Recktenwald [17] (1993) predict the convective heat transfer from an array of heated blocks that simulate electronic devices with a simplified numerical method. While solving the three dimensional momentum and continuity equations for the fluid, simple assumptions for the fluid velocity profile are used to construct the convection diffusion coefficients that appear in the discrete form of the energy equation. Unfortunately, since the quantitative accuracy of the model depends on the assumed shape of the velocity profile, the model is not yet capable of being used as a universal design tool. 
The study done so far doesn't deal with the comparison of the experimental, numerical and matching the fan to the system methods for fluid flow in a typical computer chassis.

\subsection{Present Approach}

Fan curves provided by the fan manufacturer are often used to predict the airflow in electronic enclosures. These fan curves, which show the air delivery capacity of the fan at various pressure drops, are usually generated with no obstructions close to the fan. Most modem electronic systems contain densely packaged components including airflow obstructions such as inlet and outlet grills in close proximity to the fan. It is therefore possible that methods that use fan curves can often be inaccurate for predicting the airflow. Fan curves are used in computational fluid dynamics packages as well as with system impedance curves. The main objective of this study is to compare the airflow predicted by different methods with that obtained experimentally using a wind tunnel.

The following airflow prediction methods were compared:

1. Computational Fluid Dynamics 1 (CFD-1): In this method, the pressure loss coefficient of the inlet and outlet grills used in the CFD model is found from a data handbook.

2. Computational Fluid Dynamics 2 (CFD-2): In this method the pressure loss coefficient of the inlet and outlet grills used in the CFD model is found using wind tunnel tests. 
3. Matching the Fan to the System: In this method, the system impedance curve is first created by measuring the pressure drop across the box using a wind tunnel for different airflow. The airflow through the system is found from the intersection of the system impedance curve and the manufacturer's fan curve.

4. Experimental (Baseline): In this method, the actual airflow through the system was measured using a wind tunnel. The test chamber is designed in accordance with AMCA 210-85 and is used for measuring fan performance and system pressure drop testing. Since this method is independent of the fan curve, it was chosen as the baseline for comparing methods 1,2 and 3 .

The details of the airflow prediction methods are discussed in Chapter 2.

The basic system used in this study is chosen to be representative of typical electronic systems. However, the model is highly simplified to include only the major components such as fans, inlet and outlet grills and an array of stacked printed circuit boards (PCB). A test mockup was built with the outer wall fabricated from plywood and the internal dimensions of the enclosure were $29 \times 16 \times 14 \mathrm{~cm}$. An off-the-shelf $60 \times 25 \mathrm{~mm}$ fan was selected to pressurize the system. The inlet grill was intentionally placed in close proximity to the fan inlet (offset by $1 \mathrm{~cm}$ from the fan) in order to study the effect of close proximity of the grill to the fan.

A computational fluid dynamics (CFD) model of the system was also created using a software package called ICEPAK. It included all the major airflow blockages such as printed circuit boards, inlet and outlet grills, fans, etc. The fan was modeled using the fan 
curve data obtained from the manufacturer. The inlet and outlet grills were modeled by specifying the pressure loss coefficient. The basic conservation equations for mass, momentum and energy (Navier-Stokes) are solved numerically using the finite volume method. The total airflow is calculated from the velocity field obtained as part of the CFD solution.

After the study was done with the basic model, a detailed model was fabricated by including capacitors, inductors, heat sinks etc. The model was made denser to create more pressure drop across the system.

Using the basic and detailed model described above, three different variations were studied:

1. The percentage open area of the inlet and outlet grills was varied from $20 \%$ to $40 \%$.

2. The fan size was varied from a diameter of $60 \mathrm{~mm}$ up to $92 \mathrm{~mm}$.

3. Two fans were used in series and parallel configurations.

Finally, the solutions obtained by using CFD techniques were checked for mesh independence. 


\section{Chapter 2}

\section{Airflow Prediction Methods}

Traditionally, both experimental and theoretical methods have been used to develop designs involving fluid flow and heat transfer. With the advent of the digital computer, a third method, the numerical approach, has become available. Although experimentation continues to be important, especially when the flows involved are very complex, the trend is clearly toward greater reliance on computer based predictions in design because of the cost effectiveness. Designing forced convection electronic systems requires one or more reliable ways to predict the airflow and pressure drop characteristics of the system. To predict airflow and pressure drop characteristics, three different methods were used:

\section{Experimental}

2. Matching the Fan to the System

3. Numerical (CFD)

\subsection{Experimental}

The air flow and pressure drop are measured using a wind tunnel (as shown in Figure 2.1). The test chamber is designed in accordance with AMCA $210-85$ and is used for measuring fan performance and system pressure drop testing. The chamber is designed with multiple nozzles to cover the airflow range of the design. The cross-sectional area of the chamber should be approximately 16 times the cross-sectional area of the axial fan under test. 


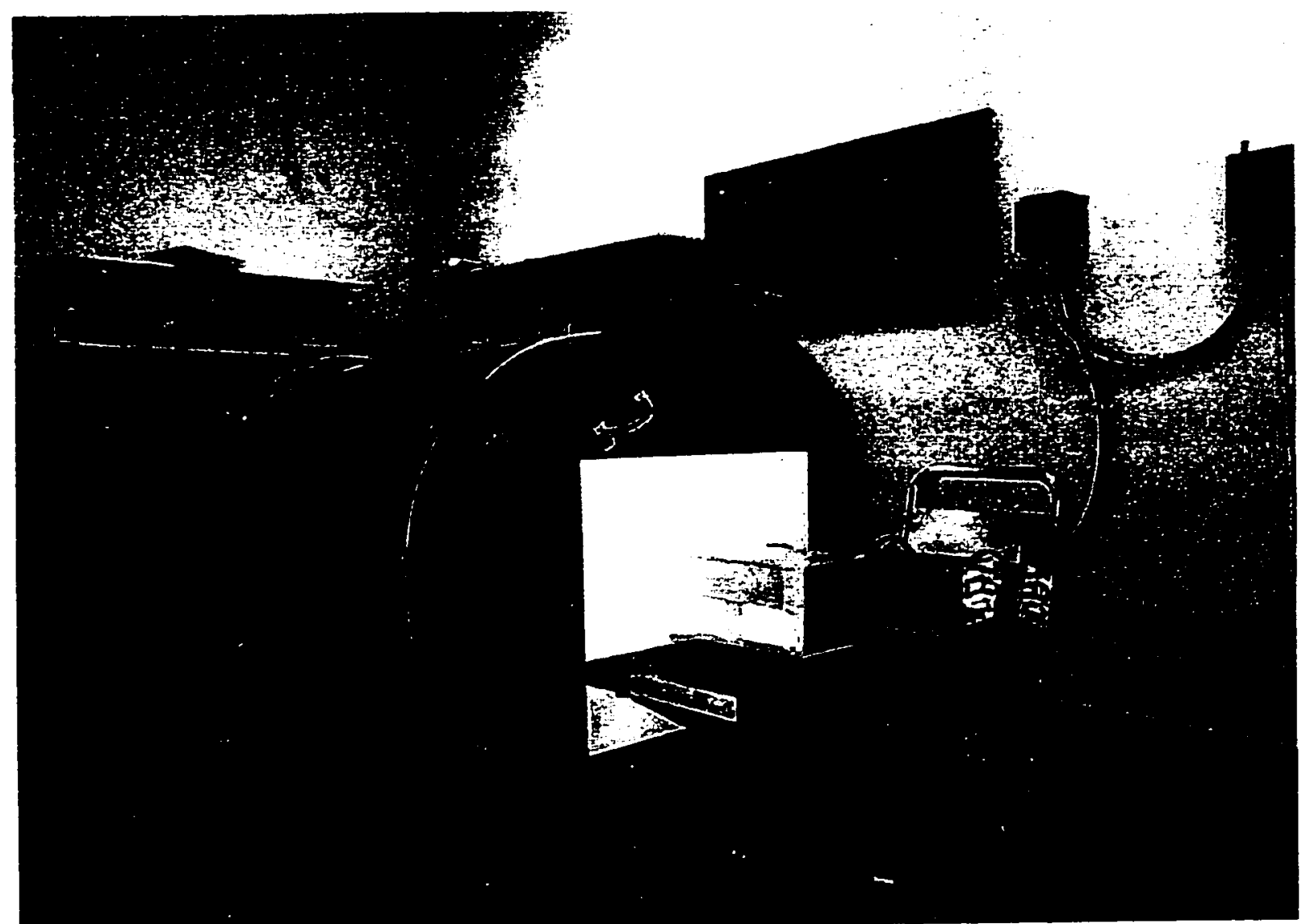

Figure 2.1: Wind Tunnel

The chamber is constructed with pressure taps on each side of the nozzle to measure differential pressure and with another pressure tap near the front plate to measure static pressure. In all cases, the static pressure will be a differential pressure between atmospheric and the pressure in the chamber. Therefore, if a fan has airflow into the chamber, the static pressure represents a pressure rise across the fan. In an impedance test, the pressure in the chamber is negative and the static pressure represents the pressure drop across the system under test. 
The nozzle array is selected so that the full range of flow may be covered with a minimum differential pressure of 0.1 inches and maximum of 4.0 inches of water. The lower limit is a result of Reynolds Number and fully turbulent flow for accuracy. The blast gate is essentially a sliding gate valve that is used to vary the amount of air through the chamber.

The front plate is on one end of the chamber and the blast gate is on the other end. The airflow is always in the same direction with respect to the nozzles. The nozzles face downstream with flow going from the larger diameter towards the smaller diameter. There are four static pressure pick ups. The two at the nozzle plate are used for differential pressure across the nozzle, to determine airflow. The taps at each end are used for static pressure.

\subsubsection{Inflatable Seals}

The chambers with inflatable seals have seals on each side of the nozzle plate and a seal around the front plate. The hose connections are connected to a manifold on the side of the chamber that is used for inflating and deflating the seals. The air is supplied with the small compressor. The air regulator must be set at a maximum of 30 PSIG. The valve is closed on the manifold and the system is air tight. The compressor is turned on and the pressure in the seals is to increase to $30 \mathrm{psig}$.

\subsubsection{Manometer Connections}

The level should be checked periodically to verify the manometers are leveled. The zero point should be checked before each test. If the liquid is not at zero, the scale may be 
moved by loosening the thumb nuts holding the scale on the bottom of the manometer. If the scale does not adjust adequately, additional fluid may be required. The manometers are provided with cork floats that will shut off if excessive pressure is applied to the manometer and prevent liquid from entering the connecting hoses. The manometers are also provided with shut off valves for transporting the manometers. If pressure is applied to the manometer and the liquid does not move, one has to check to verify the hose connection ports are open and the cork float is not stuck. This can be checked by connecting a short piece of tubing to each port and gently blow into the tubing.

\subsubsection{Set-Up}

The set-up of the test is critical in obtaining accurate results. The flow range of the fan will determine the proper nozzle selection. The nozzle should be selected such that a majority of test can be conducted without changing nozzles. In order to obtain better accuracy, differential pressure should be at least in the 1.5 inches of water range at free delivery. In addition, other nozzles are to be checked to verify they are securely plugged. In most tests, the differential pressure may be measured with the manometer, which has a range of 0-6 inches of water. The static pressure may be measured with either $0-1$ or $0-4$ inches of water. The fan to be tested should be mounted on the front plate and sealed to prevent leakage. The fan should be energized and the manometers monitored to verify they are connected properly.

\subsubsection{Calculating Airflow}

The airflow of the fan can be found by the following steps: 
1. Put on the power supply of the fan. The fan should be allowed to stabilize (approximately 20 to 30 seconds).

2. Bring the static pressure of the system to zero which is referred to as free delivery and represents a fan in open space with zero pressure rise across the fan.

3. Find out the differential pressure across the nozzle, which is inside the chamber (in inches of water).

4. Find the appropriate graph from the user manual, which will match with the nozzle selection.

5. The $X$ and the $Y$-axis of the graph represents airflow in CFM and differential pressure in inches of water respectively. With the help of the graph, the corresponding airflow in CFM can be determined.

\subsection{Matching the Fan to the System}

To tackle a problem in this approach, many simplifying assumptions are made. In this approach, airflow is determined using fan performance curves provided by the manufacturer. This involves generating a system impedance curve, showing the pressure drop variation with mass flow, and using wind tunnel tests.

\subsubsection{The System Impedance Curve}

The system impedance curve is determined from the individual pressure losses in the system. It cannot be accurately established until a test is run on the equipment and its air distribution system. The total pressure loss is then plotted as the ordinate against the airflow, usually in CFM, as the abscissa. 
The curve obtained is usually parabolic in shape. However, contrary to the positive statement made in many references, this curve is not necessarily a parabola of the form $y=a x^{2}$. The reason for this is that the friction factor decreases as velocity increases, the friction loss is not a function of square of the velocity. Some studies shows that the system impedance curve is of approximate form $y=a x^{1.85}$.

\subsubsection{Impedance Testing}

The impedance test is used to measure the resistance to flow in a given system. The system to be measured should be connected to the chamber so that the direction of airflow is the same as the proposed design of the system. The system offers a resistance to airflow and the pressure drops across the system. The static pressure and differential pressure, both must be monitored. The minimum differential pressure is 0.1 inches of water and the static pressure must be readable. When the flow at 0.1 inches differential pressure is not adequate to obtain a static pressure reading, airflow through the chamber is continuously increased, until a static pressure reading is obtainable. Monitor the static pressure and differential pressure so the data covers the intended flow range for the system. Normally, five to six data points are adequate for plotting the system resistance curve.

\subsubsection{Characteristic Fan Curves}

The performance of the fan is adequately represented by a group of curves known as characteristic curves. These sets of curves are provided by fan manufacturers to assist 
engineers in fan selection. The characteristic fan curve used in the analytical analysis indicates how the static pressure varies with the volumetric airflow of the fan.

\subsubsection{Operating Point}

The fan operating in the system must have its characteristic curve. which is provided by the fan manufacturer. The system impedance curve is superimposed on the fan curve. The system operating point is found at the intersection of both the curves.

\subsection{Numerical}

A limited number of assumptions are made and a high-speed digital computer is used to solve the resulting governing fluid dynamic equations. A computer simulation is free of some constraints imposed on the experimental method for obtaining information upon which to base a design. Experimental testing is to evaluate the performance of a relatively inexpensive small-scale version of the prototype device. In performing such tests, it is not always possible to simulate the true operating conditions of the prototype. The relative cost of computing has decreased by almost three orders of magnitude during the past 20 years. Many believe that wind tunnels will someday play a secondary role to the computer. Even in today's world most of the industries are relying on computers rather than wind tunnels because of the cost effectiveness.

\subsubsection{Limitations}

Computational methods also have some shortcomings. Among these are the computer storage and speed. Error in the computational methods also occurs due to truncation. 
Other limitations arise due to our inability to understand and mathematically model certain complex phenomena. None of these limitations of the computational methods are insurmountable in principle and current trends show reason for optimism about the role of the computational model in the future.

\subsubsection{Computational Modeling with ICEPAK}

Computer modeling of the system is done using a computational fluid dynamics package called ICEPAK. ICEPAK is a software package specifically designed to analyze the flow and thermal distribution in enclosed space, particularly those containing electronic components. According to the philosophy underlying the development of ICEPAK, it was to create a program, which would help the design engineer create, test and refine new designs and update, revise or improve old designs.

\subsubsection{Design Problems}

The design engineer faces specific problems, which, without computer modeling and simulation, are difficult, time-consuming, costly and sometimes impossible to solve. Most common problems are:

1. Reducing enclosure sizes.

2. Increasing component density

3. Meeting noise constraints

4. Locating hot spots

5. Optimizing fan and vent locations 


\subsubsection{Computer Prototyping}

The contemporary alternative to physical prototyping is computer prototyping, which while in use for the past decade has achieved its current level of sophistication during the last few years. Computer prototyping involves building a computer model that reflects the design to be studied as accurately as possible. In addition to the exact dimensional specifications of all parts of the design, a computer model also encompasses all the physical characteristics associated with each individual part. For example, a model containing a printed circuit board would have built into it, not only the size, dimensions and placement of the PCB in the cabinet, but also specifications about the board itself, including roughness, heights, numbers of components, and heat dissipation for individual components and for the board overall.

An accurate computer model also works, just like the physical prototype, but its engine is mathematical rather than physical. When a computer model is made to work, that process is called a computer simulation. It involves solving the set of partial differential equations that exactly describes the physics of the model.

\subsection{Computational Fluid Dynamics}

The foundation of a thermal/fluid flow simulation package is an analytic methodology known as "computational fluid dynamics" (CFD). CFD simulates heat transfer and fluid flow mathematically by solving a set of coupled non-linear, second order, partial differential equations. No general analytic solution exists for a set of such equations. 
Rather, the solution must be sought numerically, using techniques, which have been under development for the past two decades.

Simulating fluid flow involves three steps: deriving a set of mathematical equations that describe the physics of the problem, transforming the equations into a discrete set of equations and solving the discretized set of equations. Each of them is presented below.

\subsubsection{Deriving Equations}

The first step in the process involves defining the problem mathematically. ICEPAK utilizes the Navier-Strokes equations to describe fluid flow and the energy equation to describe the temperature distribution. These equations characterize all aspects of fluid flow (laminar and turbulent) in complete detail.

ICEPAK solves for the five variables: $u, v$ and $w$, which are the $x, y$ and $z$ components of the velocity, respectively; the pressure, $p$; and the temperature, $T$ of the fluid or solid materials. All these variables are functions of $x, y, z$ and time. The differential equations satisfied by these five variables are known as conservation equations, which are conservation of mass, conservation of momentum and conservation of energy.

In defining the problem to be solved, three additional specifications are needed: the threedimensional region within which the differential equations are to be solved, appropriate boundary conditions, and the properties of the fluid, including specific heat, density, viscosity, etc. 


\subsubsection{Transforming the Equations}

The equations for fluid flow are highly nonlinear and cannot be solved analytically. Due to this, a discretized solution at a finite number of points in the flow domain must be sought. ICEPAK derives the equations for the discretized model using a highly accurate computational engine based on the Finite Volume Method. The Finite Volume Method can represent a body whose geometry is arbitrarily complex, and to apply the boundary conditions exactly. The use of the finite volume method allows the mesh density to vary from very fine to very coarse within the same model. This means that regions where great accuracy is required can be studied in close detail, while regions of less importance can be approximated more coarsely. The conservation equations are discretized for each element in the mesh and the numerical values of the material properties associated with each component in the model are used as coefficients in the Navier-Strokes and energy equations. This results in a set of discrete nonlinear algebraic matrix equations, which is solved.

\subsubsection{Solving the Equations}

There are a choice of methods for solving the nonlinear systems of equations. The solution method determines how the differential equations are manipulated in order to reduce them to algebraic equations and the manner in which the resulting nonlinear system of algebraic matrix equations are solved. IcePak provides three different solution methods:

1. Segregated iterative method solves the momentum equations and energy equations one at a time sequentially at a given iteration and uses an iterative linear equation solver for the linear systems of equations that arise at each nonlinear outer iteration. 
2. Segregated direct method uses the same nonlinear solution approach as the Segregated iterative method, but employs direct Gaussian elimination to solve the linear system of equations.

3. Coupled method differs from the Segregated approaches that, at each nonlinear outer iteration, it solves the momentum and energy equations simultaneously rather than sequentially. For the Coupled method, the linear systems of equations are always solved by direct Gaussian elimination.

The segregated method requires more number of iterations than the coupled method, but uses less memory and CPU time than the coupled method because each iteration is much faster. The Segregated methods are more robust - i.e., they will converge for a wider range of problems. The segregated iterative method is recommended and it is the default approach in ICEPAK.

\subsubsection{Algorithm Summary}

The steps outlined below summarize the algorithm used by the default segregated iterative solver in ICEPAK for solving the momentum and energy equations:

1. Initialize pressure $(p)$, temperature $(T)$ and velocities $(u, v$ and $w)$.

2. Increase the outer nonlinear iteration count by 1 .

3. Solve for a pressure correction.

4. Mass adjust the velocity field to satisfy continuity.

5. Increment the pressure solution.

6. Solve the $x$ momentum equation for $u$.

7. Solve the $y$ momentum equation for $v$. 
8. Solve the $z$ momentum equation for $w$.

9. Solve the energy equation for $T$.

10. Check for convergence and return to step 2 if necessary. 


\section{Chapter 3}

\section{Modeling and Simulation}

In today's world, design engineers have several ways to address and solve problems. The traditional approach, and for years the only one available, has been to construct a physical prototype of the design and test it in the laboratory. Physical prototyping has many drawbacks, however. Physical prototypes are expensive to build, costly to modify, and by their very nature they lengthen design cycles. In spite of few disadvantages, physical prototyping gives us realistic solutions.

Computer prototyping on the other hand is comparatively easier to build. The aim is to study how much a computer prototype creates a realistic solution, when it comes to airflow in compact electronic enclosures. In this chapter, both experimental and computational models are described.

\subsection{Physical Model}

The basic system (Figure: 3.1) used in this study is chosen to be representative of typical electronic systems. The basic system was highly simplified to include only the major components such as fans, inlet and outlet grills and an array of stacked printed circuit boards (PCBs). After the study was done with the basic model, a detailed model was fabricated by including capacitors, inductors, heat sinks etc. The model was made denser to create more pressure drop across the system. Each of these models is presented in detail below. 


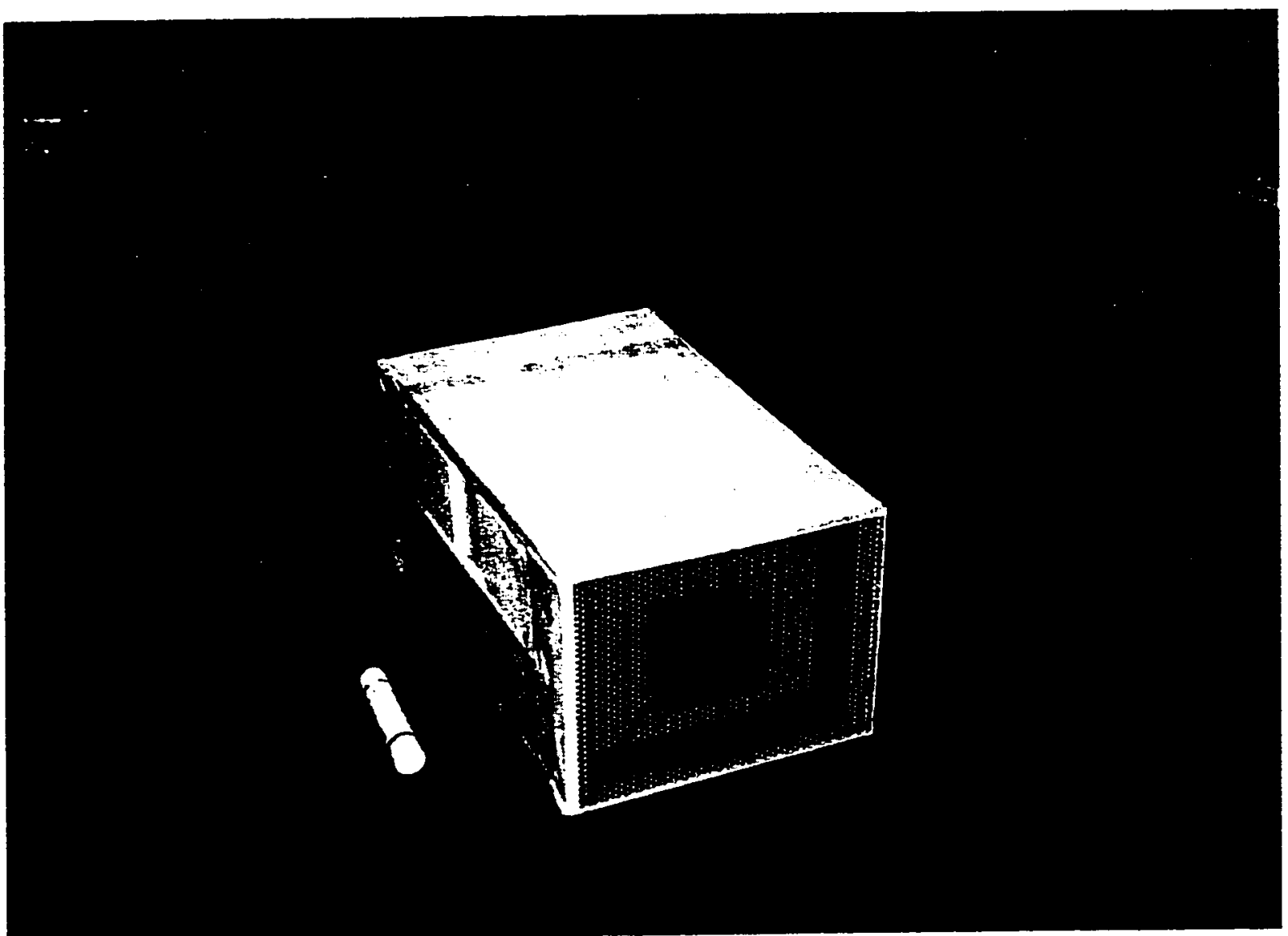

Figure 3.1: Physical model of the enclosure from outside.

\subsubsection{Basic Physical Model (Figure: 3.2)}

The enclosure was fabricated from $5 \mathrm{~cm}$ thick plywood. The internal dimensions of the enclosure are $29 \mathrm{~cm}$ length by $16 \mathrm{~cm}$ width by $14 \mathrm{~cm}$ height. The airflow is across the length of the enclosure. An off-the-shelf $60 \times 25 \mathrm{~mm}$ axial flow, circular fan was selected to pressurize the system. The fan having a free airflow of 22 CFM is mounted on the center of the plate. Distance of the fan from the front face of the enclosure is $3.25 \mathrm{~cm}$. The width and height of the plate is $16 \mathrm{~cm}$ and $14 \mathrm{~cm}$ respectively. The $60 \mathrm{~mm}$ fan used has a model \# KDE1206PKSI, manufactured by Sunon Ltd. 


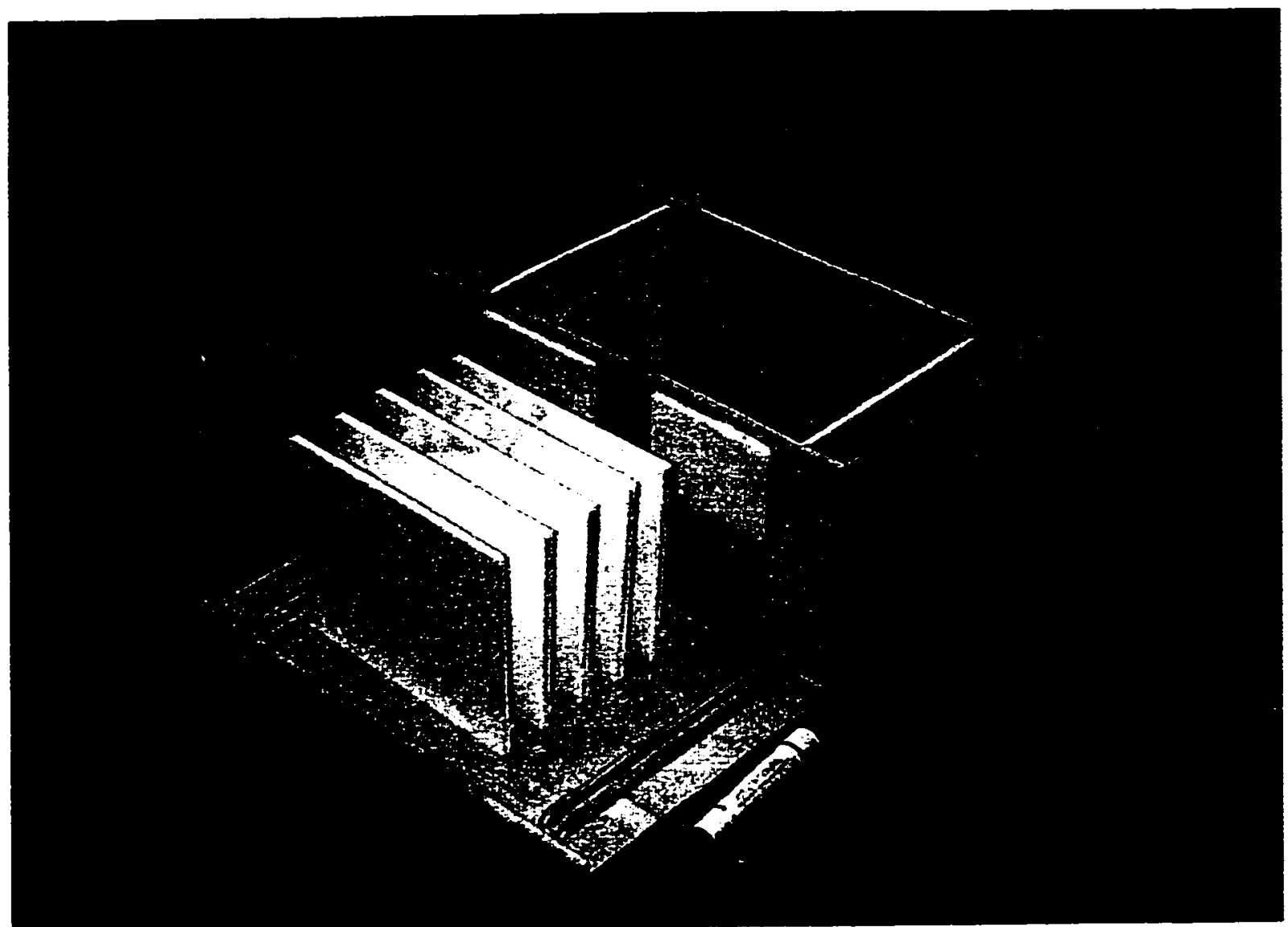

Figure 3.2: Inside the basic model

The group of five printed circuit boards made with foam core having thickness of $5 \mathrm{~mm}$ was placed at a distance of $8.5 \mathrm{~cm}$ from the front face. Dimensions of the printed circuit boards were $16 \mathrm{~cm}$ length by $13.2 \mathrm{~cm}$ width. The boards fit into the slots made with the plywood. The spacing between the boards was $2.6 \mathrm{~cm}$. Both ends of the enclosure were covered with $33 \%$ open area grill. The grill are made with low carbon steel. The perforated metal has a hole diameter of 0.094 inch and center to center spacing of $5 / 32$ inch staggered at 60 degree ordered from McMaster Carr Supply Co. Grill area is critical in an enclosure. Even in well-designed enclosures, inlet and exhaust grills each typically contribute about one-third of the pressure drop created by the air movement through the 
enclosure. The inlet grill was intentionally placed in close proximity to the fan inlet in order to study the discrepancies, if any, in the fan curve data.

\subsubsection{Variations of Basic model}

In the basic model described above, three different variations were studied. The variations are described as follows:

1. The percent open area of the inlet and outlet grills were varied from $20 \%$ to $40 \%$. The grills are $60^{\circ}$ staggered and have round holes. The hole diameter of the $23 \%$ open area grill is 0.0625 inch and center to center spacing is $1 / 8$ inch. Likewise the hole diameter of the $40 \%$ open area grill is 0.125 inch and center to center spacing is $3 / 16$ inch.

2. Analysis was conducted with the change in fan size while the rest of the model remained unchanged. Three different fan sizes were considered which were $60 \mathrm{~mm}$, $80 \mathrm{~mm}$ and $92 \mathrm{~mm}$. The fan was fitted on a plate, which can slide inside the slot fabricated in the enclosure. Because of this, fans of different sizes can be fitted inside the enclosure very easily. The description of the fan are as follows:

a. $60 \mathrm{~mm}$ fan :

The model \# KDE1206PKSI

Size: $60 \mathrm{~mm}$ sq. $\times 25 \mathrm{~mm}(2.36 \mathrm{in}$. sq. $\times 0.98 \mathrm{in}$.

Voltage: 12 Volt

Airflow: 22.0 CFM

Pressure: 0.21 inches of water ( $5.34 \mathrm{~mm}$ of water)

Manufacturer: Sunon Ltd.

b. $80 \mathrm{~mm}$ fan : 
The model \# NMB3110KL-04W-B30

Size: $80 \mathrm{~mm}$ sq. $\times 25 \mathrm{~mm}(3.15$ in. sq. $\times 0.98 \mathrm{in}$.)

Voltage: 12 Volt

Airflow: 31.8 CFM

Pressure: 0.10 inches of water ( $2.54 \mathrm{~mm}$ of water)

Manufacturer: NMB Technologies Inc.

c. $92 \mathrm{~mm}$ fan :

The model \# NMB3610KL-04W-B40

Size: $92 \mathrm{~mm}$ sq. $\times 25 \mathrm{~mm}(3.62$ in. sq. $\times 0.98$ in.)

Voltage: 12Volt

Airflow: 48.0 CFM

Pressure: 0.15 inches of water ( $3.81 \mathrm{~mm}$ of water)

Manufacturer: NMB Technologies Inc.

3. The variation was studied when two similar fans were kept as follows:

a. Series mode: The fans used in these cases are $60 \times 25 \mathrm{~mm}$ fans having a free airflow of $22 \mathrm{cfm}$. The two fans were mounted centrally on two plates, placed at a distance of $3.25 \mathrm{~cm}$ from the front end and back end of the enclosure respectively.

b. Parallel mode: $60 \mathrm{~mm}$ fans were used in parallel mode. Both the fans were mounted on a plate side by side kept at a distance of $3.25 \mathrm{~cm}$ from the front end of the enclosure.

\subsubsection{Detailed Model (Figure: 3.3)}

In the detailed model, the enclosure was kept the same as the enclosure of the basic model described earlier. The detailed model was fabricated by including capacitors, inductors, transformers and heat sinks on the printed circuit boards. All five sets of 
printed circuit boards have exactly same setting of components. Since, we are not concerned with the thermal part of the design; the components like inductors and transformers are fabricated by foam core.

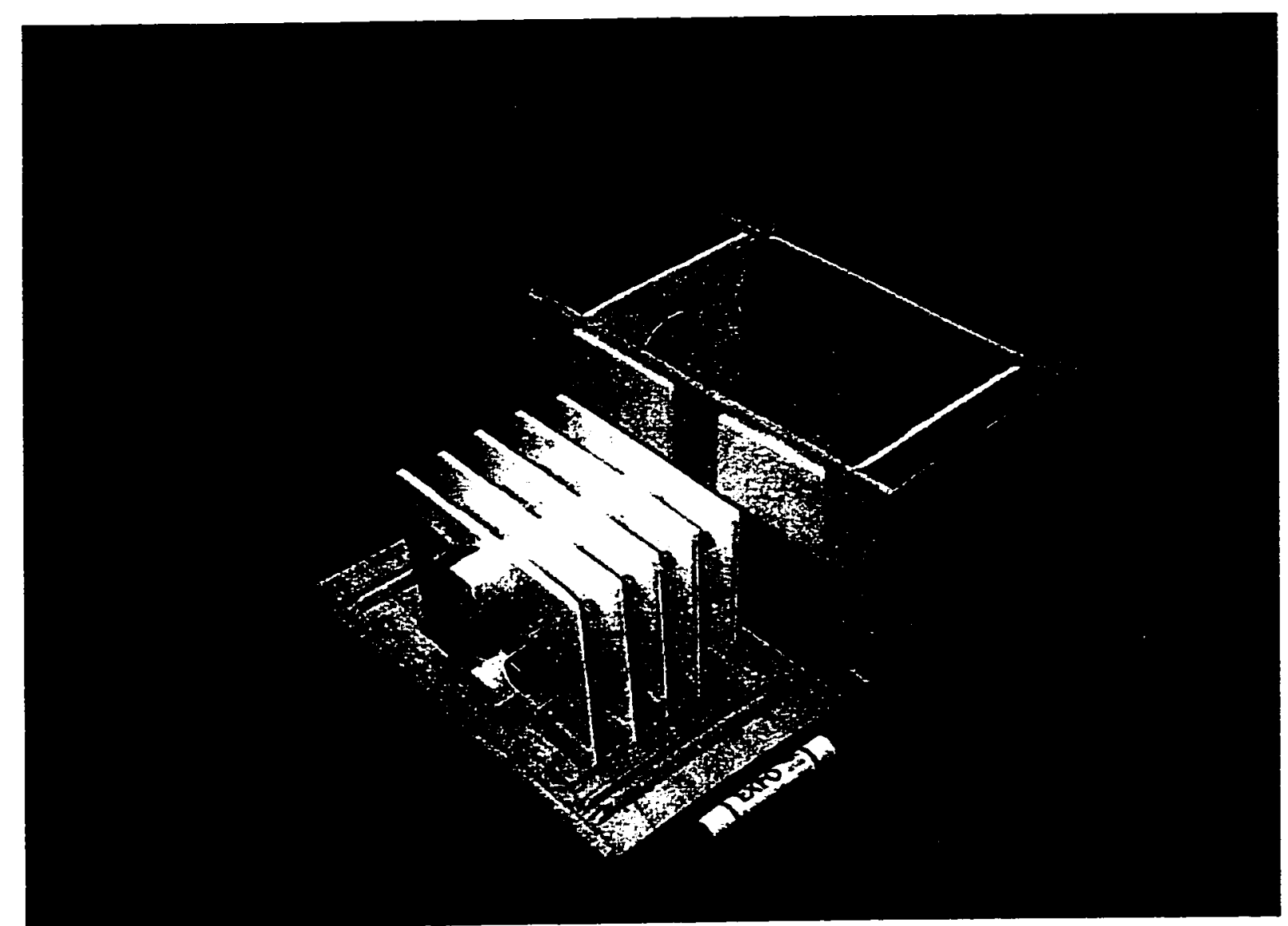

Figure 3.3: Inside the detailed model.

There are two big capacitors (diameter: $2.3 \mathrm{~cm}$; height: $2.0 \mathrm{~cm}$ ); two small capacitors (diameter: $1.0 \mathrm{~cm}$; height: $1.5 \mathrm{~cm}$ ); one inductor $(2 \mathrm{~cm} \times 2 \mathrm{~cm} \times 2 \mathrm{~cm})$; one transformer $(2 \mathrm{~cm} \times 2 \mathrm{~cm} \times 2 \mathrm{~cm})$; two heat sinks on each printed circuit board. The heat sinks are manufactured by Aavid Thermal Products Inc. The base area of the heat sink is $8.094 \mathrm{~cm}^{2}$ and manufactured by extrusion process. Heat sinks used for the experiments have straight fins. These types of fins are considered to simplify the study of comparison of different 
methods. The variations done with the detailed model are similar to that of the basic model.

\subsection{Computational Model}

A computer model of the physical enclosure described above was constructed using ICEPAK. In the model building step, we have to specify the cabinet and all its contents, including dimensions and layout, physical characteristics and other factors affecting the flow.

The standard objects available for use in the model include PCBs, blocks, fans, vents, openings, walls, plates, sources and resistances. ICEPAK can also check the model for design flaws prior to running the solution. This powerful feature saves valuable time in the design phase rather than during the solution.

After starting a new job, ICEPAK automatically creates a rectangular volume, called the cabinet, with dimensions $1 \mathrm{~m} \times 1 \mathrm{~m} \times 1 \mathrm{~m}$ (If SI units are specified on the Problem setup form) and displays it in the Graphics Window. ICEPAK allows modifying the cabinet via the Cabinet edit form. The dimensions of $0.29 \mathrm{~m}, 0.14 \mathrm{~m}$ and $0.16 \mathrm{~m}$ are allowed in the $\mathrm{x}$, $y$ and $z$ directions respectively. The basic models constructed using ICEPAK are shown in figures $3.4,3.5$ and 3.6 . 


\subsection{Constructing Objects}

The first step in the process of constructing an object is to select the object type from the Model menu. After selecting an object, one can edit its dimensions, specify its physical characteristics, and choose whether to make it an active or inactive part of the model. It can also be moved or copied elsewhere in the model. The objects that were used to construct model are described in detail.

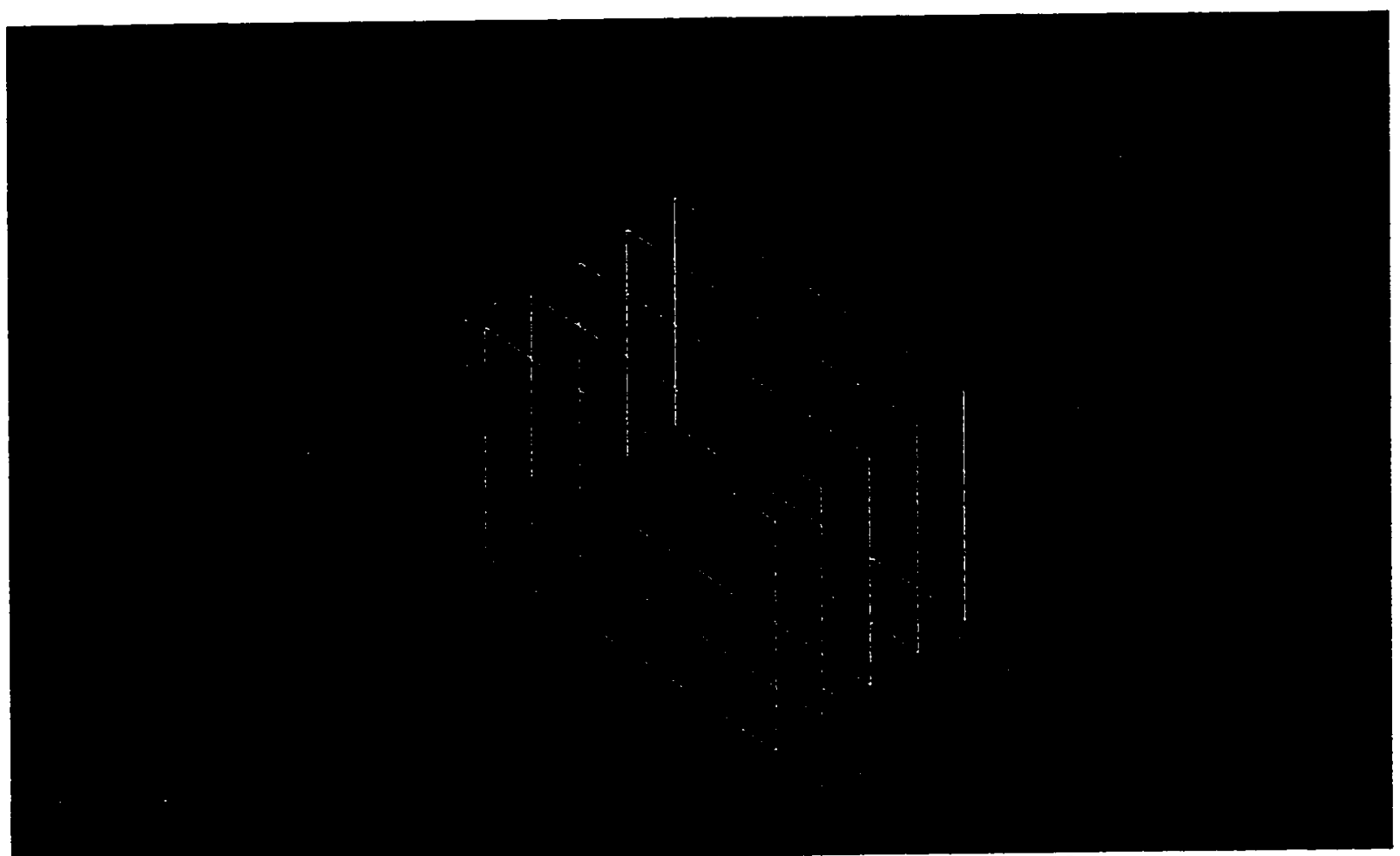

Figure 3.4: Basic model constructed using ICEPAK with $60 \mathrm{~mm}$ fan. 


\subsubsection{Printed Circuit Boards (PCBs)}

PCBs are two-dimensional rectangular objects which have two sides, each of which is modeled separately and may possess physical and thermal characteristics that differ from those of its companion sides. To distinguish the individual sides of the FCB from each other, they are referred to in ICEPAK as high and low, relative to the coordinate direction normal to the PCB. The high side of the PCB faces the higher coordinate values and vice versa. PCB location and dimension parameters include the coordinate plane in which the PCB lies and its physical dimensions. In addition, it can be specified whether the PCB represents an individual board or a rack of boards. In our case, we have assumed that all the heat is dissipated from the high side of the PCB.

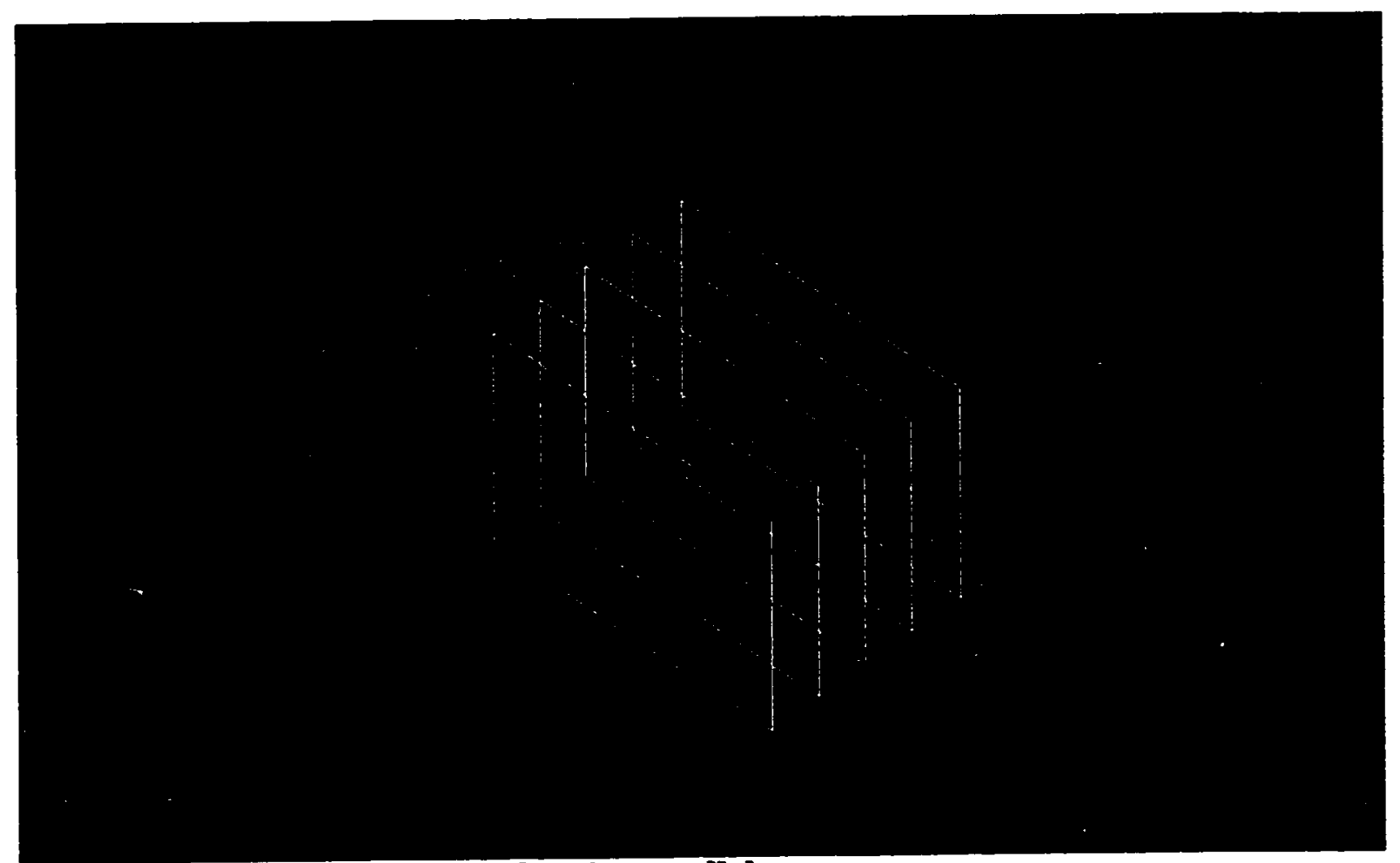

Figure 3.5: Basic model using fans in parallel. 


\subsubsection{Fans}

Fans are two-dimensional modeling objects, the purpose of which is to move fluid into, out of or within the enclosure. Fan geometries include circular and rectangular. Fan types include internal and external. Fans are always associated with magnitude and direction of mass flow. The magnitude of the flow may be specified either as a fixed value or as a function of pressure drop across the fan. To configure a fan in the model, geometry (including location and dimensions) type and mass flow rate associated with the fan must be specified. In the case of our model, the fan specified is an internal fan, because it lies inside the cabinet. The fan used in our case is circular fan, which is defined by the coordinate location of its center $(\mathbf{x C}, \mathbf{y C}, \mathbf{z C})$ and its overall size (outer radius). Multiple fans can be arranged in ICEPAK as in series or in parallel.

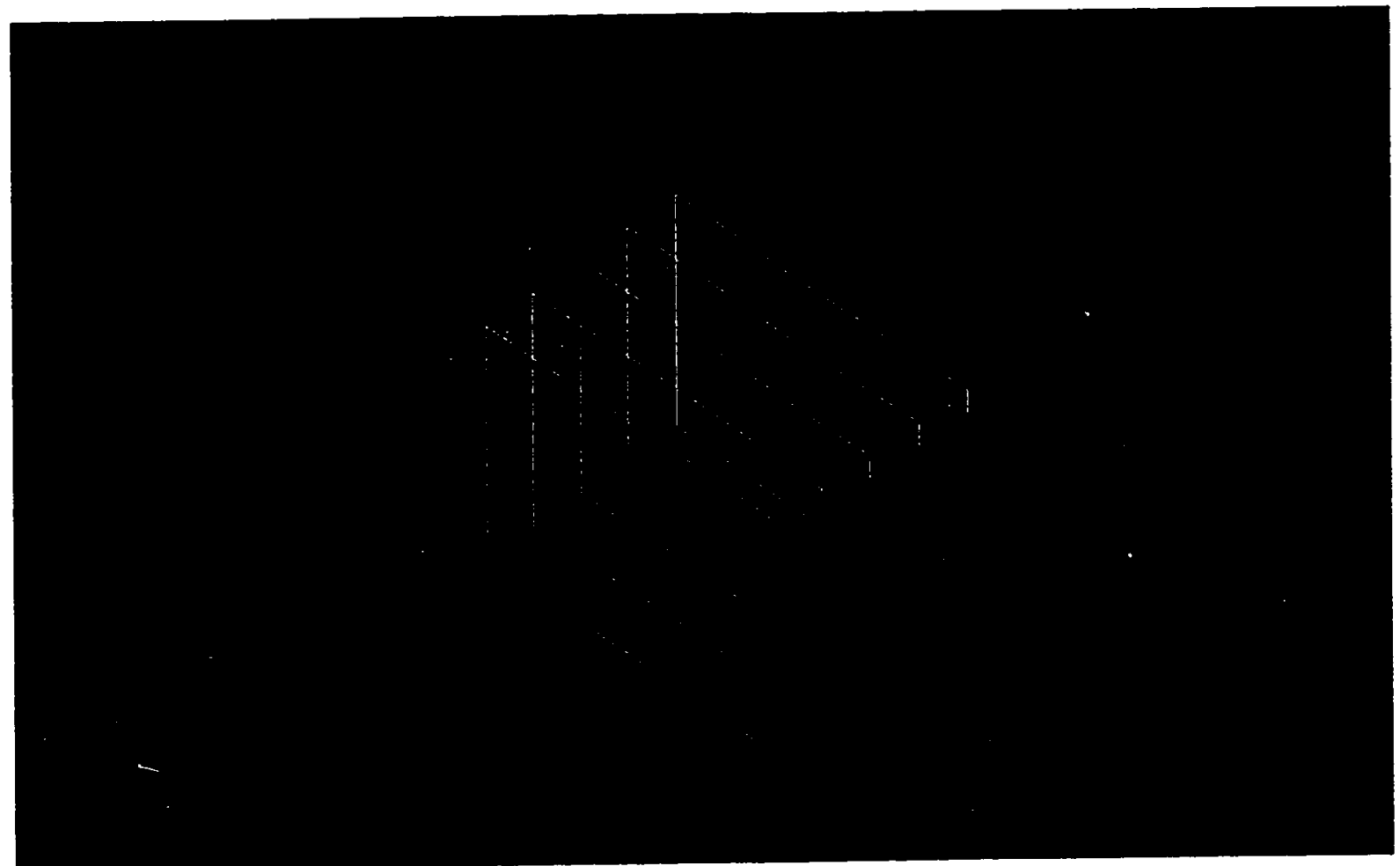

Figure 3.6: Basic model with fans in series. 
In real-world application, the mass flow rate through the fan is governed by its characteristic curve. The relationship between mass flow rate and pressure drop across the fan (static pressure) is defined by the fan characteristic curve. Fan characteristic curves are usually provided by the fan manufacturer.

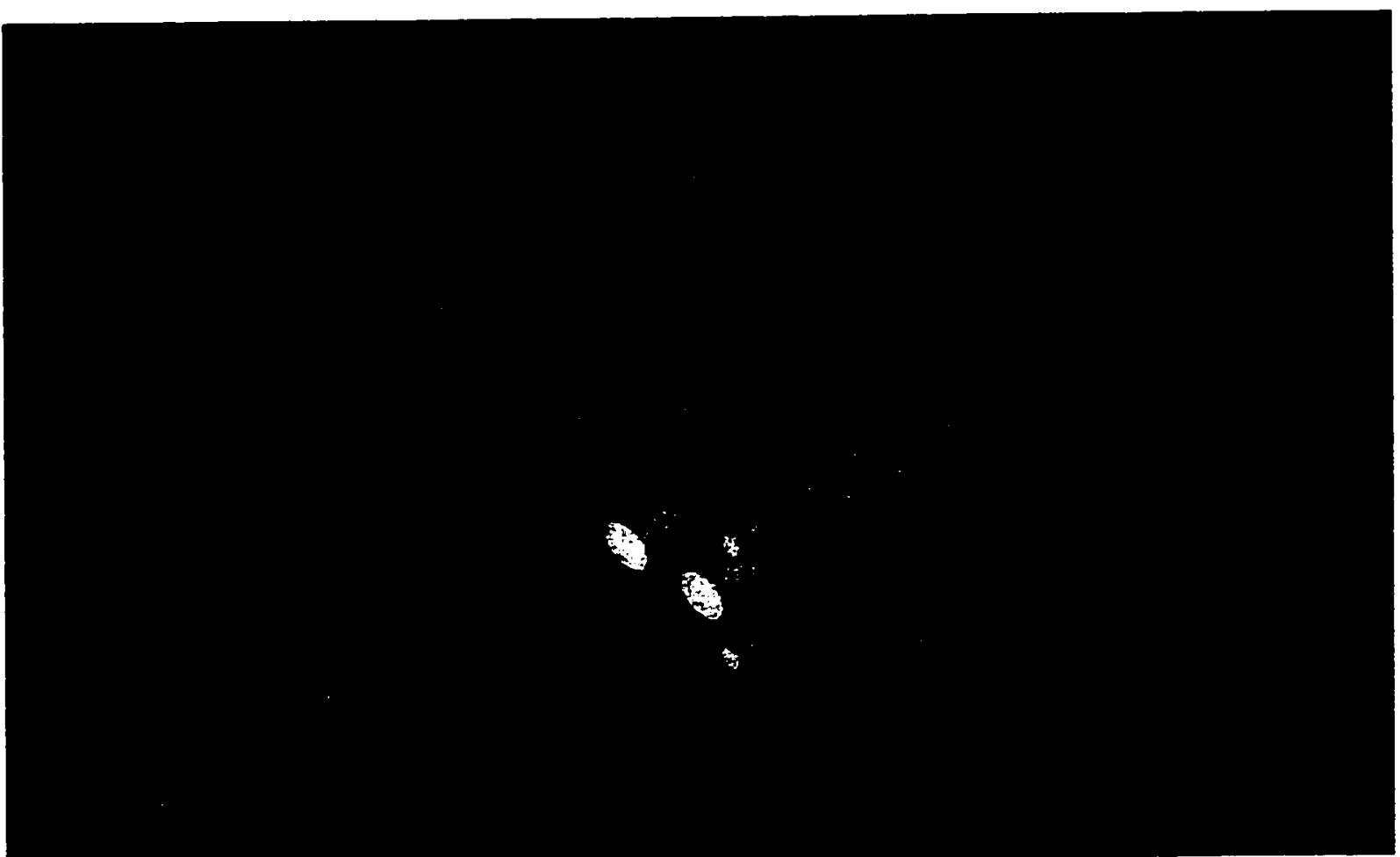

Figure 3.7: Detailed model using ICEPAK with $60 \mathrm{~mm}$ fan.

\subsubsection{Plates}

Plates are solid, flat, rectangular objects impervious to fluid flow. They may or may not possess thickness and are defined by both their geometry and type. Plates types are defined by their associated thermal models. It includes adiabatic, general heat transfer or contact resistance. In our case, the plates modeled were adiabatic. Adiabatic plates do not 
conduct heat either across or in the plane of the plate. The no-slip boundary condition applies at any plate surface in contact with the fluid. To configure a plate in the model, geometry and dimensions of the plate are specified. In our model the plate is used for fitting the fan in it and then to put it inside the cabinet. Plate dimensions are same as that mentioned in the physical model.

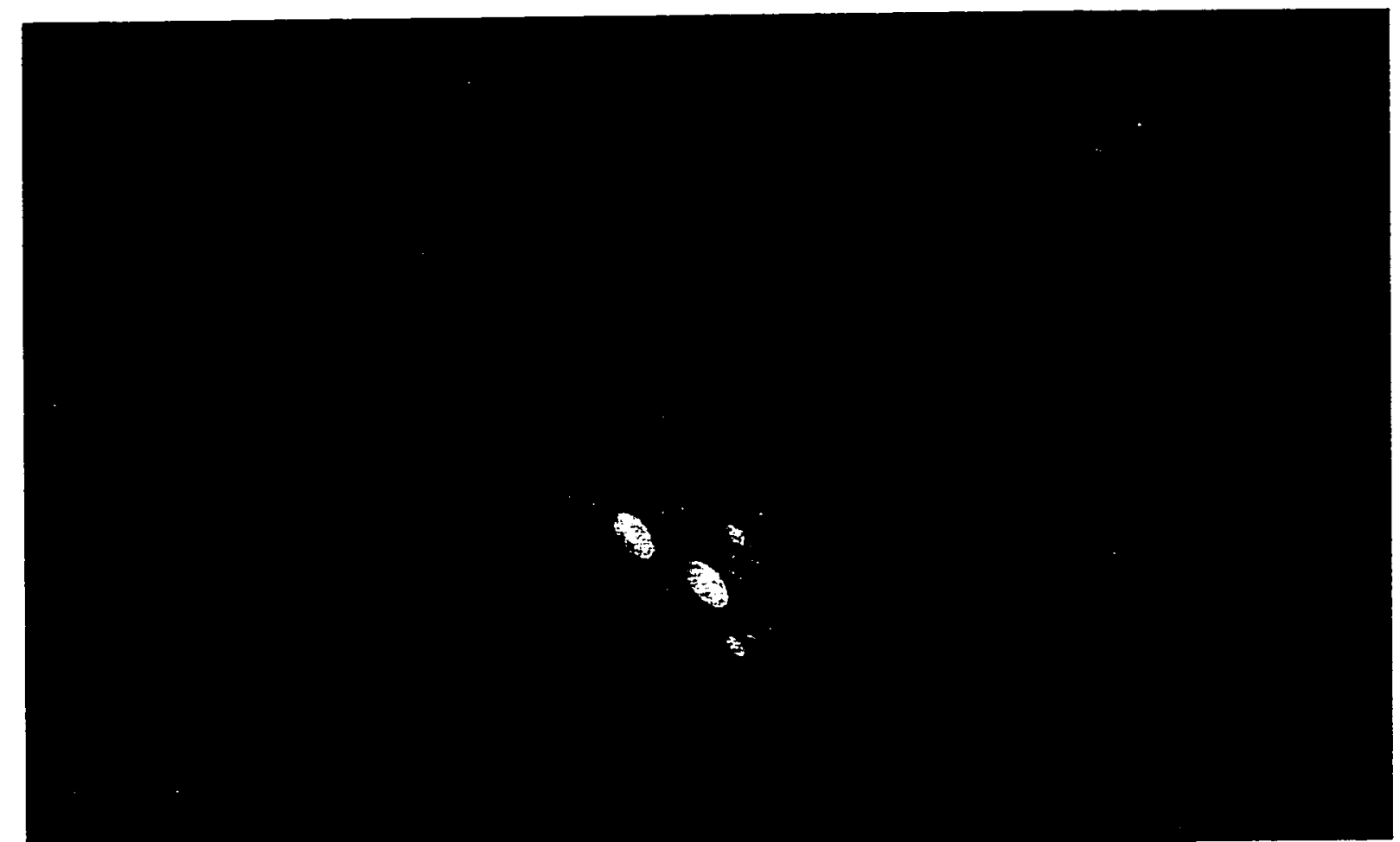

Figure 3.8: Detailed model using ICEPAK with $60 \mathrm{~mm}$ fans in parallel.

\subsubsection{Vents}

Vents represent holes through which fluid may enter or leave the enclosure. They are always located on enclosure boundaries. Vent geometry includes rectangular and circular. Vent types include inlet and outlet. By convention, fluid is assumed to enter through an inlet vent and exit through an outlet vent. In the actual simulation, however, fluid may 
enter or exit from either type of vent. In our case the grills fitted on both side of the enclosure fall under the category of vent. Its lower left corner and upper right corner define the location and dimensional parameters of the rectangular vent. Vents are created and defined via the vent edit and specification forms. Velocity loss coefficient has to be provided for the vents. Loss coefficients were found from the handbook and using wind tunnel tests and the simulation results were compared.

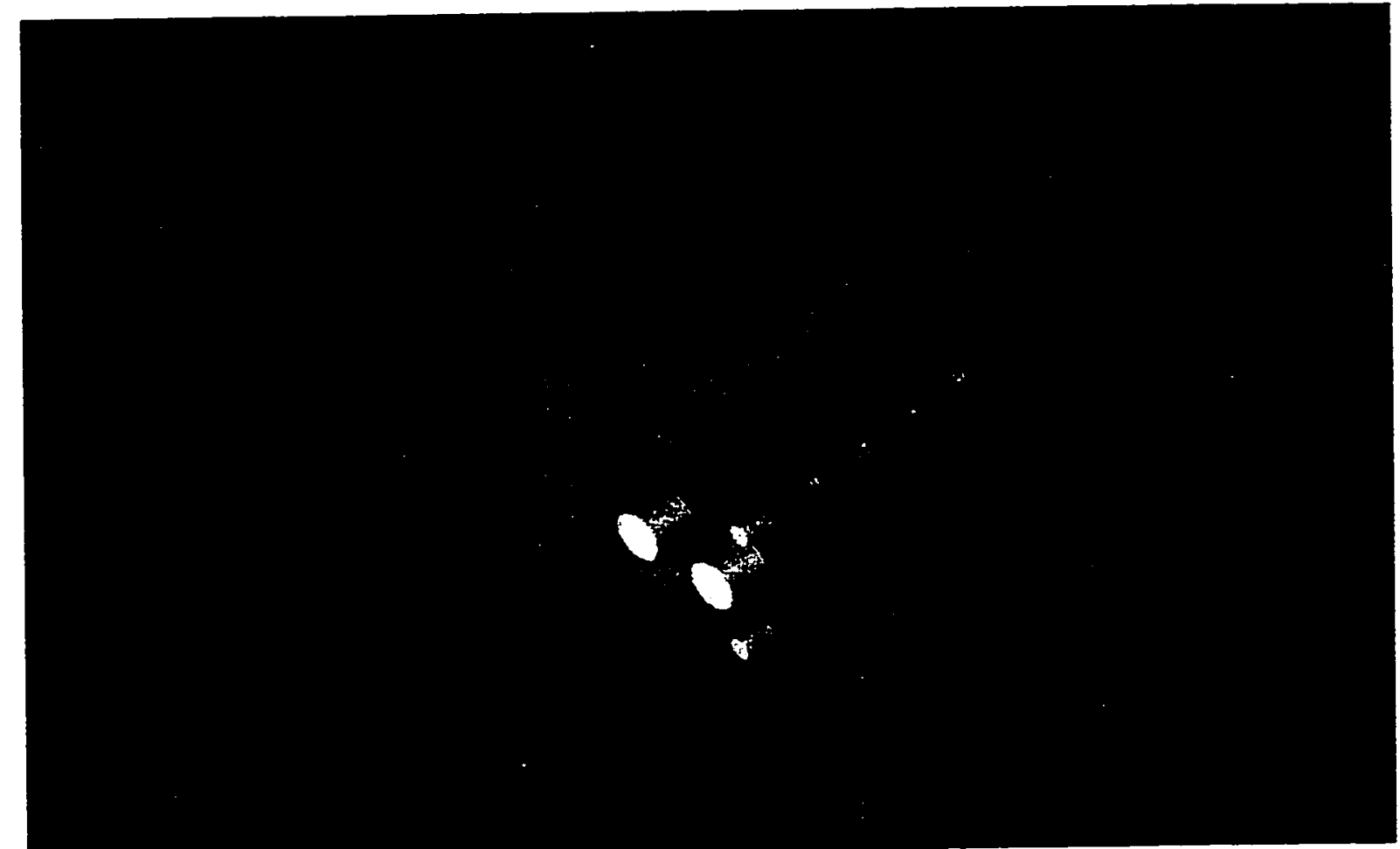

Figure 3.9: Detailed model using ICEPAK with $60 \mathrm{~mm}$ fans in series.

\subsubsection{Components on Printed Circuit Boards using Blocks}

Blocks are three-dimensional modeling objects of specified geometry and type. Block geometry includes prism (rectangular box), cylinder and polygon. Block types include solid, hollow and fluid. 
Blocks are the most versatile of all ICEPAK modeling objects. They may be used to represent a wide variety of components such as power supplies, heat sinks, pipes, capacitors and computer chips. They may also be used to alter the shape of the cabinet by masking specified regions from ICEPAK meshing and computational procedure. All the components on the printed circuit boards are modeled with the help of blocks.

Capacitors used in the modeling are made with cylinder blocks. Inductors, transformers and heat sinks are all made up of rectangular blocks or prisms. To configure a block in the model, the geometry, type and physical or thermal characteristics are specified. For cylinder and polygon blocks, coordinate planes on which the base lies have to be specified. Block location and dimension parameters vary according to block geometry. In case of heat sink, one prism block is used to represent the base of the heat sink. Seven prism blocks parallel to one another are used to model the fins of the heat sink. By using the copy command one can easily model the components on other printed circuit boards having similar set of arrangements. The ICEPAK modeling of the detailed model is shown in figures 3.7, 3.8 and 3.9.

\subsection{Mesh Generation}

Once the model building is finished, computational mesh generation comes into the picture. A good computational mesh is an essential ingredient for a successful and accurate solution. If the mesh is too coarse in one area and too fine in another, the solution procedure may not converge. If the mesh is too coarse globally, an inaccurate solution may result. If the mesh is too fine globally, the solution cost may be excessive. 
ICEPAK employs a sophisticated automated meshing procedure to generate the computational mesh. ICEPAK allows generating computational meshes at varying level of complexities. One can set from virtually no parameters to one for which one can specify the particulars for mesh to be generated in the region of each object in the model. The mesh is graded toward the object to take into account thermal and velocity gradients that are often present near the boundaries of the object. The open spaces between objects are filled with larger elements to minimize computational costs.

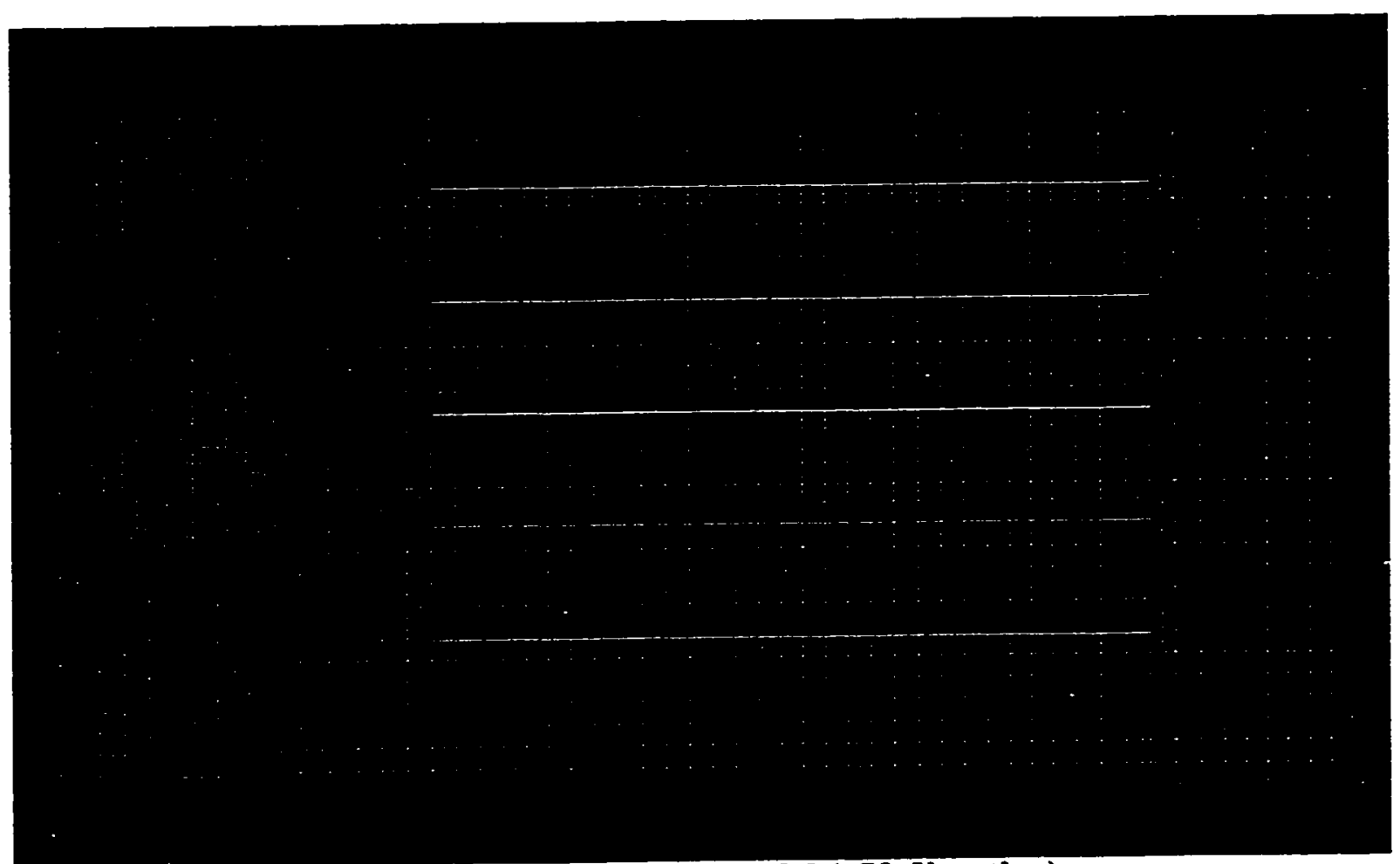

Figure 3.10: Mesh generation for the basic model (+Y-direction).

For generating mesh, there are many different options. The recommended method for generating a mesh suitable for a simulation is to use $\mathbf{M a x} X, Y, Z$ size options and possibly the Max initial height options. The $\operatorname{Max} \mathbf{X}, \mathbf{Y}, \mathbf{Z}$ size options limit the 
maximum length of any mesh element in the corresponding $\mathrm{x}, \mathrm{y}$ or $\mathrm{z}$ coordinate direction. The Max initial height options specify the maximum height of the first element layer generated around any ICEPAK object (e.g., PCB, block or fan) in the mesh. One can view the mesh on the surface of any individual object or any type of modeling object. Thus, for example, one can study the mesh on the surface of all blocks in the model or restrict the view to a single specific block. It is also possible to view the surface mesh on all objects simultaneously or display the entire mesh. This latter option is not recommended for large models as the amount of data displayed makes it difficult to distinguish anything on the screen. One can also define a plane in space and then display the generated mesh on the portion of the plane, which intersects with the model. This capability allows close inspection of the mesh in any area of the model.

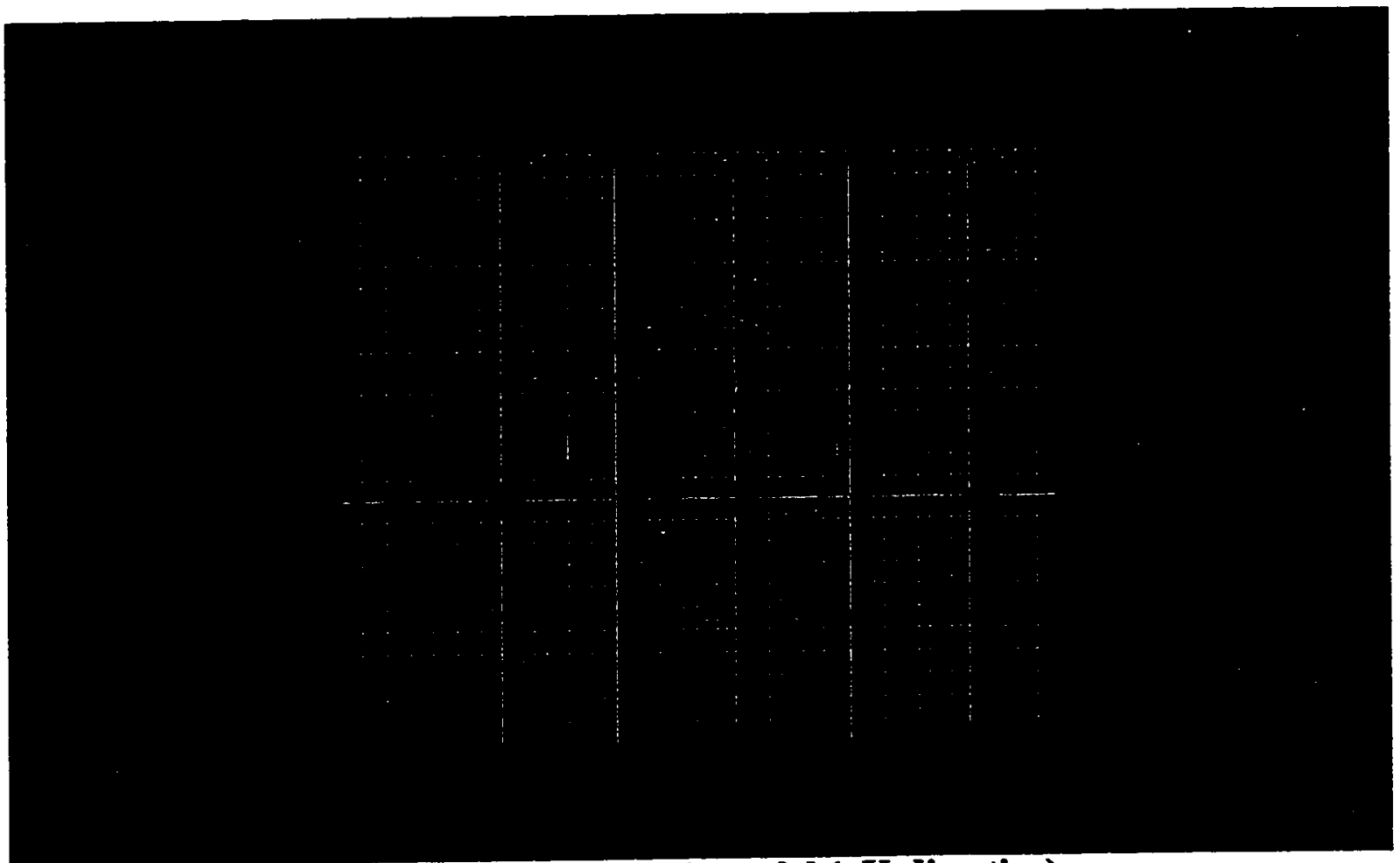

Figure 3.11: Mesh generation for the basic model (+X-direction) 
There are other options to display the mesh across all surfaces and throughout the threedimensional space of the model. There is an user-friendly option, which provides an interactive alternative to the options for defining a plane. By clicking on the Into screen, and then on Horizontal or Vertical button is to be done. Finally clicking on a point on the screen, the horizontal or vertical plane perpendicular to the plane of the screen and passing through the selected point is defined. When using this option, the model should first be oriented as desired before clicking on the Horizontal or Vertical button. Mesh generations for the basic and detailed model are shown in 3.10, 3.11 and 3.12.

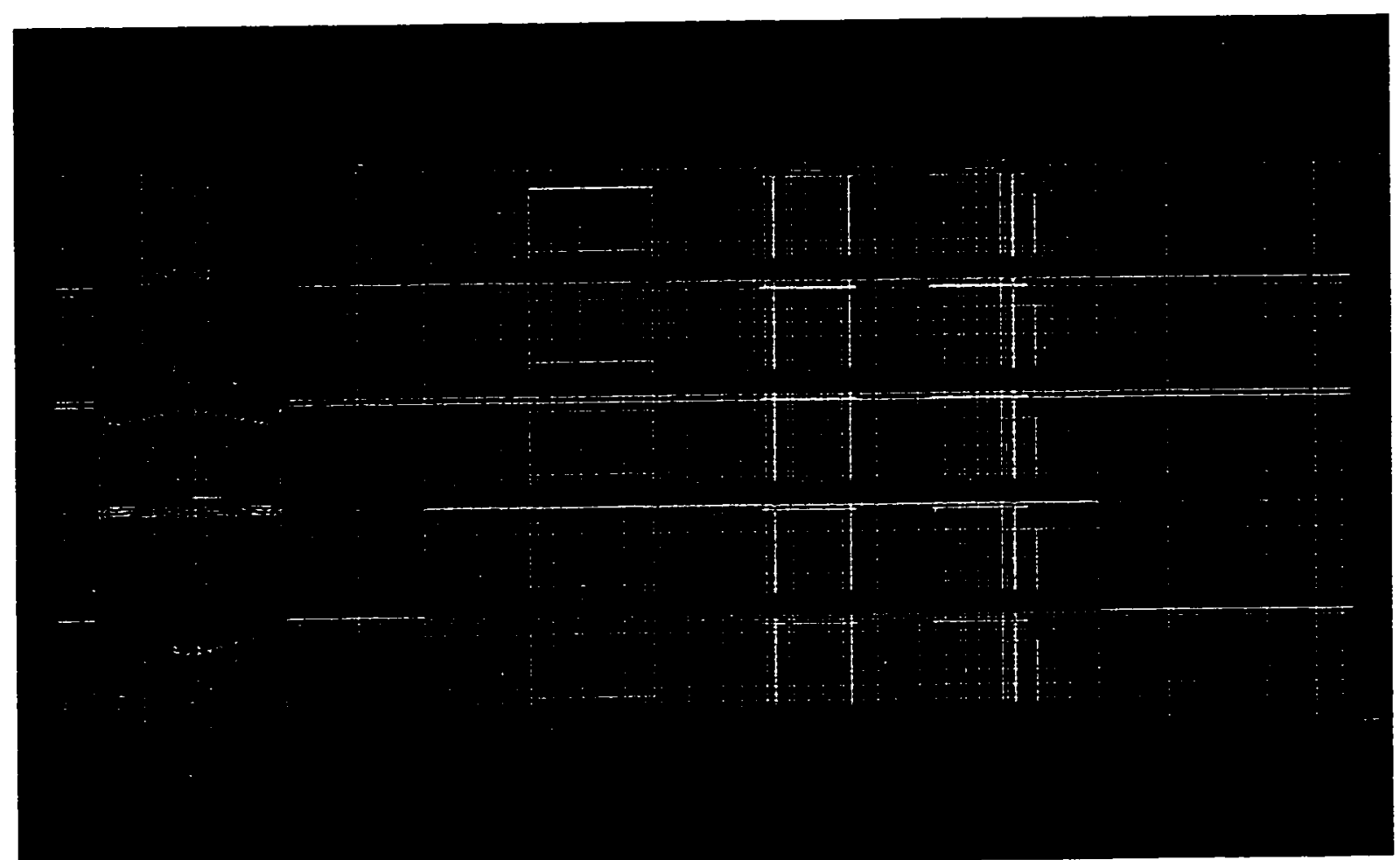

Figure 3.12: Mesh generation for the detailed model (+Y-direction). 


\subsection{Solving and Post-Processing}

Once the initial design and setup of the model is completed, numerical simulation is done. In simulation, one can solve for the velocity and/or temperature fields. Since we are concerned with the airflow and pressure drop across the enclosure, we will deal with only velocity fields. As the solution proceeds, ICEPAK monitors the change in solution between each cycle or outer iteration of the above procedure. Once this difference or solution residual falls below a preset tolerance for each solution variable, the solution is considered to have converged. An important issue in the simulation of any nonlinear phenomena is the ability to achieve convergence. Many factors can affect convergence, including the physical characteristics of the problem, density of the mesh used and aspects of numerical techniques employed.

For flows dominated by natural convection, ICEPAK computes the Reynolds number $(\mathrm{Re})$ and Peclet number $(\mathrm{Pe})$, both of which are dimensionless. For flows dominated by natural convection (i.e., buoyancy driven flows), ICEPAK computes and displays the Rayleigh number (Ra) and Prandtl number (Pr), which are also dimensionless.

The Reynolds number measures the relative importance of inertial forces and viscous forces. When it is large, inertial forces dominate, boundary layer forms and the flow may become turbulent. The Peclet number is similar to the Reynolds number and measures the relative importance of diffusion for the transport of heat. For most flows simulated with ICEPAK, both the Reynolds and the Peclet number are large. If the Reynolds number is greater than 2,000 or the Rayleigh number is greater than $5 \times 10^{7}$, then it is strongly recommended that Turbulent flow be selected on the Problem setup form. 
ICEPAK provides a number of different post-processing methods for examining the data generated by the solution of the model. For the most part, the methods are graphical in nature and are designed to visualize the results of the simulation.

\subsection{Calculating Pressure Loss Coefficient}

For calculating pressure loss coefficient of the grills experimentally, the grill is fitted to the wind tunnel and the pressure drop through the grill was determined for a particular flow rate. The loss coefficient of the grill is determined by using

$$
\zeta=\frac{\Delta p}{\rho \omega_{0}^{2} / 2}
$$

Where $\quad \zeta=$ loss coefficient

$$
\begin{aligned}
\Delta p & =\text { static pressure for a particular flow rate }(\mathrm{Pa}) \\
\rho & =\text { density of fluid }\left(\mathrm{kg} / \mathrm{m}^{3}\right) \\
\omega_{o} & =\text { velocity }(\mathrm{m} / \mathrm{s})
\end{aligned}
$$

Example: Calculating loss coefficient for $33 \%$ open area grill

Airflow through the grill: 14.75 CFM

Static pressure $(\Delta p): 0.0035$ " of $\mathrm{H}_{2} \mathrm{O}=0.875 \mathrm{~Pa}$

Velocity :

$$
\omega_{o}=\frac{14.75}{1850 \times 1.16 \times 0.14 \times 0.16}=0.3068 \mathrm{~m} / \mathrm{s}
$$


Loss coefficient:

$$
\zeta=\frac{0.875 \times 2}{1.16 \times 0.3068^{2}}=16.02
$$

Similarly, the pressure loss coefficient of other grills was determined.

\subsection{Problems Encountered During Simulation}

While performing ICEPAK modeling, many problems were encountered, which are discussed as follows:

1. In the detailed model, it was seen that the solution was not converging. The reason for this was because there were many squish elements in the model after the mesh generation. One of the reasons for squish elements is when one component in the model is off from another component in its plane by less than a tolerance limit (in this case it was $1 \mathrm{~mm}$ ). Some of the squish elements were removed by aligning the components. The value of the squish should not be more than 10 . By aligning the components, the squish still came below 10. The necessary steps taken to get rid of the squish element are:

a. Makes the O-grid height small (in this case, it was made 0.001).

b. When there is very little gap between the upper surface of the component placed on the PCB and the next PCB, it shows few squish. It was removed by placing the fluid element in between the gap.

c. Per object mesh parameter specification was provided to remove squish. 
2. It was observed that the analytical results were absolutely not matching with the ICEPAK and experimental results. For example, in the case of the basic model with the $60 \mathrm{~mm}$ fan, the experimental and ICEPAK results were some where around 16.0 CFM, where as the analytical value was around 22.0 CFM. It was discovered that the plate on which the fan was mounted has to be there while conducting the impedance test in the wind tunnel.

3. While modeling with the $80 \mathrm{~mm}$ fan, it was observed that the graph was not converging smoothly. The solution to this problem was achieved by considering the under relaxation factor to be 0.3 and 0.5 for pressure and momentum respectively, instead of 0.3 and 0.7 . 


\section{Chapter 4 \\ Comparison of Different Techniques}

In this chapter, the different methods employed to determine airflow through the system are compared with the experimental method, which is the baseline case. The comparisons of different cases are presented below.

\subsection{Basic Model with $60 \mathrm{~mm}$ Fan and 33\% Open Area Grills}

Experiment conducted with 1" nozzle:

Total airflow of the system: 15.5 CFM@0.075 lbs $/ \mathrm{ft}^{3}$ Density

Matching the fan to the system:

The impedance test was done with a 1 " nozzle and the fan curve was obtained from the manufacturer. The operating point obtained from figure 4.1 is $16.6 \mathrm{CFM}$.

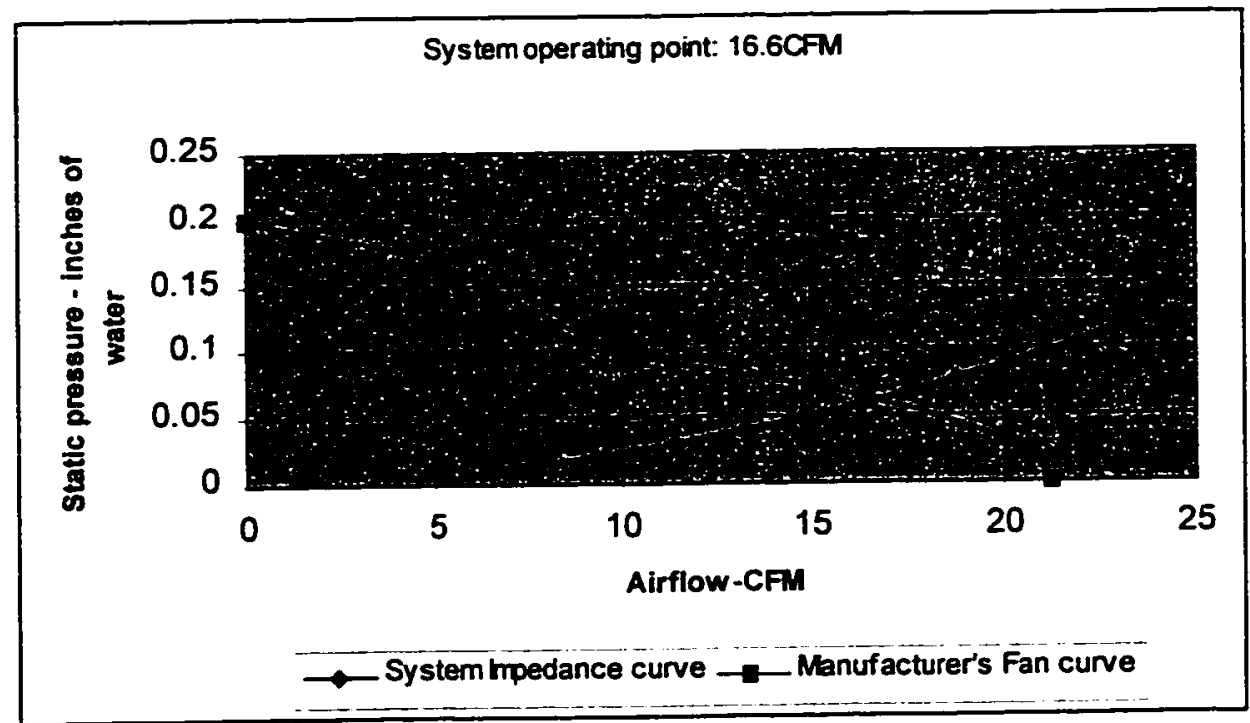

Figure 4.1: Fan-System performance curves of basic model with $33 \%$ opening. 
Computational Fluid Dynamics 1: The pressure loss coefficient of the inlet and outlet grills obtained from a data handbook is 20 .

Total airflow of the system is 15.9 CFM $(0.00859626 \mathrm{~kg} / \mathrm{s})$.

Computational Fluid Dynamics 2: The pressure loss coefficient of the inlet and outlet grills obtained using a wind tunnel test is 16.

Total airflow of the system is 16.2 CFM $(0.00876021 \mathrm{~kg} / \mathrm{s})$.

The velocity vectors of this model are shown in figure 4.2. Here a plane is cut in the horizontal plane and the velocity vectors are displayed in that plane.

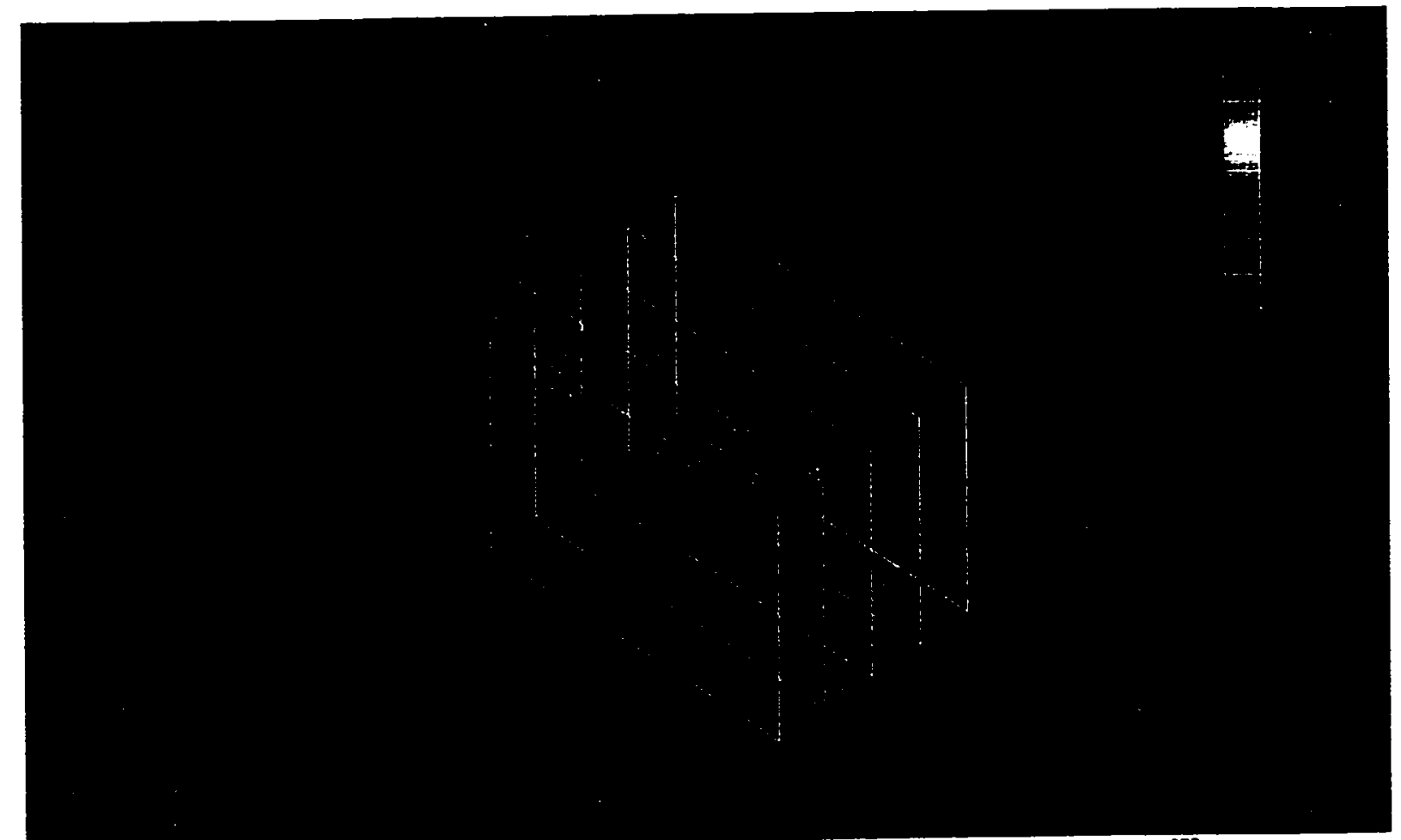

Figure 4.2: Velocity profiles of the basic model with $33 \%$ open area grills

\subsection{Basic Model with $60 \mathrm{~mm}$ Fan and 23\% Open Area Grills}

Experiment conducted with 1" nozzle: 
Total airflow of the system: 14.25 CFM@ $0.075 \mathrm{lbs} / \mathrm{ft}^{3}$ Density

Matching the fan to the system:

The impedance test was done with a 1 " nozzle and the fan curve was obtained from the manufacturer. The operating point obtained from figure 4.3 is $16.0 \mathrm{CFM}$.

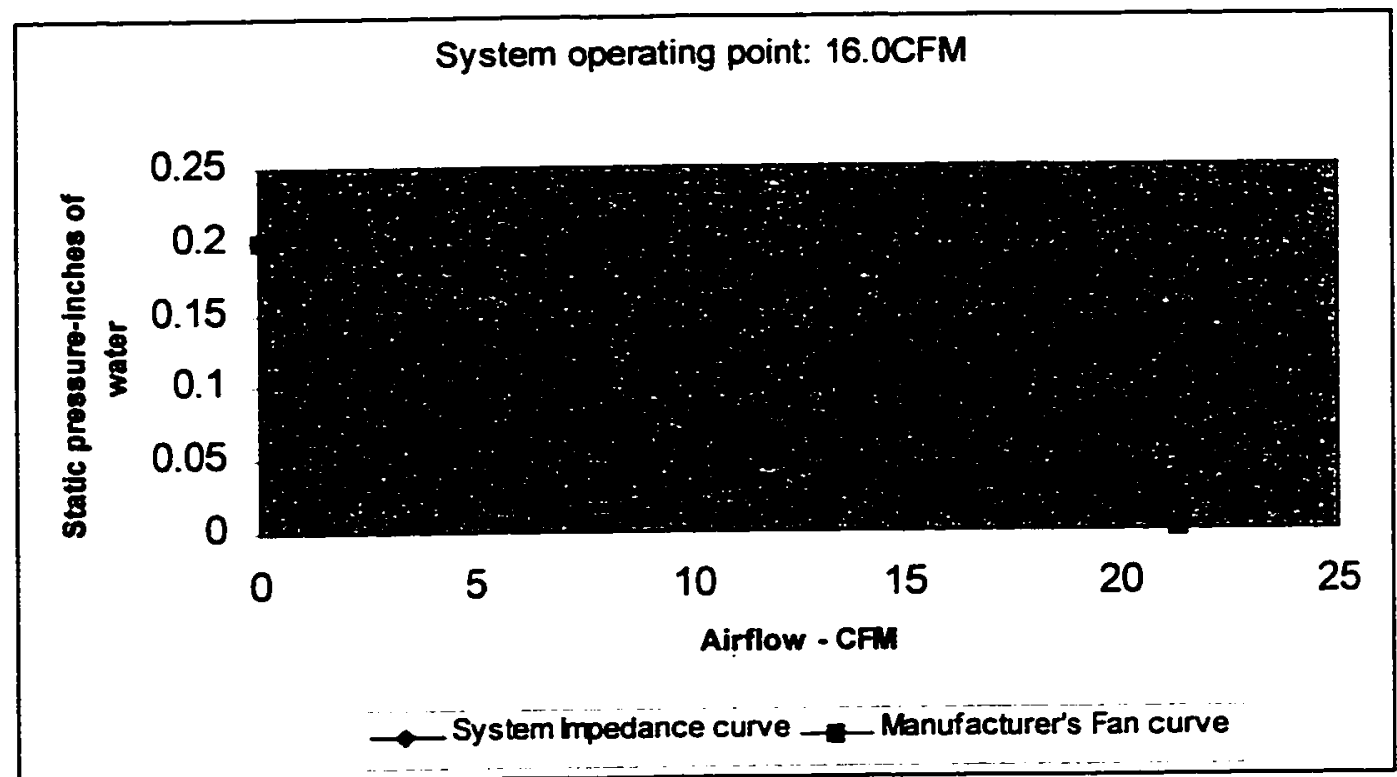

Figure 4.3: Fan-System Performance curves of basic model with $23 \%$ opening.

Computational Fluid Dynamics 1: The pressure loss coefficient of the inlet and outlet grills obtained from a data handbook is 45 .

Total airflow of the system is $15.28 \mathrm{CFM}(0.00825945 \mathrm{~kg} / \mathrm{s})$.

Computational Fluid Dynamics 2: The pressure loss coefficient of the inlet and outlet grills obtained using a wind tunnel test is 33 .

Total airflow of the system is 15.54 CFM $(0.00840172 \mathrm{~kg} / \mathrm{s})$.

The velocity vectors of this model are shown in figure 4.4. Here a plane is cut in the horizontal plane and the velocity vectors are displayed from positive $y$-axis. 


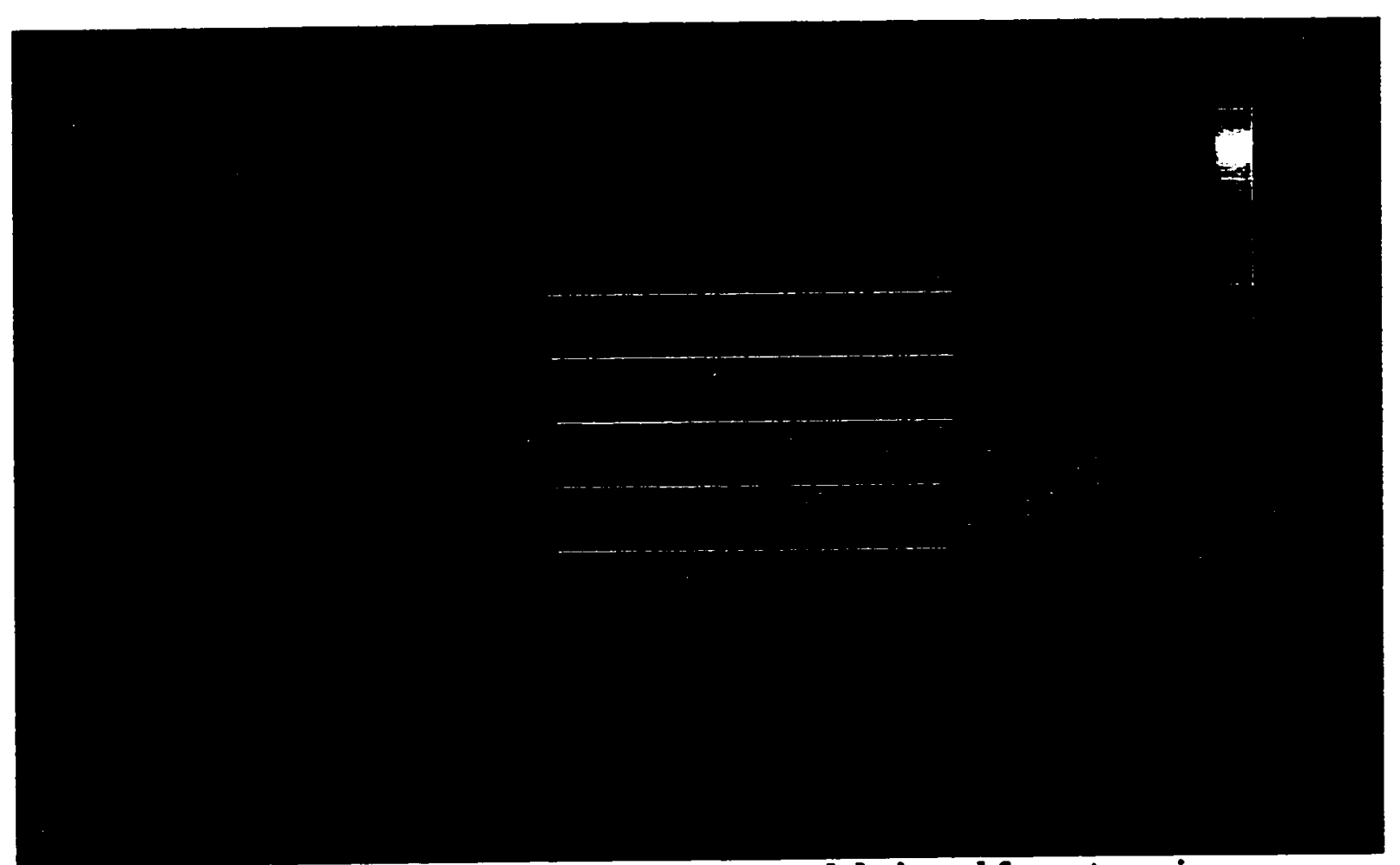

Figure 4.4: velocity profiles of $23 \%$ open area model viewed from $+y$-axis.

\subsection{Basic Model with $60 \mathrm{~mm}$ Fan and $40 \%$ Open Area Grills}

Experiment conducted with 1" nozzle:

Total airflow of the system: 16.25 CFM@ $0.075 \mathrm{lbs} / \mathrm{ft}^{3}$ Density

Matching the fan to the system:

The impedance test was done with a 1" nozzle and the fan curve was obtained from the manufacturer. The operating point obtained from figure 4.5 is 16.7CFM.

Computational Fluid Dynamics 1: The pressure loss coefficient of the inlet and outlet grills obtained from a data handbook is 11 .

Total airflow of the system is 16.41 CFM $(0.0087020 \mathrm{~kg} / \mathrm{s})$. 


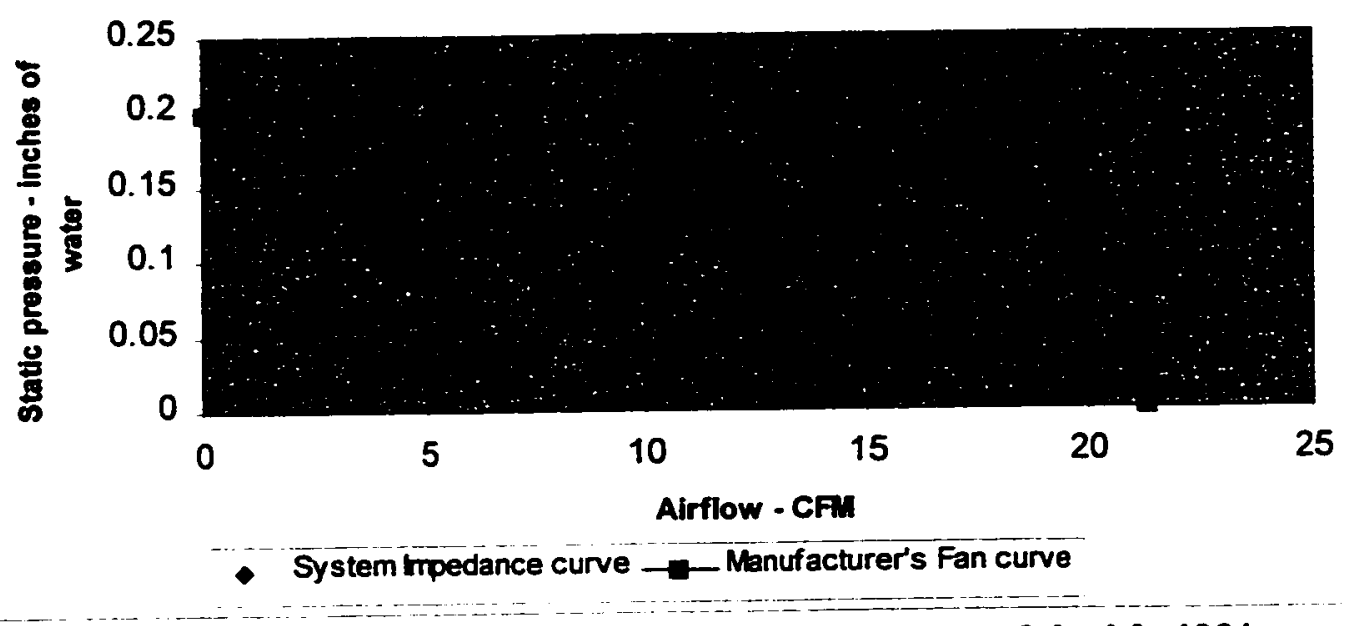

Figure 4.5: Fan-System Performance curves of basic model with $40 \%$ opening.

Figure 4.6: Velocity profiles of the basic model ( $40 \%$ open area) from $+y$-axis. 
Computational Fluid Dynamics 2: The pressure loss coefficient of the inlet and outlet grills obtained using a wind tunnel test is 10 .

Total airflow of the system is 16.44 CFM $(0.0088850 \mathrm{~kg} / \mathrm{s})$.

The velocity vectors of this model are shown in figure 4.6 .

\subsection{Basic Model with $80 \mathrm{~mm}$ Fan}

Experiment conducted with 1" nozzle:

Total airflow of the system: 25 CFM@ $0.075 \mathrm{lbs} / \mathrm{ft}^{3}$ Density Matching the fan to the system:

The impedance test was done with a 1 " nozzle and the fan curve was obtained from the manufacturer. The operating point obtained from figure 4.7 is $22.4 \mathrm{CFM}$.

System operating point: $22.4 \mathrm{CFM}$

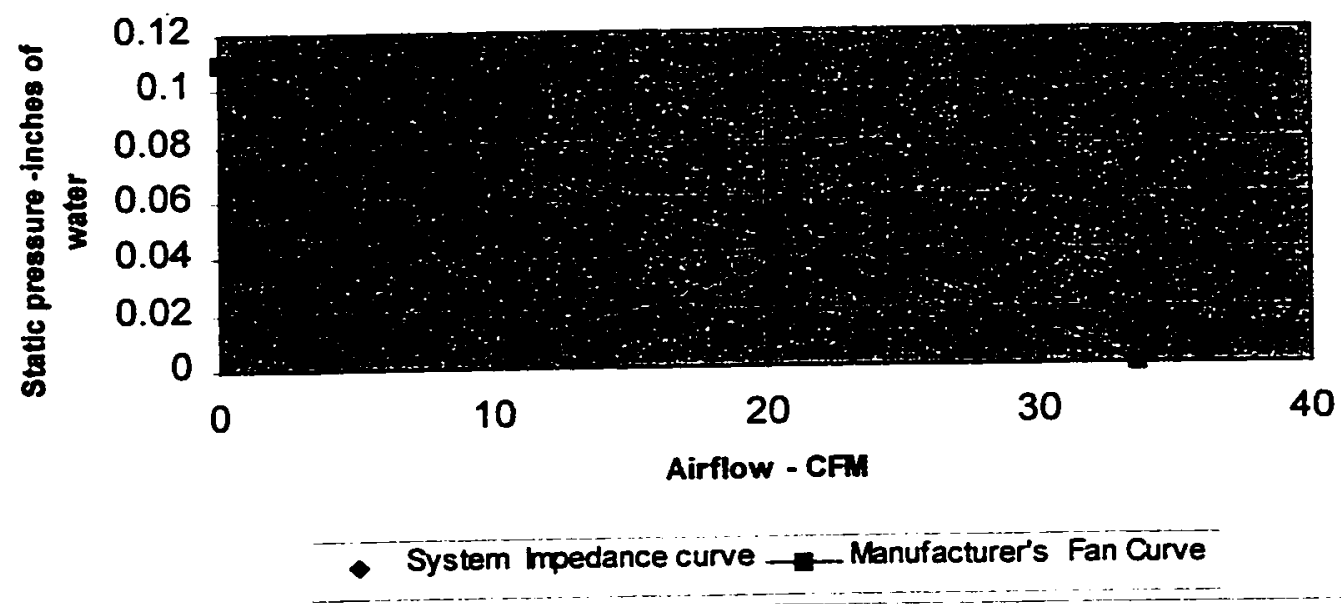

Figure 4.7: Fan-System Performance Curves with 80 mm Fan (Basic Model). 


\section{Computational Fluid Dynamics 1:}

Total airflow of the system is $20.6 \mathrm{CFM}(0.0111340 \mathrm{~kg} / \mathrm{s})$.

\section{Computational Fluid Dynamics 2:}

Total airflow of the system is 22.2 CFM $(0.0119897 \mathrm{~kg} / \mathrm{s})$.

The velocity vectors of this model are shown in figure 4.8 .

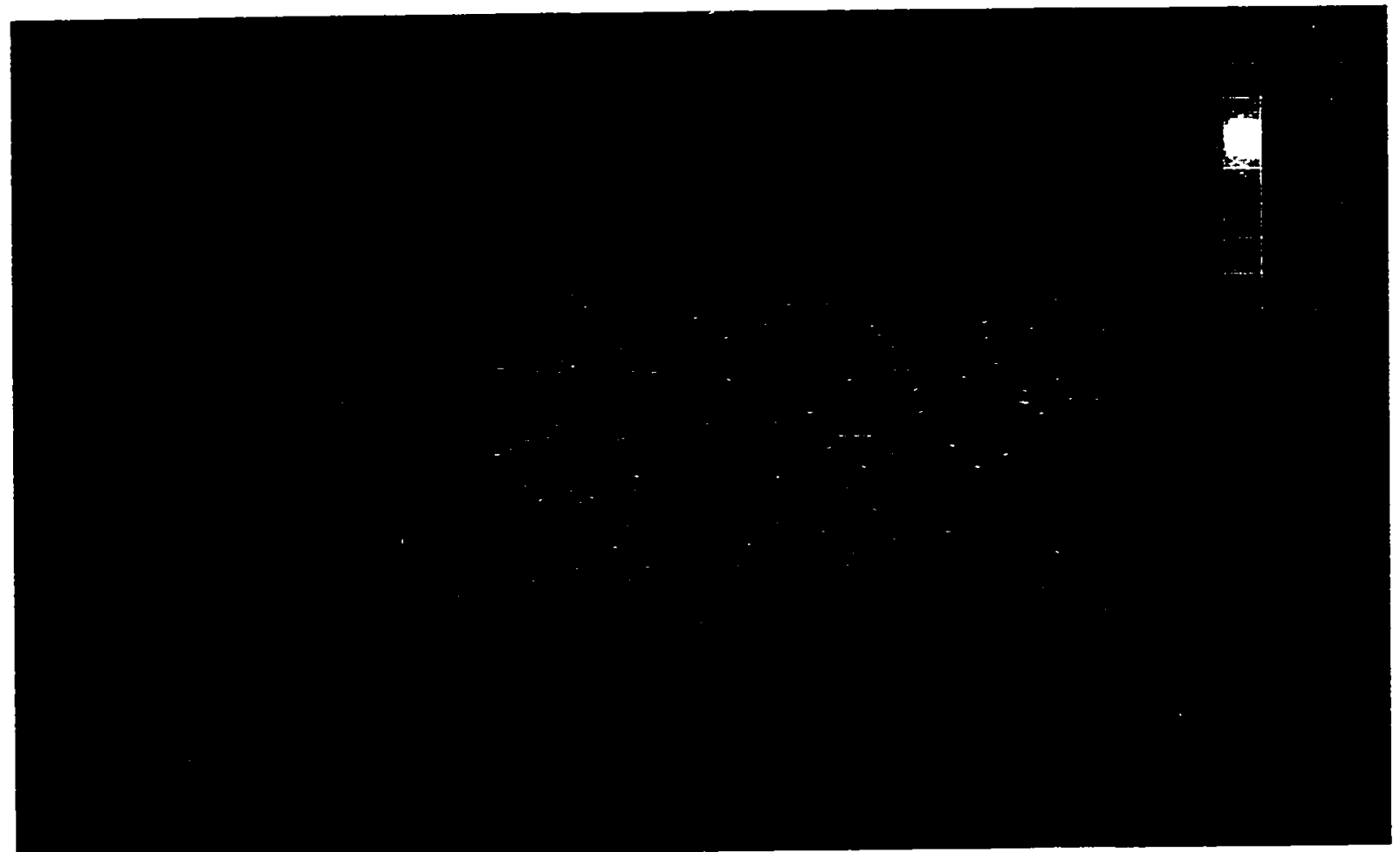

Figure 4.8: Velocity profiles of the basic model with $80 \mathrm{~mm}$ fan.

\subsection{Basic Model with $92 \mathrm{~mm}$ Fan}

Experiment conducted with 1.6" nozzle:

Total airflow of the system: 35.5 CFM@ $0.075 \mathrm{lbs} / \mathrm{ft}^{3}$ Density

Matching the fan to the system: 
The impedance test was done with a 1.6" nozzle and the fan curve was obtained from the manufacturer. The operating point obtained from figure 4.9 is 32.5 CFM.

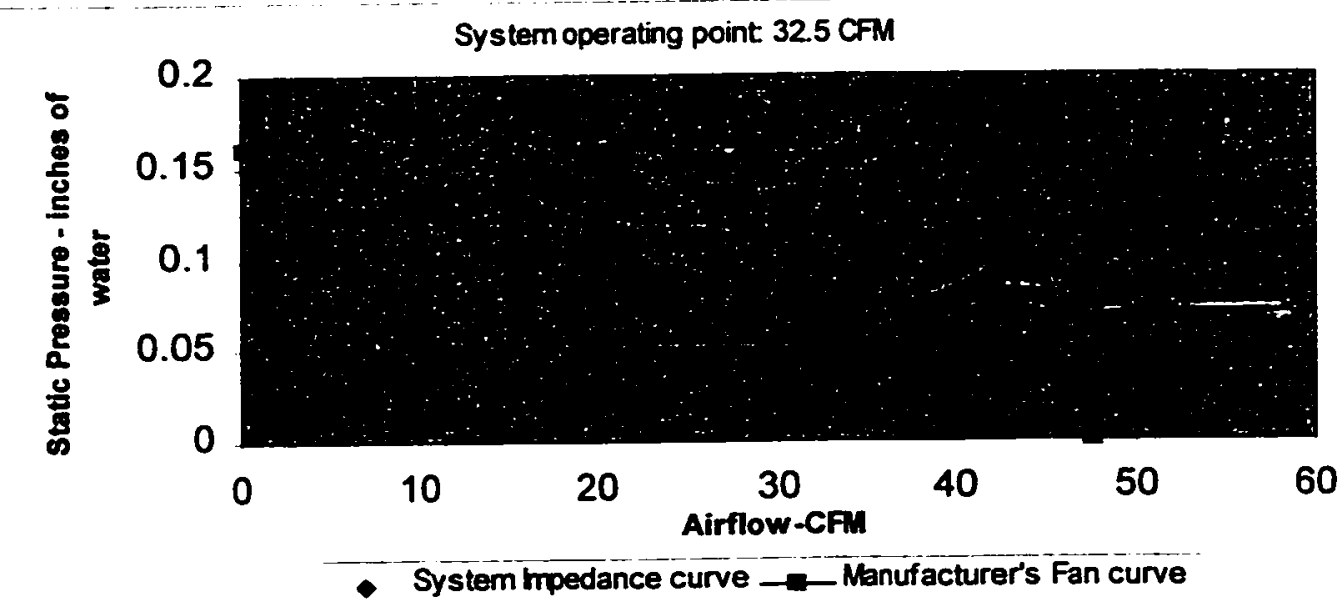

Figure 4.9: Fan-System Performance Curves with $92 \mathrm{~mm}$ Fan (Basic Model).

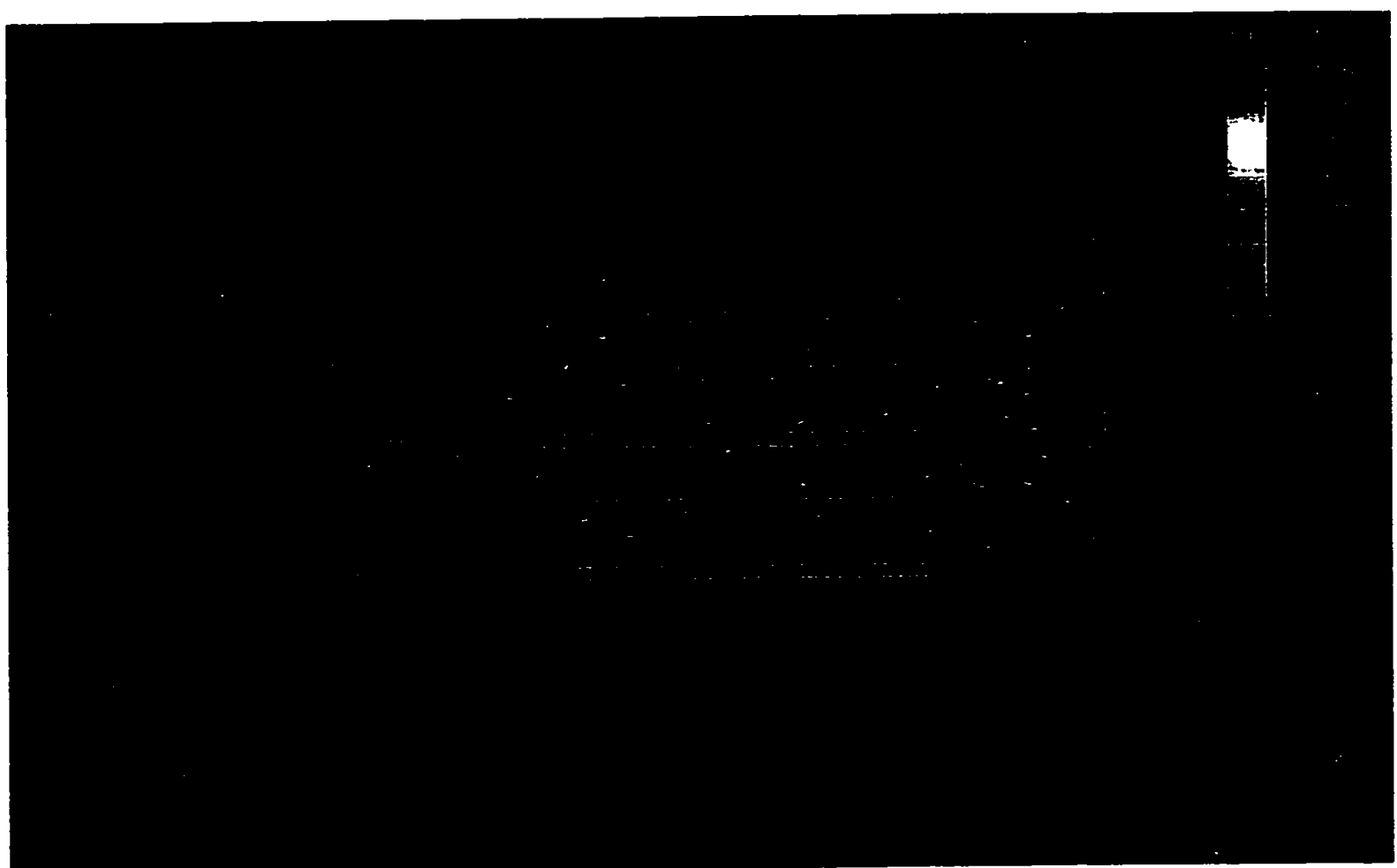

Figure 4.10: Velocity profiles of $92 \mathrm{~mm}$ fan (Basic Model). 


\section{Computational Fluid Dynamics 1:}

Total airflow of the system is 27.64 CFM $(0.014940 \mathrm{~kg} / \mathrm{s})$.

\section{Computational Fluid Dynamics 2:}

Total airflow of the system is 30.2 CFM $(0.016324 \mathrm{~kg} / \mathrm{s})$.

The velocity vectors of this model are shown in figure 4.10 viewed from $+y$-axis.

\subsection{Basic Model with $60 \mathrm{~mm}$ fans in Series}

Experiment conducted with 1" nozzle:

Total airflow of the system: 16 CFM@ $0.075 \mathrm{lbs} / \mathrm{ft}^{3}$ Density

Matching the fan to the system:

The impedance test was done with a 1" nozzle and the fan curve was obtained from the manufacturer. The operating point obtained from figure 4.11 is $18.3 \mathrm{CFM}$.

System operating point: $18.3 \mathrm{CFM}$

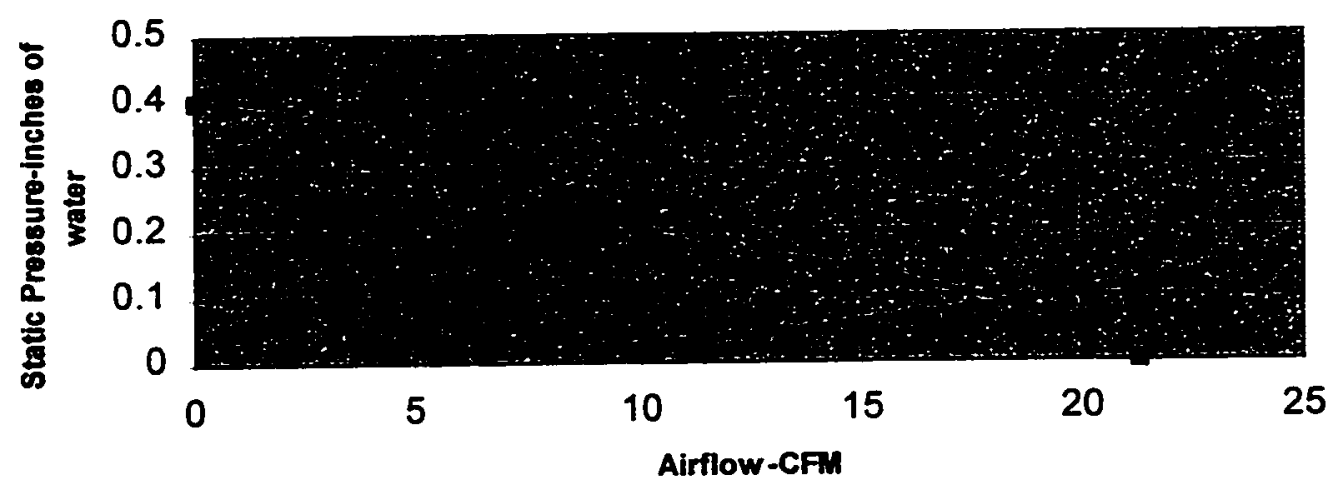

- System mpedance curve - Manufacturer's Fan curve

Figure 4.11: Fan-System Performance Curves for fans in series (Basic Model). 


\section{Computational Fluid Dynamics 1:}

Total airflow of the system is 17.24 CFM $(0.0093189 \mathrm{~kg} / \mathrm{s})$.

Figure 4.12: Velocity profiles of basic model with fans in series (+y-axis).

\section{Computational Fluid Dynamics 2:}

Total airflow of the system is 17.39 CFM $(0.0093998 \mathrm{~kg} / \mathrm{s})$.

The velocity vectors of this model are shown in figure 4.12 , oriented from $+y$-axis.

\subsection{Basic Model with $60 \mathrm{~mm}$ Fans in Parallel}

Experiment conducted with 1.6" nozzle:

Total airflow of the system: 27.0 CFM@ $0.075 \mathrm{lbs} / \mathrm{ft}^{3}$ Density

Matching the fan to the system: 
The impedance test was done with a 1.6" nozzle and the fan curve was obtained from the manufacturer. The operating point obtained from figure 4.13 is 28.0 CFM.

System operating point: $28.0 \mathrm{CFM}$

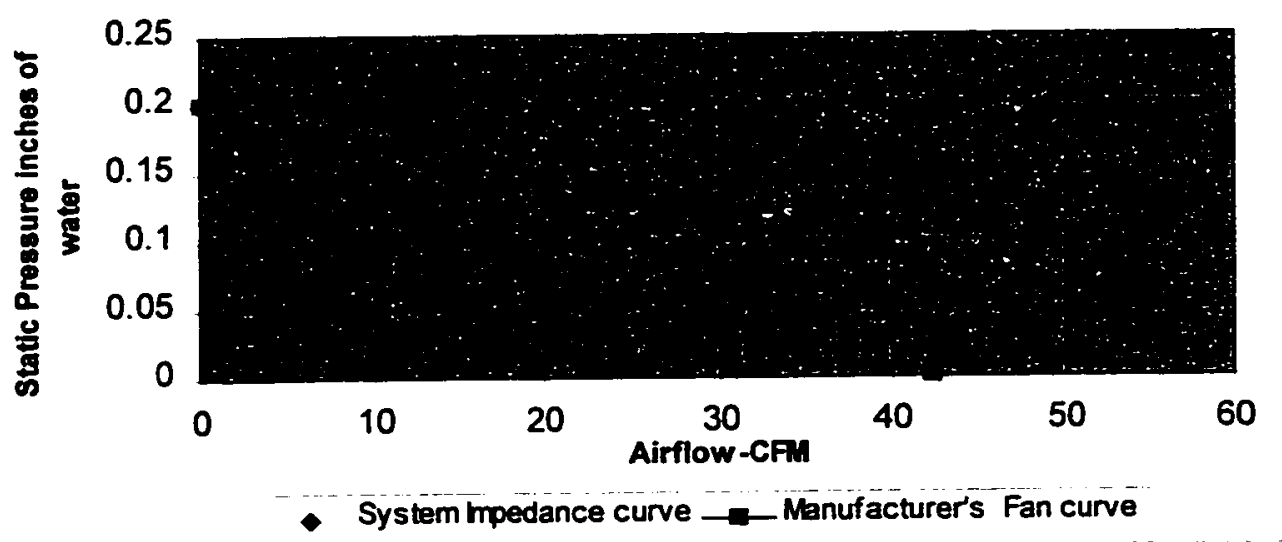

Figure 4.13: Fan-System Performance Curves for fans in parallel (Basic model).

\section{Computational Fluid Dynamics 1:}

Total airflow of the system is 28.22 CFM $(0.015254 \mathrm{~kg} / \mathrm{s})$.

\section{Computational Fluid Dynamics 2:}

Total airflow of the system is 29.6 CFM $(0.0159978 \mathrm{~kg} / \mathrm{s})$.

\subsection{Detailed Model with $60 \mathrm{~mm}$ Fan}

Experiment conducted with a 1" nozzle:

Total airflow of the system: 15 CFM@0.075 lbs $/ \mathrm{ft}^{3}$ Density

Matching the fan to the system:

The impedance test was done with a 1 " nozzle and the fan curve was obtained from the manufacturer. The operating point obtained from figure 4.5 is 16.75 CFM. 
Computational Fluid Dynamics 1:

Total airflow of the system is 15.91 CFM $(0.0086110 \mathrm{~kg} / \mathrm{s})$.

System operating point : $16.75 \mathrm{~cm}$

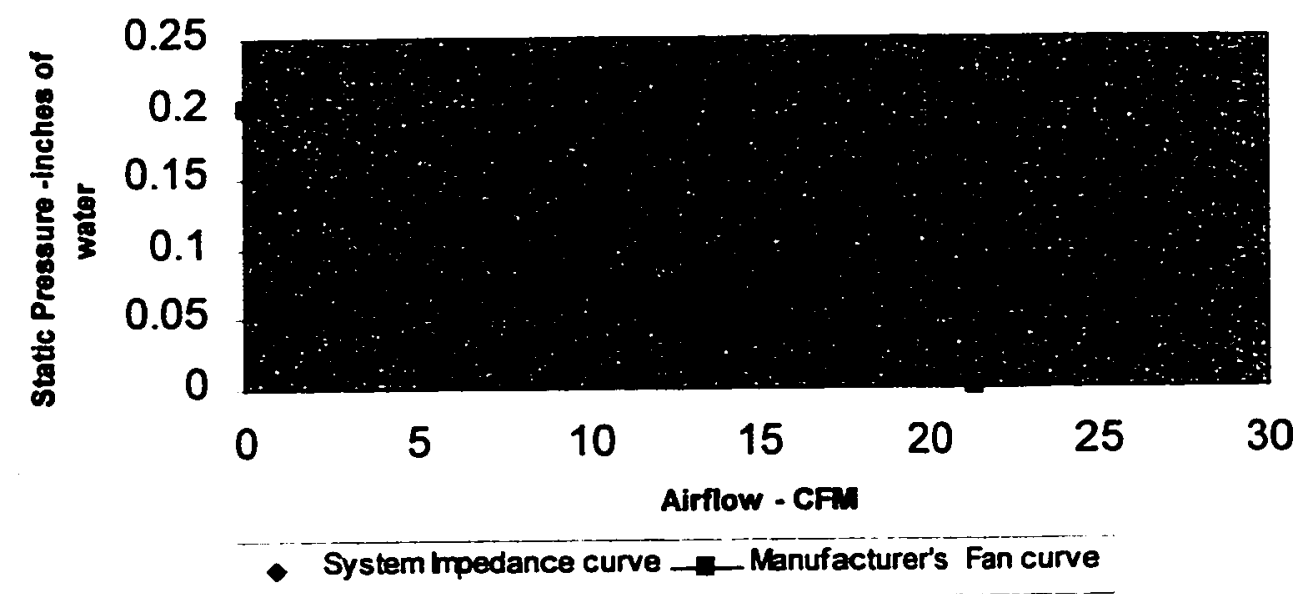

Figure 4.14: Fan-System Performance curves of $60 \mathrm{~mm}$ fan (Detailed Model).

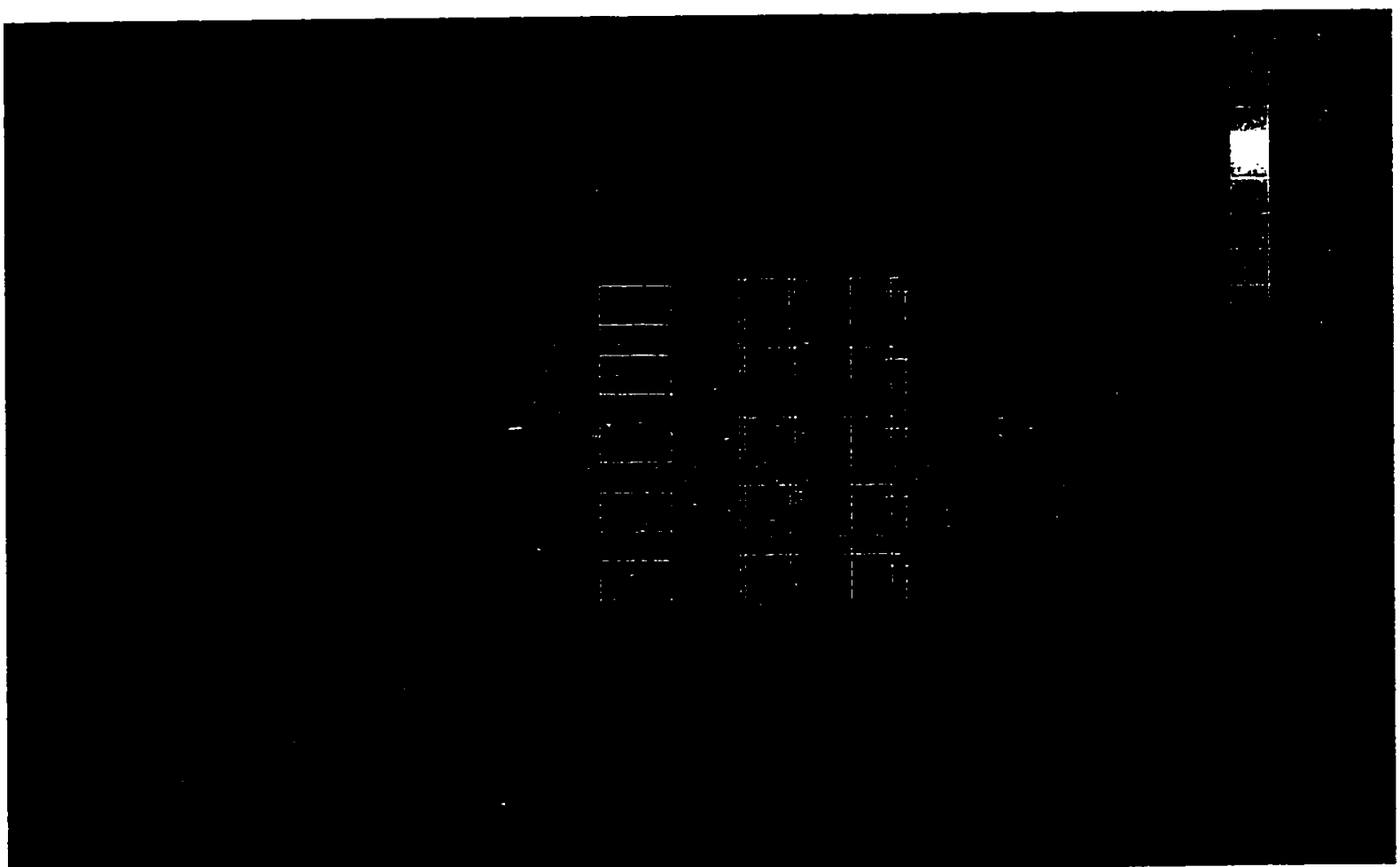

Figure 4.15: Velocity profiles of the detailed model ( $60 \mathrm{~mm}$ fan and $33 \%$ open area). 


\section{Computational Fluid Dynamics 2:}

Total airflow of the system is 16.3 CFM $(0.0088108 \mathrm{~kg} / \mathrm{s})$.

The velocity vectors of this model are shown in figure 4.15 . The projected view is taken from $+\mathrm{y}$-axis.

\subsection{Detailed Model with $80 \mathrm{~mm}$ Fan}

Experiment conducted with 1" nozzle:

Total airflow of the system: 23.5 CFM @ $0.075 \mathrm{lbs} / \mathrm{ft}^{3}$ Density

Matching the fan to the system:

The impedance test was done with a 1 " nozzle and the fan curve was obtained from the manufacturer. The operating point obtained from figure 4.16 is 22.5 CFM.

System operating point : $22.5 \mathrm{cfm}$

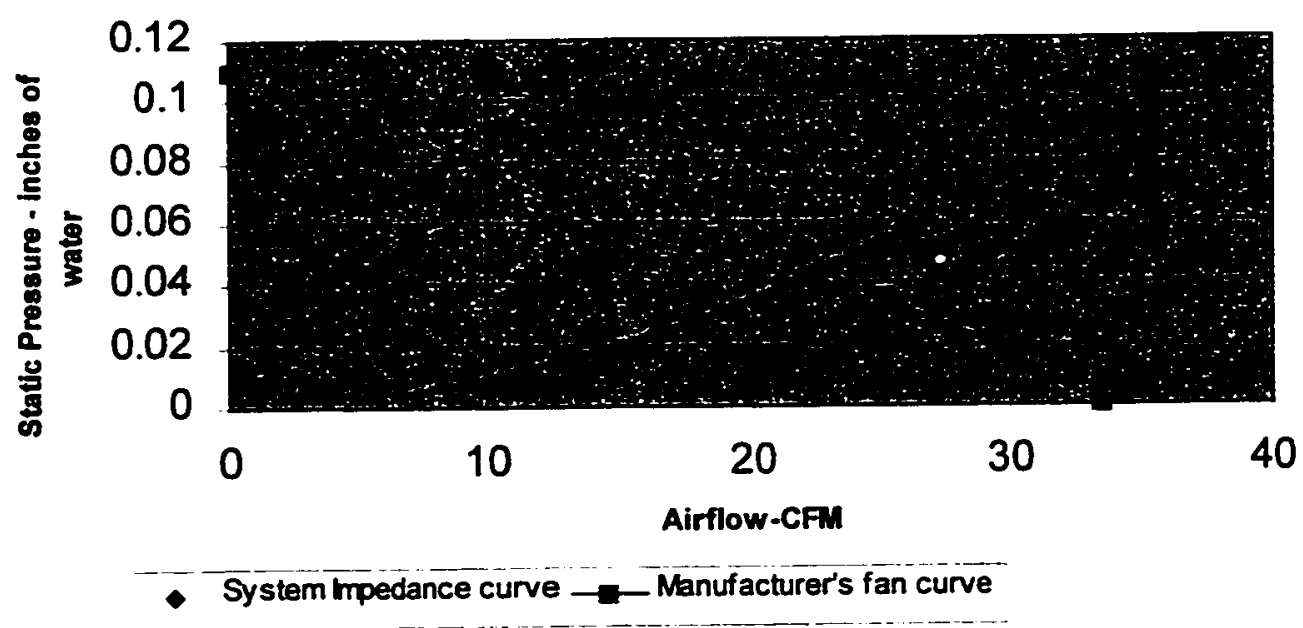

Figure 4.16: Fan-System Performance curves for $80 \mathrm{~mm}$ fan (Detailed model). 


\section{Computational Fluid Dynamics 1:}

Total airflow of the system is 19.4 CFM $(0.0104805 \mathrm{~kg} / \mathrm{s})$.

\section{Computational Fluid Dynamics 2:}

Total airflow of the system is $21.0 \mathrm{CFM}(0.0113510 \mathrm{~kg} / \mathrm{s})$.

The velocity vectors are shown in figure 4.17 with $80 \mathrm{~mm}$ fan.

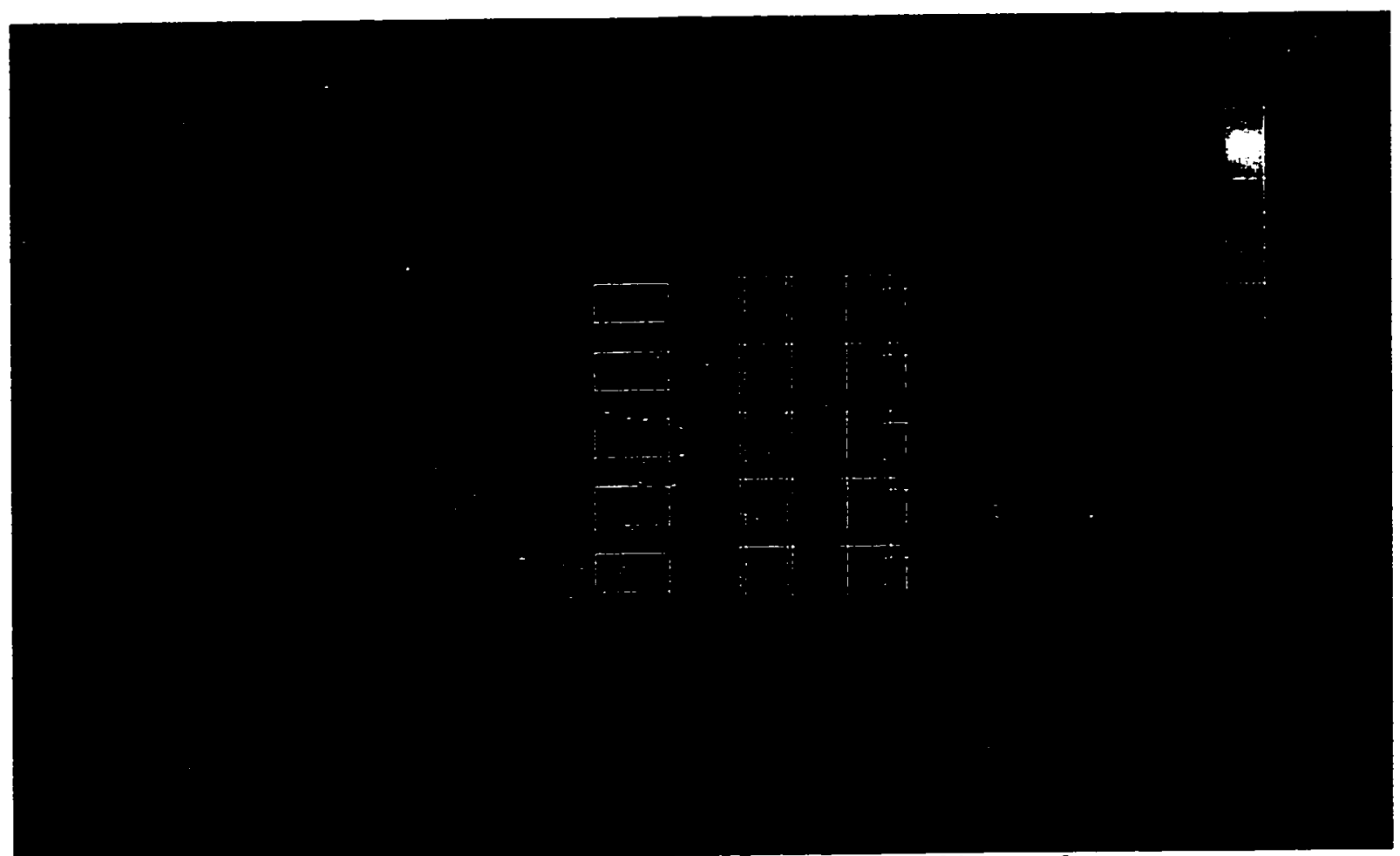

Figure 4.17: Velocity profiles of the detailed model with $80 \mathrm{~mm}$ fan.

\subsection{Detailed Model with $92 \mathrm{~mm}$ Fan}

Experiment conducted with 1.6" nozzle:

Total airflow of the system: 32.0 CFM@ $0.075 \mathrm{lbs} / \mathrm{ft}^{3}$ Density

Matching the fan to the system:

The impedance test was done with a 1.6" nozzle and the fan curve was obtained from the manufacturer. The operating point obtained from figure 4.18 is 29.5 CFM. 


\section{Computational Fluid Dynamics 1:}

Total airflow of the system is 25.36 CFM $(0.013708 \mathrm{~kg} / \mathrm{s})$.

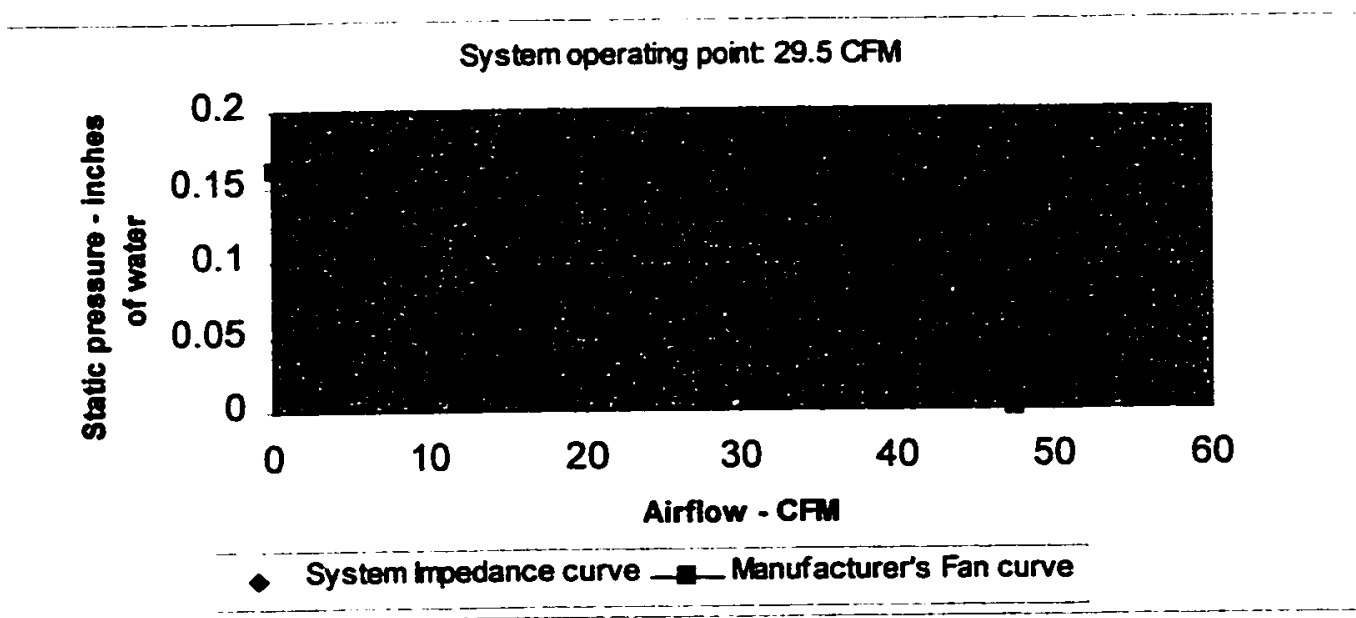

Figure 4.18: Fan-System Performance curves with $92 \mathrm{~mm}$ fan (Detailed model).

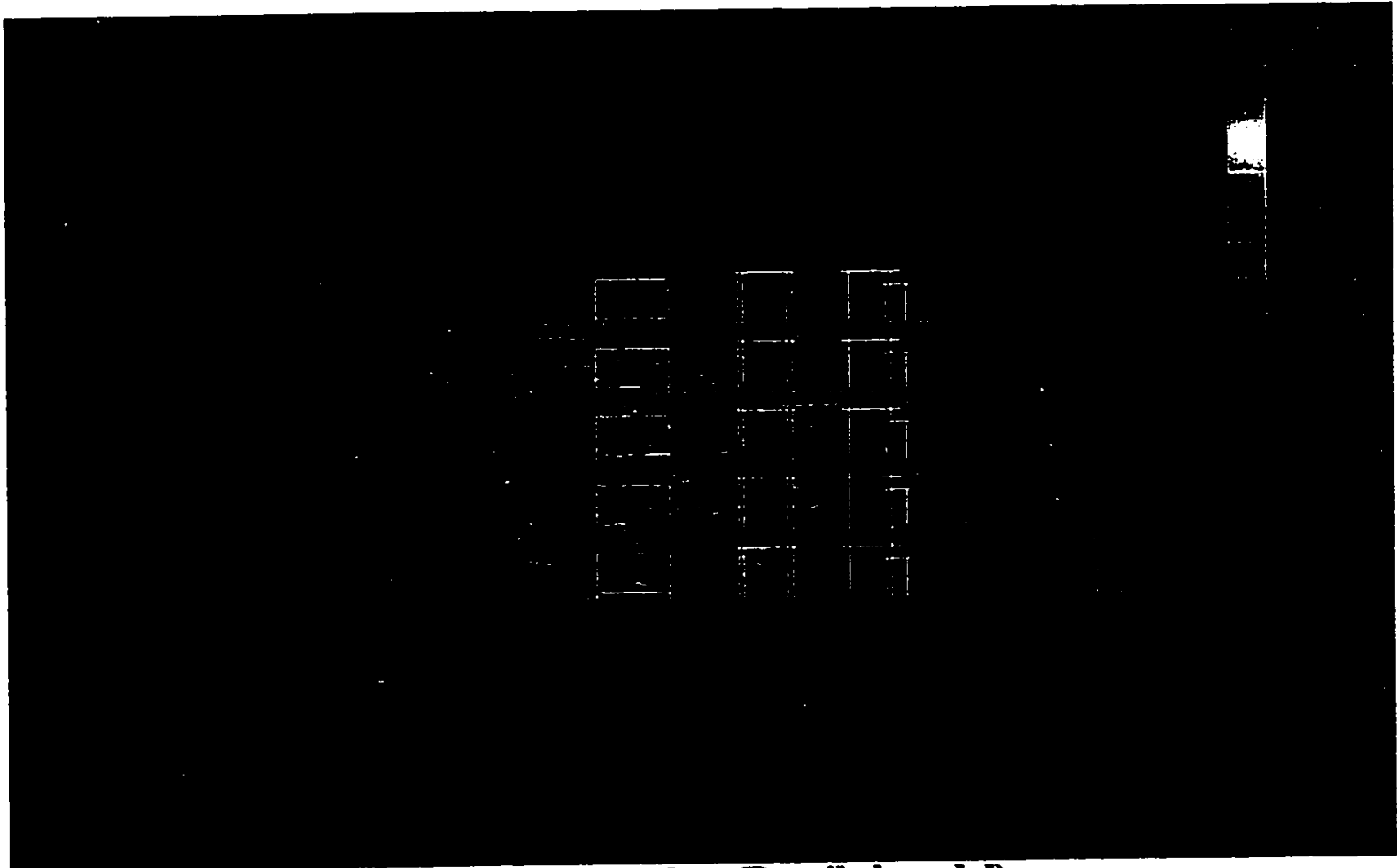

Figure 4.19: Velocity profiles of $92 \mathrm{~mm}$ fan. (Detailed model). 


\section{Computational Fluid Dynamics 2:}

Total airflow of the system is 28.0 CFM $(0.015135 \mathrm{~kg} / \mathrm{s})$. The velocity vectors are shown in figure 4.19.

\subsection{Detailed Model with $60 \mathrm{~mm}$ Fans in Series}

Experiment conducted with 1" nozzle:

Total airflow of the system: 16.0 CFM@0.075 lbs/ $\mathrm{ft}^{3}$ Density

Matching the fan to the system:

The impedance test was done with a 1" nozzle and the fan curve was obtained from the manufacturer. The operating point obtained from figure 4.20 is 17.2 CFM

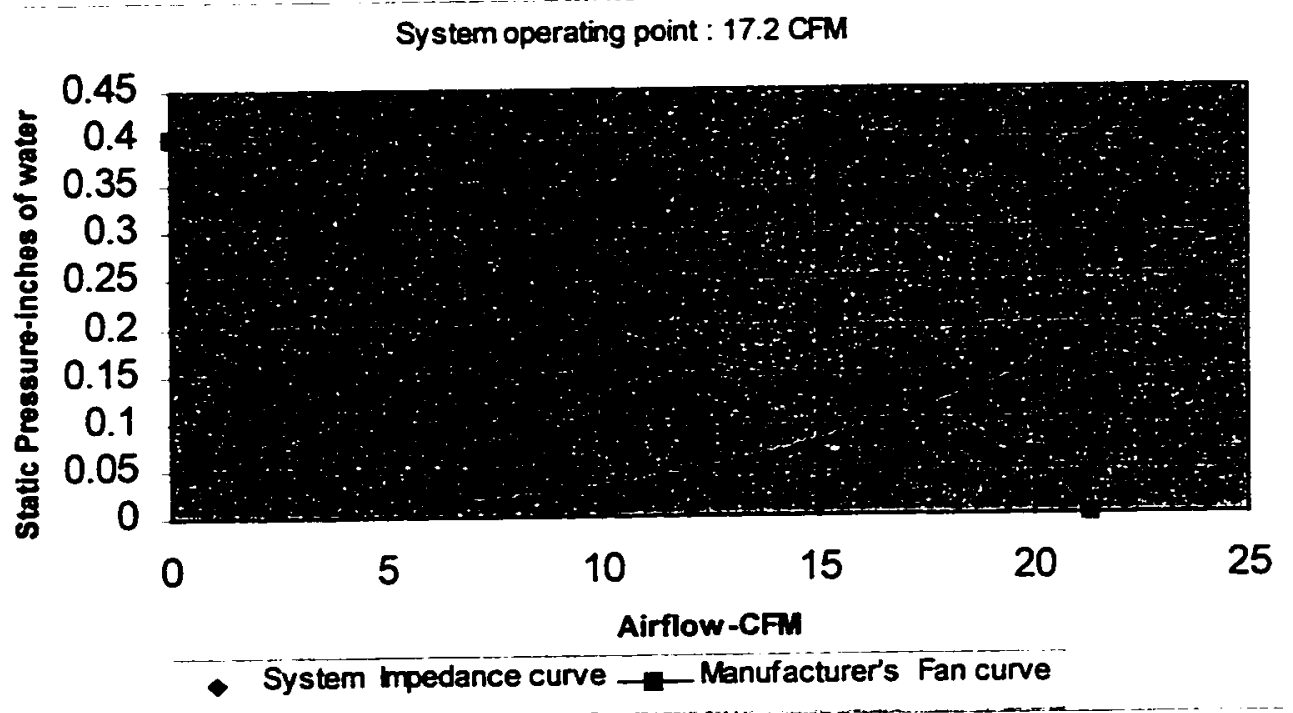

Figure 4.20: Fan-System Performance curves with fans in series (Detailed model)

\section{Computational Fluid Dynamics 1:}

Total airflow of the system is 17.04 CFM $(0.0092108 \mathrm{~kg} / \mathrm{s})$. 


\section{Computational Fluid Dynamics 2:}

Total airflow of the system is 17.29 CFM $(0.0093450 \mathrm{~kg} / \mathrm{s})$. The velocity vectors are shown in figure 4.21 with the fans in series.

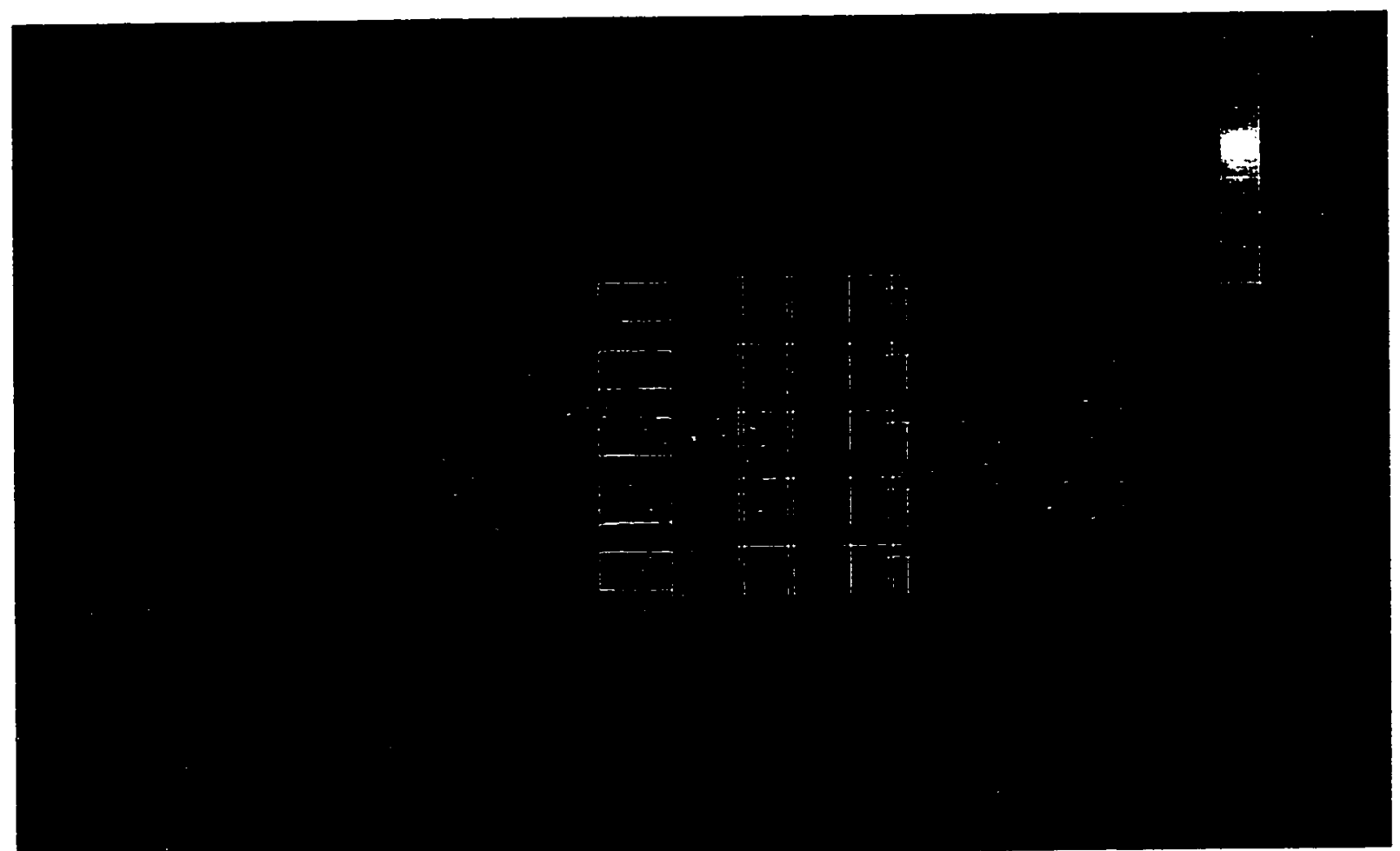

Figure 4.21: Velocity profiles of fans in series (Detailed model).

\subsection{Detailed Model with $60 \mathrm{~mm}$ Fans in Parallel}

Experiment conducted with 1.6" nozzle:

Total airflow of the system: 26.0 CFM@ $0.075 \mathrm{lbs} / \mathrm{ft}^{3}$ Density

Matching the fan to the system:

The impedance test was done with a 1.6" nozzle and the fan curve was obtained from the manufacturer. The operating point obtained from figure 4.22 is 29.0 CFM.

\section{Computational Fluid Dynamics 1}

Total airflow of the system is 26.80 CFM $(0.0144862 \mathrm{~kg} / \mathrm{s})$. 


\section{Computational Fluid Dynamics 2:}

Total airflow of the system is 28.86 CFM $(0.0156002 \mathrm{~kg} / \mathrm{s})$.

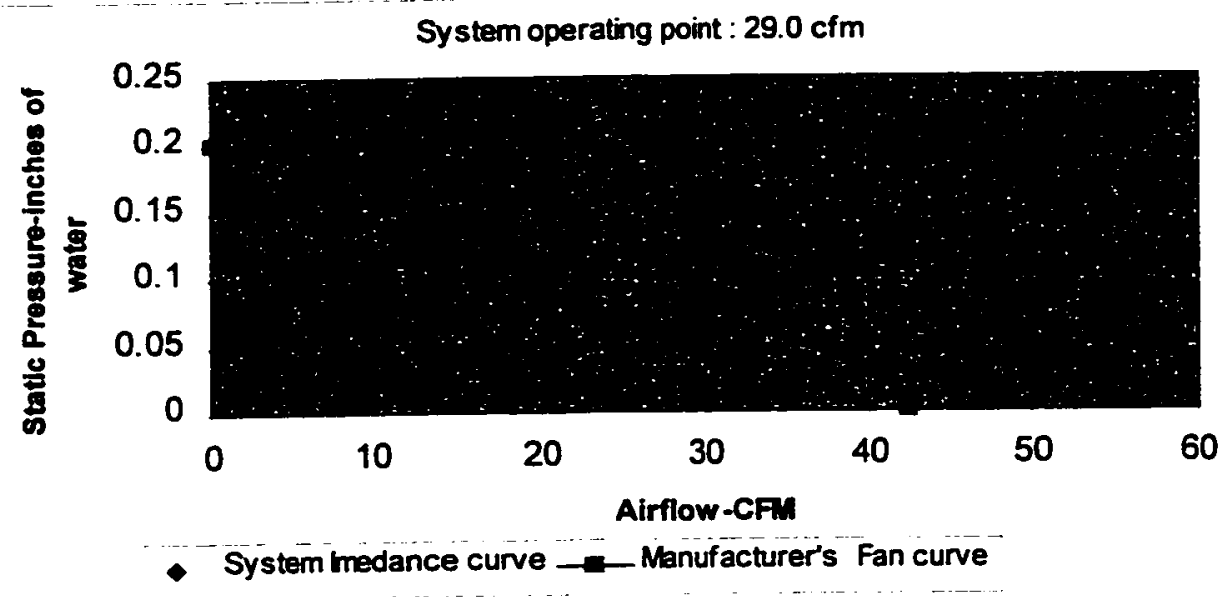

Figure 4.22: Fan-System Performance curves with fans in parallel (Detailed model).

\subsection{Results and Discussion}

Comparative study was done between experimental, CFD-1, CFD-2 and total volume flow obtained using fan-system performance curves. Figure 4.23 compares the airflow with respect to the open area of the grills. From this figure it can be deduced that as the percent open area continues increasing, the airflow in CFM continues increasing.

The free airflow of the fan is 22 CFM. With $40 \%$ open area the percentage error between the experimental and CFD-1/ CFD-2/ Using fan-system performance curves is the minimum as shown in figure 4.24. The explanation of this is, as the open area continues decreasing, more and more pressure drop occurs in the region of inlet and outlet grills and thus the total airflow continues decreasing. From the graph it can be inferred that the percentage error in the case of results using fan-system performance curves is the 
maximum compared to CFD-1 and CFD-2. It was found that the percentage error of up to $10 \%$ occurs in those cases.

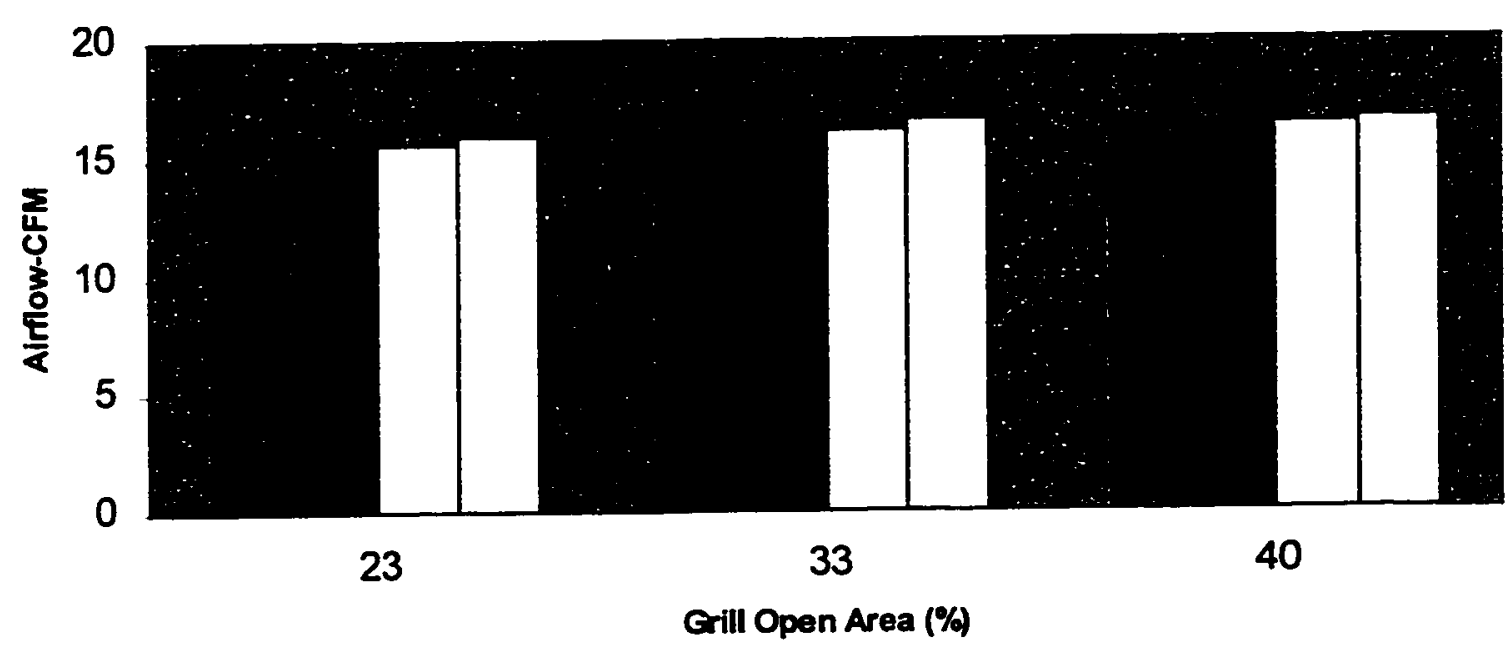

Expt ECD-1 aCFD-2 םUsing Fan-System Performance Curves

Figure 4.23: Comparison of airflow with percent open area of grill.

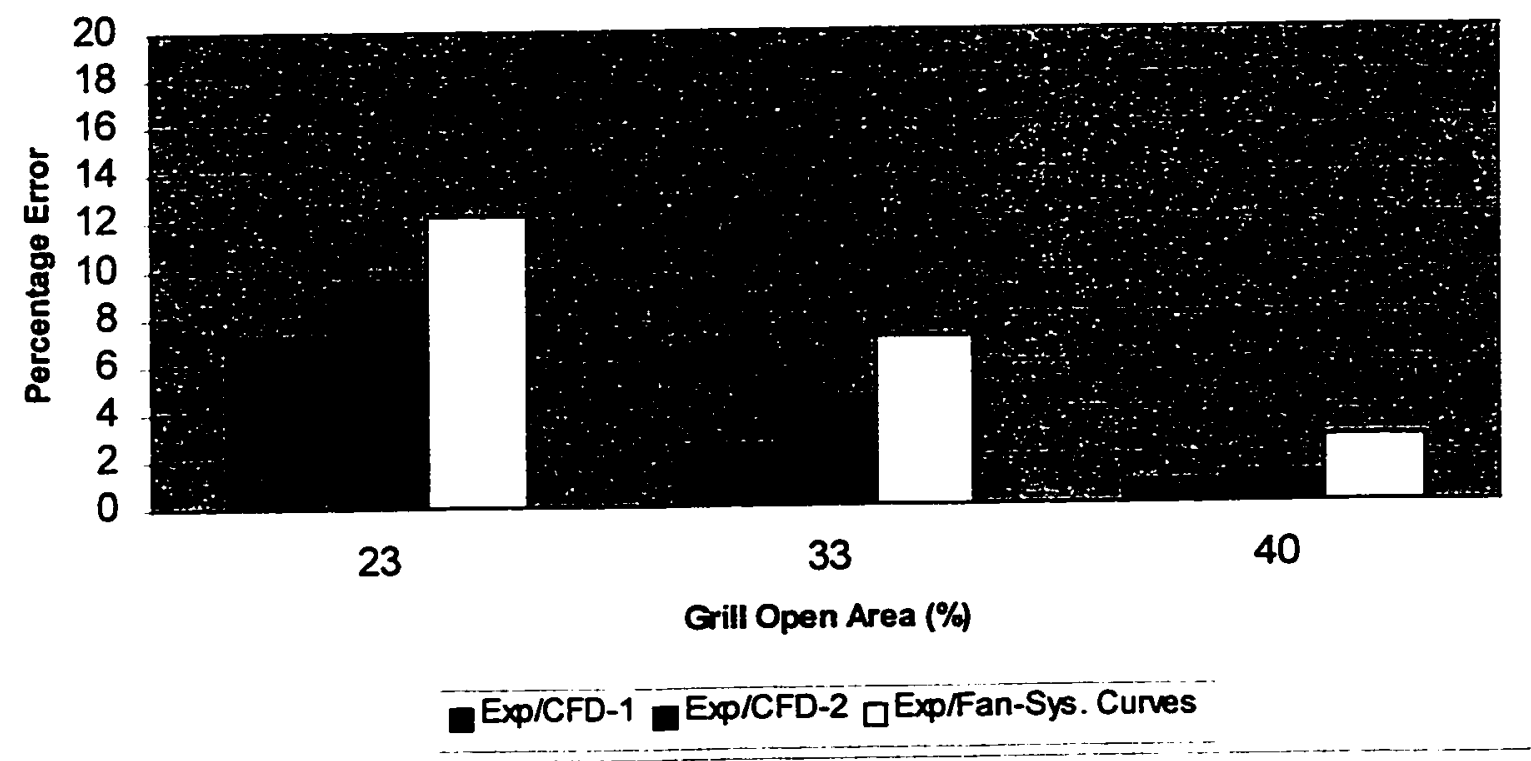

Figure 4.24: Percentage error in airflow versus percentage open area of grill. 


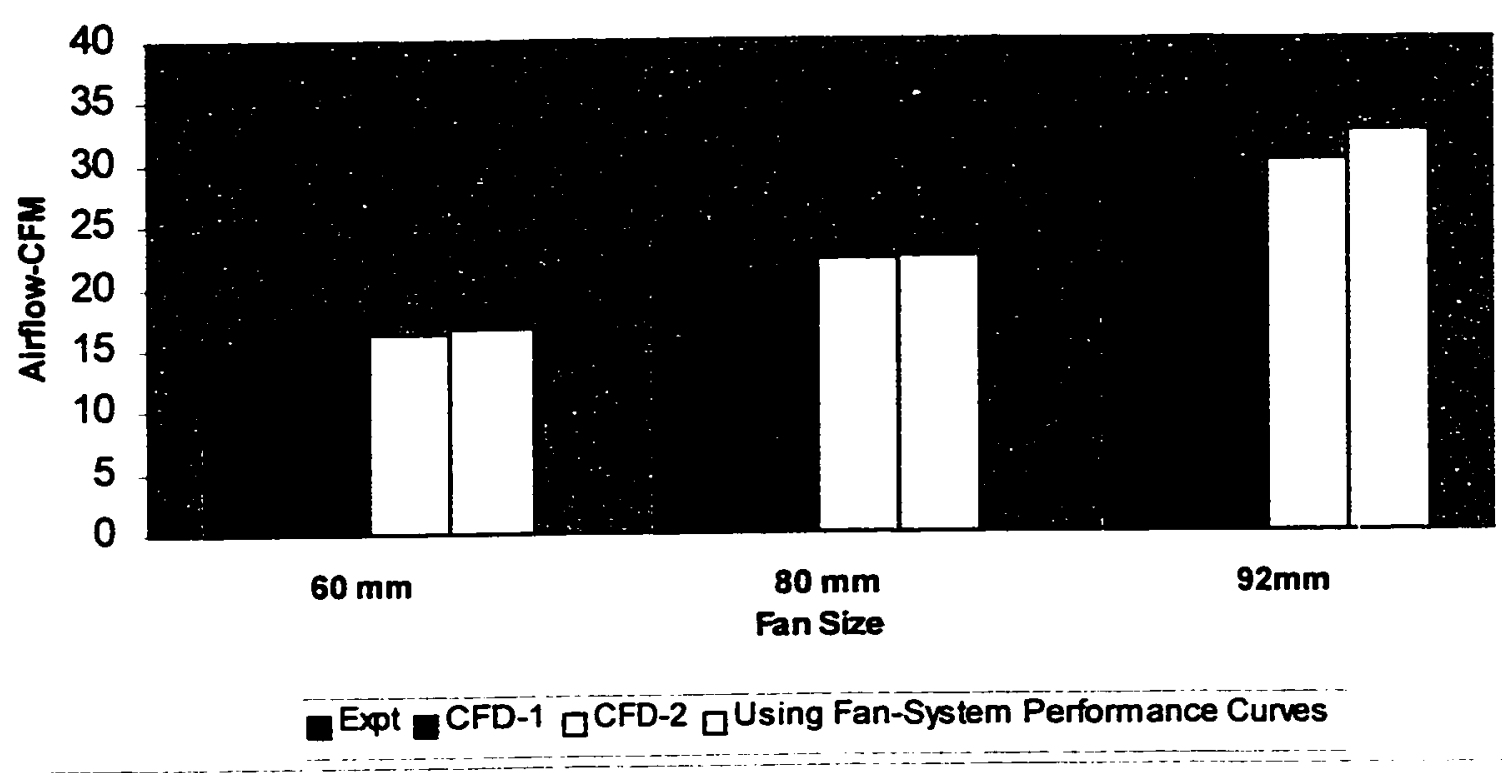

Figure 4.25: Comparison of airflow with change in fan size (Basic Model).

Figures 4.25 and 4.26 illustrate the comparison of different methods with change in fan size. In most of the cases the highest airflow is given by the experimental results.

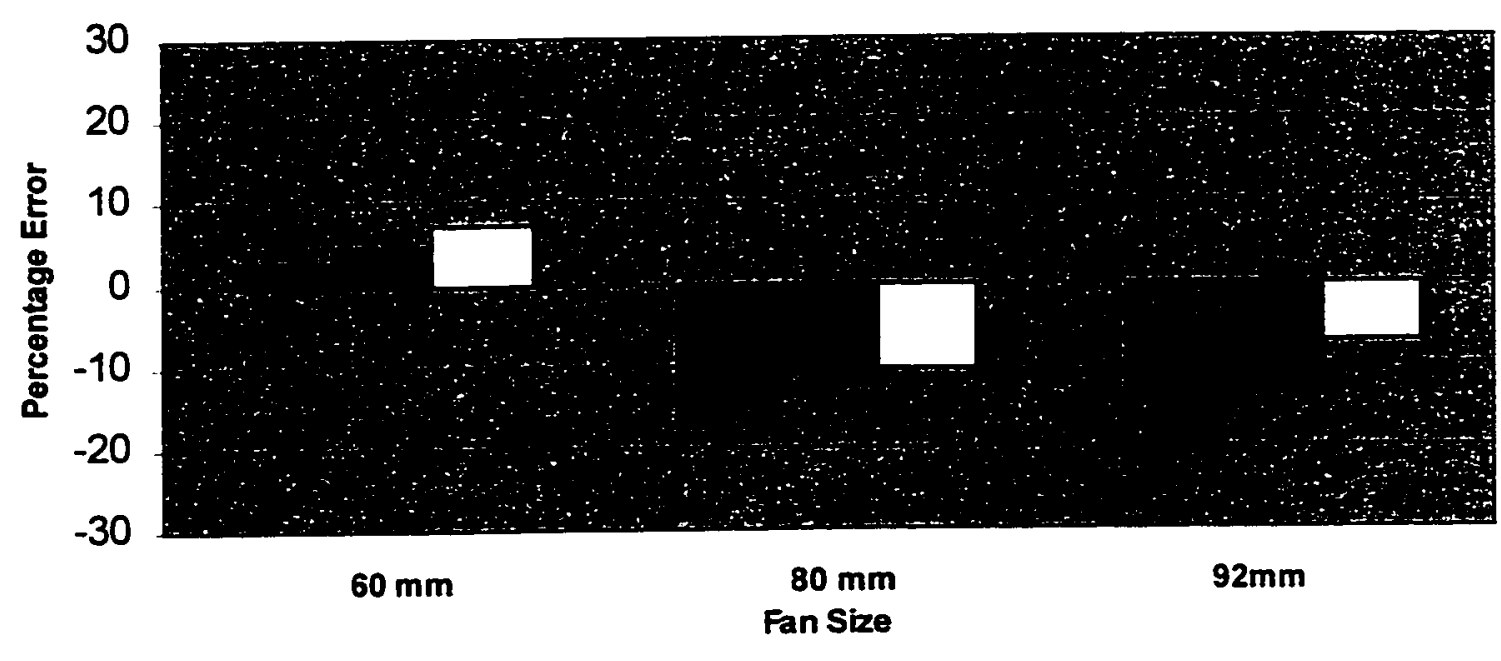

Exp/CFD-1 Expt/CFD-2 aExp/Fan-Sys. Cunves

Figure 4.26: Percentage error of airflow versus fan size (Basic Model). 
Figures 4.27 and 4.28 compare different techniques with change in fan size for the detailed model.

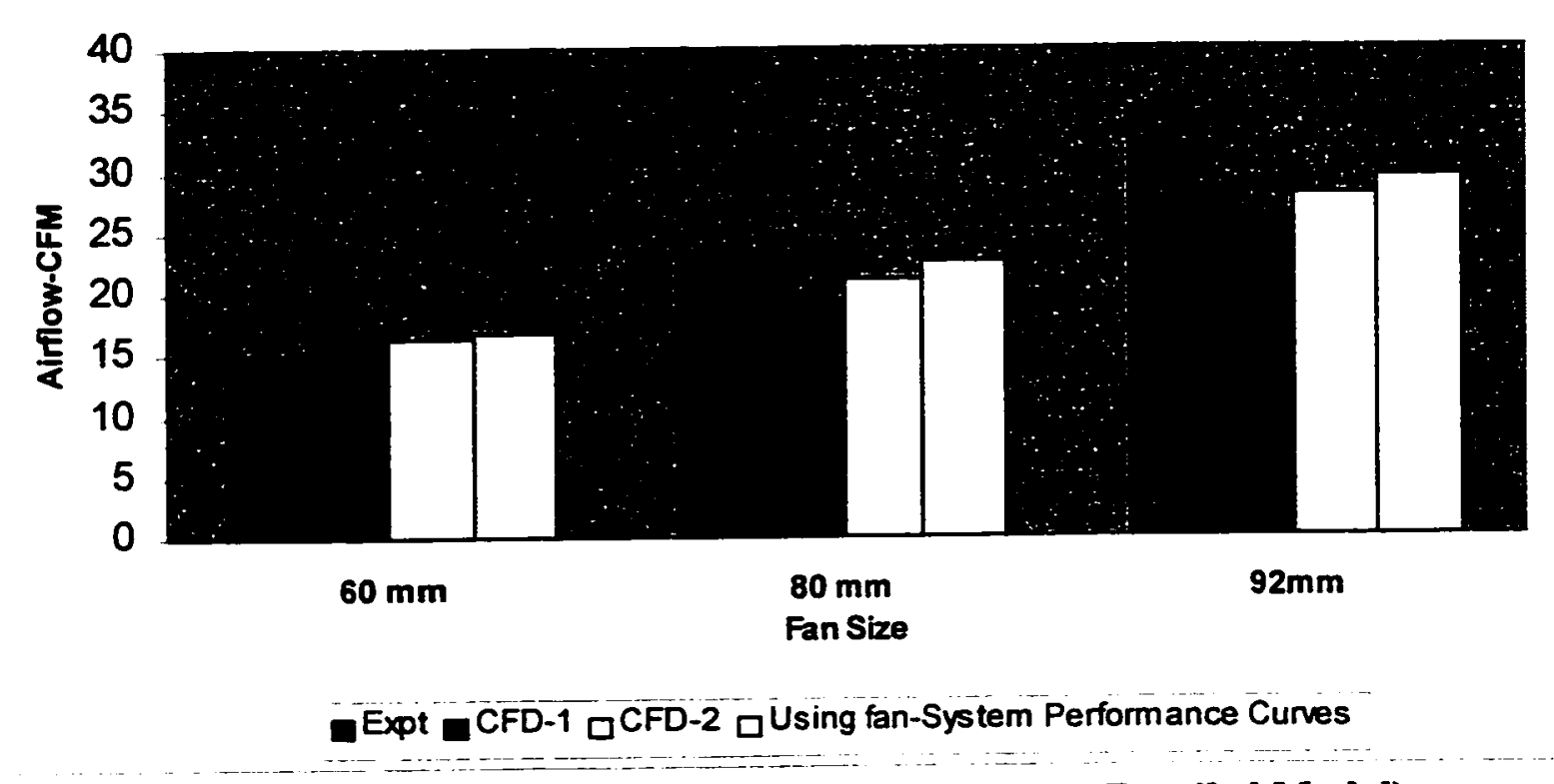

Figure 4.27: Comparison of airflow with change in fan size (Detailed Model).

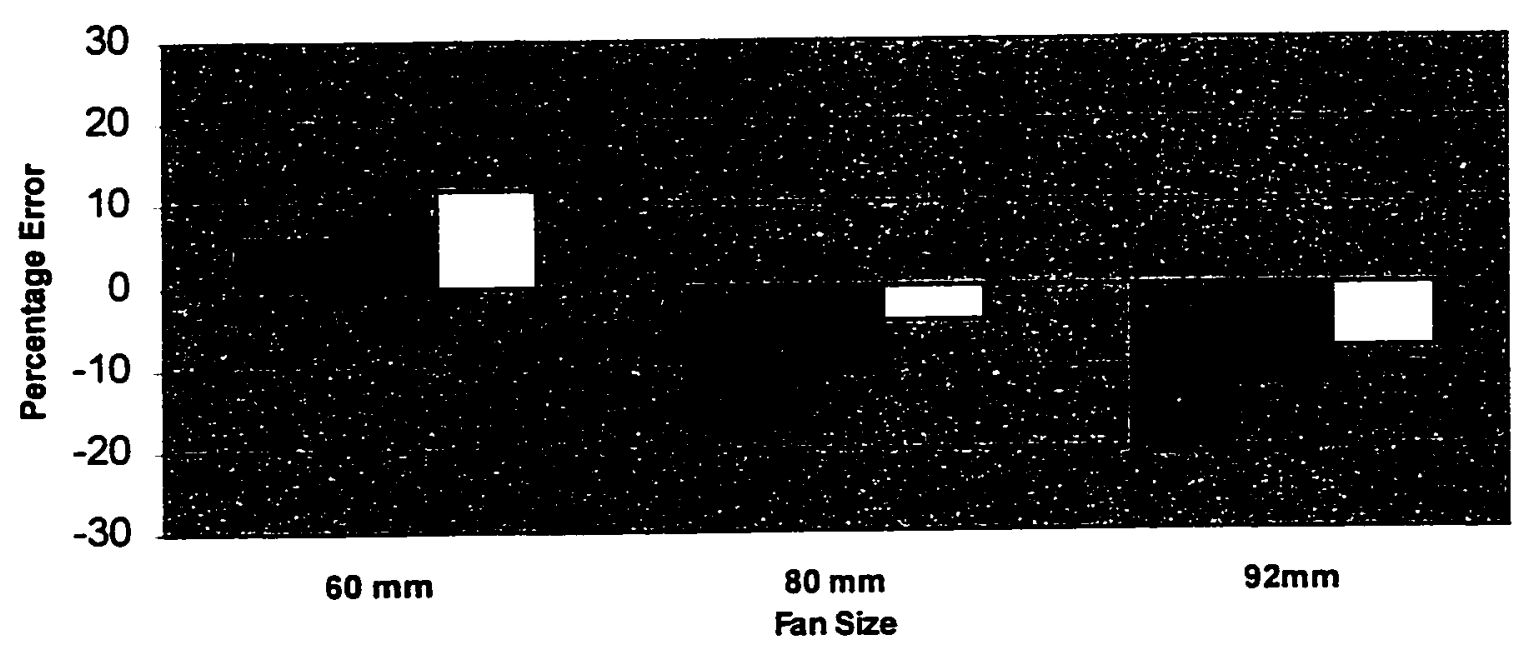

ExptCFD-1 ExptCFD-2 axptusing Fan-Sys. curves.

Figure 4.28: Percentage error in airflow versus fan size (Detailed Model). 
The trend for the detailed model in figures 4.27 and 4.28 is similar to that of basic model shown in figures 4.25 and 4.26 . In both basic and detailed model for $80 \mathrm{~mm}$ and $92 \mathrm{~mm}$ fans the experimental result has the highest airflow compared to CFD-1, CFD-2 and airflow found using fan-system performance curves.

In the variation of the fan size, the percentage error goes up to $21 \%$. In case of CFD-1 (modeling done with the loss coefficient given in the handbook) the error in airflow rose $21 \%$.

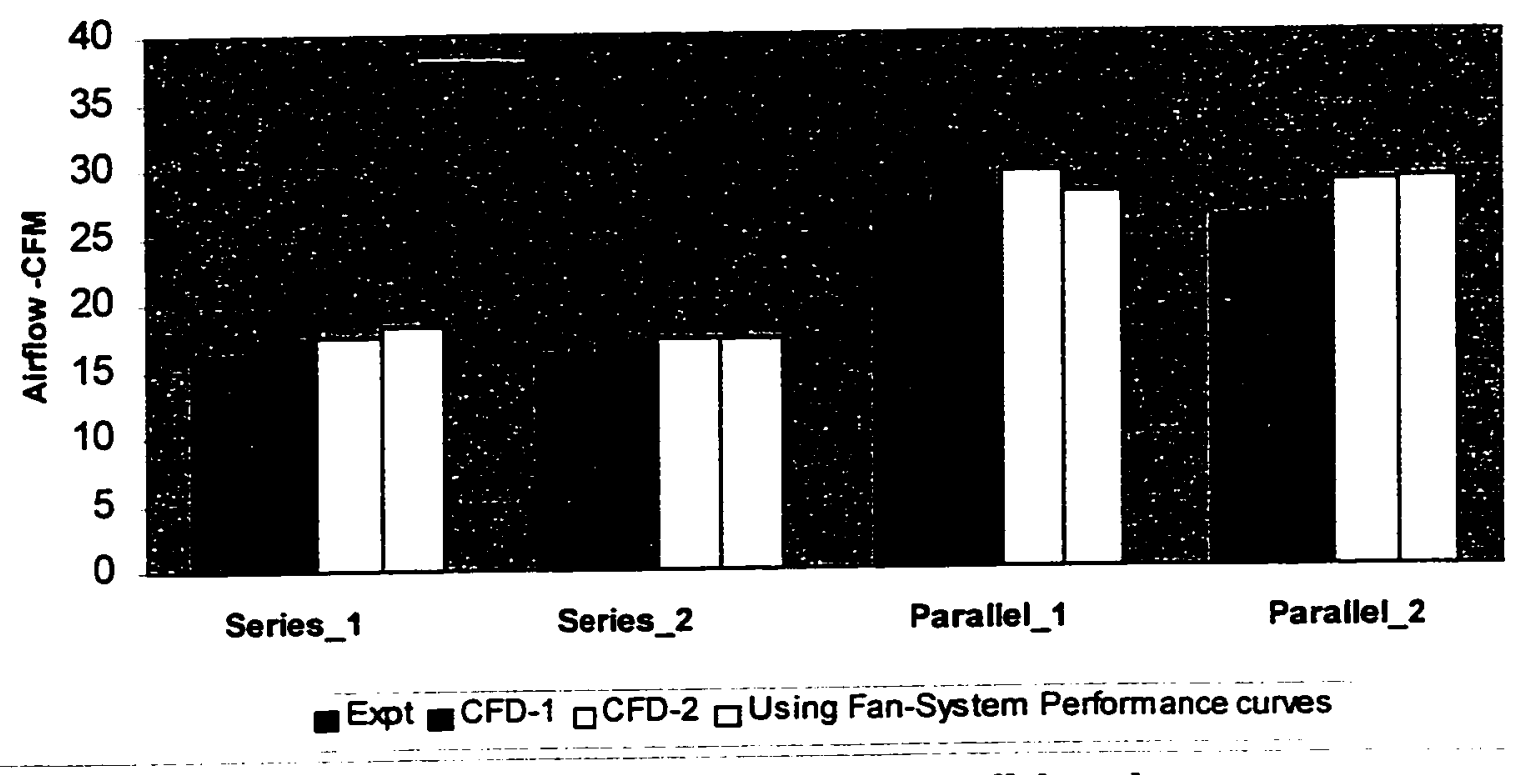

Figure 4.29: Comparison of airflow for series and parallel mode.

Series_1: Fans in series for the basic model.

Series_2: Fans in series for the detailed model.

Parallel_1: Fans in parallel for the basic model.

Parallel_2: Fans in parallel for the detailed model. 
Figures 4.29 and 4.30 illustrate the measured airflow of fans in series and parallel mode for both the basic and detailed models. When the fans are in parallel the airflow increased compared to one fan is more than when the fans are in series mode. In both the basic and detailed models the airflow is almost identical for series and parallel cases. The reason behind this is that the maximum pressure drop is occurring because of the inlet and outlet grills. Thus adding any extra component to the PCBs hardly makes any difference. The percentage error in this case lies between $15 \%$.

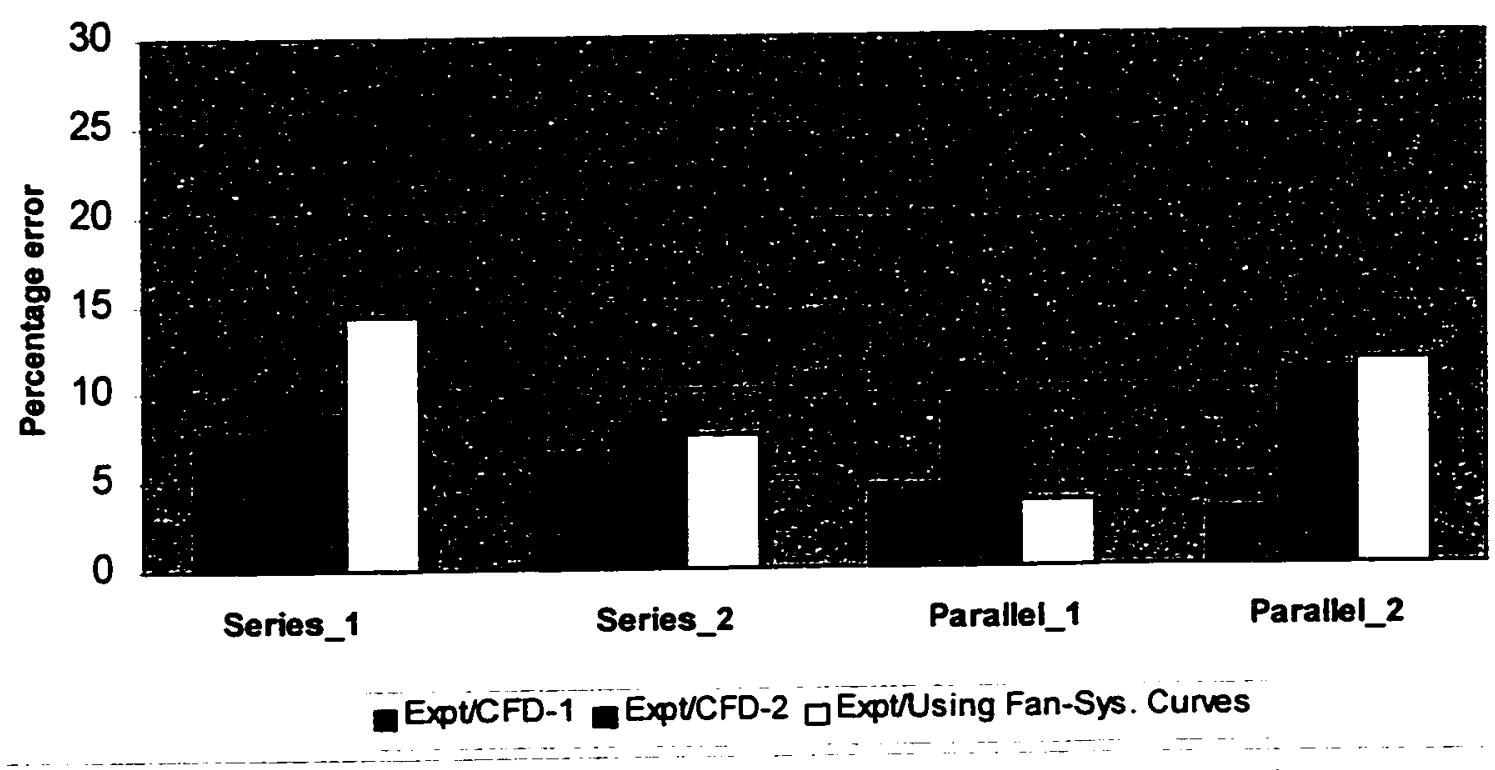

Figure 4.30: Percentage error in airflow with fans in series and parallel.

Figure 4.31 shows the solution obtained from ICEPAK to be mesh independent. This checked with the basic model (60mm fan with $33 \%$ open area grill). The element count in the CFD model varied from 17,000 to 90,000 . 


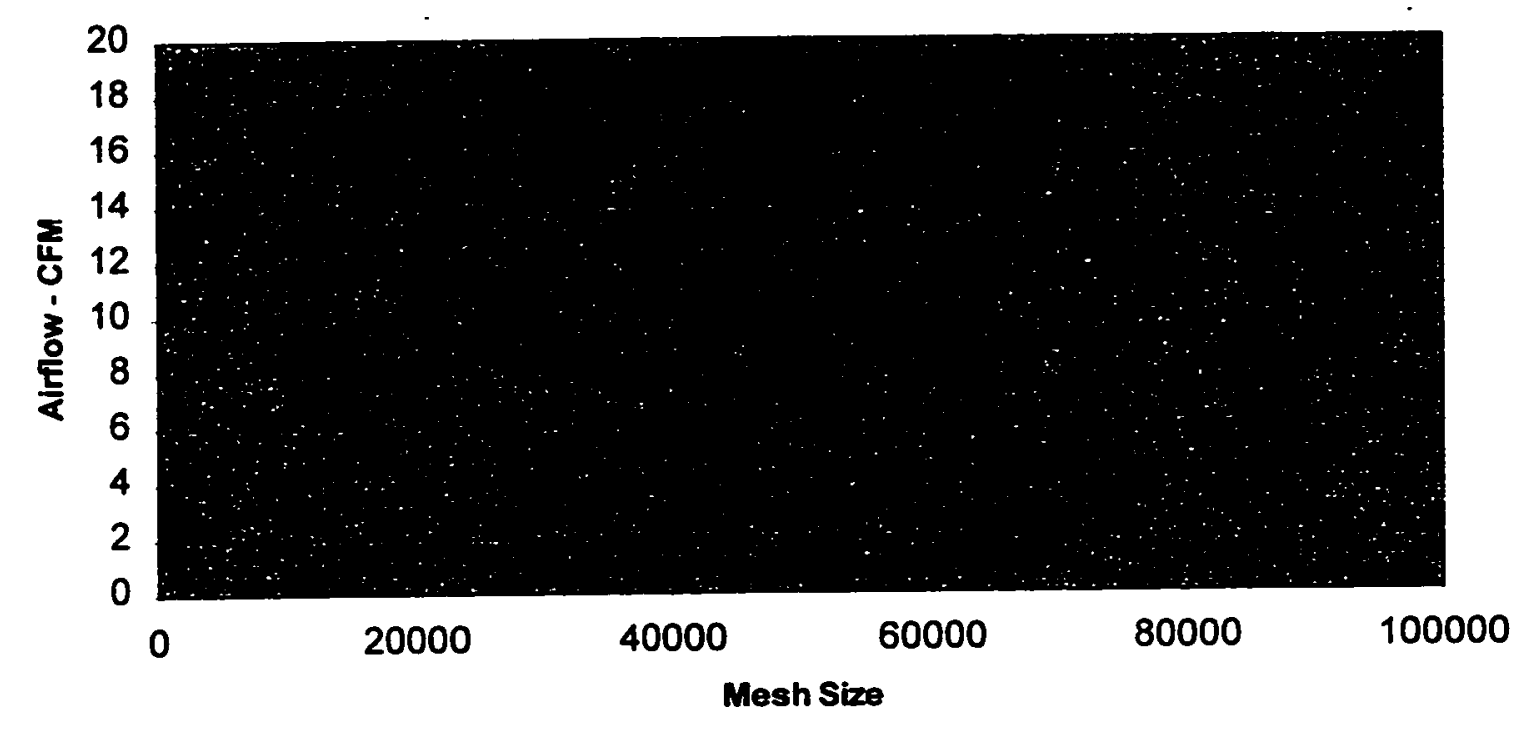

Figure 4.31: Graph showing mesh independent solution.

To investigate the reason behind the rise of percentage error with the increase in the fan size, several different modifications were conducted with the CFD model. It was observed that by adding the swirl magnitude and the hub radius of the fan, there is almost no change in the airflow compared to the previous cases (without swirl magnitude and hub radius). 


\section{Chapter 5}

\section{Conclusions}

During the design of forced convection cooled electronic enclosures, one of the most important parameters needed is airflow through the enclosures. The airflow through the enclosure depends mainly upon the pressure drop in the enclosures and the fan characteristic.

The system chosen for this analysis represents a typical electronic enclosure, such that, the results obtained from the analysis help us solve the problems faced in electronics cooling industries. Fan curves are often used in conjunction with the system pressure drop (impedance) characteristics to determine the airflow. In addition, the CFD tool uses the fan curve data provided by the manufacturer.

The system was designed to have a good understanding of the problem. Results obtained from CFD simulation and by using fan-system performance curves compared favorably with the experimental results obtained using a wind tunnel. It was found that errors of up to $20 \%$ could occur depending on the methods used to calculate the flow.

The following are the main conclusions of this study:

1. It was found that using the pressure loss coefficients of the inlet and outlet grills from the data handbook in the CFD model can cause up to $20 \%$ error in airflow prediction. 
However, this error is reduced to $13 \%$ when the pressure loss coefficients were experimentally measured using the wind tunnel.

2. The pressure loss coefficient is inversely proportional to square of the velocity. As the fan size increases the percentage error calculated with the pressure loss coefficients given in the handbook increases by $5 \%$ to $10 \%$. The numerical values of the pressure loss coefficient given in the handbook are more than the values calculated experimentally.

3. As expected, the percentage errors reduced significantly with increase in percentage open area of the inlet and the outlet grills.

4. The total airflow obtained with detailed models in which the printed circuit boards have components such as capacitors, inductors, transformers and heat sinks does not differ much, as compared to the basic model in identical situations. This is because the maximum pressure drop is occurring across the inlet and outlet grills and thus making the model denser by adding components to the printed circuit boards does not decrease the total airflow through the system.

5. The flow predicted by the experimental method is less in most of the cases compared to the flow predicted by fan-system performance curves and by CFD modeling. Only in the case with $80 \mathrm{~mm}$ and $92 \mathrm{~mm}$ fans, does the experimental result gives us more flow compared to the flow predicted by other different methods.

6. In the case of detailed modeling, total number of element counts were approximately 200,000 , which used to take almost 7 to 8 hours of computer time.

7. If the macro command was used to model heat sinks, instead of modeling with blocks, the number of element counts were reduced and hence the computational time. 
8. The experimental results obtained are associated with some kind of errors, such as the errors associated with the wind tunnel, zero error of the manometers etc. Those types of errors are taken care of while finding out the total airflow.

9. The simulation done with the enclosure inside the bigger cabinet reduces the percentage error to a great extent in the case of bigger fans. The possible reason for this is explained before.

10. Although the experimental approach has the capability of producing the most realistic answers, the costs are becoming greater everyday. Over the years the cost of performing numerical calculations has decreased rapidly. Therefore comparing the numerical technique (CFD) with the experimental and performance curves techniques will help us reduce both time and cost for future flow analysis.

\subsection{Future Work}

The following work can be done in the future:

1. Finding the reason for increase in percentage error with increase in fan size.

2. Extending the current work to include effect of thermal loads.

3. Extending the work to include blowers. 


\section{$\underline{\text { References }}$}

[1] Linton, R.L., and Agonafer, D., 1989, "Thermal Model of a PC," Numerical Simulation of Convection in Electronic Equipment Cooling, A. Ortega and D. Agonafer eds., American Society of Mechanical Engineers, HTD-Vol. 121, pp.6972.

[2] Mansingh, V., and Misegades, K.P.,1990, "System Level Airflow Analysis for a Computer System Processing Unit," Hewlett Packard Journal, October, 1990, pp. 82-87.

[3] Hill, T.B., and Hill, C.C., 1990, " Effects of Electronic Enclosure Layout on Fan Performance," ASME paper 90-WA/EEP-6.

[4] Deiters, T. and Hill, T.B., 1991, "Correlation of Experimental Measurements to Computer Modelling of a Forced Convection Cooled Electronic Enclosure," ASME Paper 91-WA-EEP-35.

[5] Gopalakrishna, S., 1991, "Numerical and Experimental Study of Forced Convection over Power Supply Heat Sinks," ASME Paper No.91-WA-EEP-44.

[6] Agonafer, D., and Moffatt, D.F., 1990, "Numerical Modelling of Forced Convection Heat Transfer for Modules mounted on Circuit Boards," ASME Journal of Electronic Packaging, Vol. 112, pp. 333-337.

[7] Deiters, T. and Hill, T.B., 1992, "Study of Experimental/ Analytical Correlation Sensitivities to Typical Complexities in Electronic Enclosures," EEP-Vol. 1, Proceedings of the Joint ASME / JSME Advances in Electronic Packaging. 1992, pp. 263-270.

[8] Schmidt, R.C., and Patankar, S. V., 1986, "A Numerical Study of laminar Forced Convection Across Heated Rectangular Modules Encountered in Electronic Equipment," ASME paper 86-WA/HT-88.

[9] Davalath, J.,and Bayazitoglu, Y., 1987, "Forced Convection Cooling Across Rectangular Blocks," Journal of Heat Transfer, Vol 109, pp 321-328.

[10] Oosthuizen, P.H., 1988, "Effect of Block Temperature Differences on Forced Convective Heat Transfer From Tandem Rectangular blocks on a Channel Wall," Symposium on Fundamentals of Forced convection Heat Transfer, ASME HTDVol.101, pp 63-70. 
[11] Asako, Y., and Faghri, M., 1988, "Three-Dimensional Heat Transfer and Fluid Flow Analysis of Rectangular Blocks Encountered in Electronic Equipment." Numerical Heat Transfer, Vol. 13, pp 481-498.

[12] Asako, Y., and Faghri, M., 1989, "Three-Dimensional Heat Transfer Analysis of Heated Square Blocks." International Journal of Heat and Mass Transfer. Vol. 32, pp 395-405.

[13] Asako, Y., and Faghri, M., 1991, "Three-Dimensional Heat Transfer of Arrays of Heated Blocks Encountered in Electronic Equipment," Heat Transfer in Electronic Equipment, ASME HTD-Vol. 171, pp 133-141.

[14] Anderson, A.M., 1993 "A Comparison of Computational and Experimental Results For Flow and Heat Transfer From an Array of Heated Blocks." Advances in Electronic Packaging, ASME, 1993, EEP-Vol. 4-2, pp 583-591.

[15] Ashiwake, N., Nakayama, W., Kobayashi, F., and Daikoku, T., 1983, "Forced Convective Heat Transfer From LSI Packages in an Air Cooled Wiring Card Array." Research Laboratory Hitachi Ltd, Japan.

[16] Sriskanda, N. S., and Morehouse, J. H., 1993, "Applying The Flow Resistance Model to Computer Convective Cooling." Advances in Electronic Packaging, ASME, 1993, EEP-Vol. 4-2, pp 601-607.

[17] Ma, Y., and Recktenwald, G. W., 1993, "Simplified Simulation of Convective Heat Transfer From an Array of Heated Blocks in a Rectangular Channel" Advances in Electronic Packaging, ASME, 1993, EEP-Vol. 4-2, pp 609-618.

[18] Hill, T.B., and Lind, J., 1990, "Designing Ventilation Grilles for Electronic Equipment", Technical Article Reprint From Machine Design.

[19] Azar, K., 1998, "Measuring Fluid Velocity in Electronic Enclosures." Electronic Cooling, volume 4, no. 1 . 


\section{Bibliography}

[1] Avram Bar-Cohen; Fundamentals of Heat Transfer and Fluid Mechanics.

[2] H. Schlichting; Boundary Layer Theory; McGraw Hill Publication.

[3] Anderson, D.A., Tannehill, J.C. and Pletcher, R.H.; Computational Fluid Mechanics and Heat Transfer.

[4] Principles of Electronic Packaging.

[5] Olsen, A.T. and Shelstad, K.A.; Introduction to Fluid Flow and the Transfer of Heat and Mass. Prentice-Hall.

[6] Chu, C.K.; Computational Fluid Dynamics.

[7] Binder, R.C.; Fluid Mechanics.

[8] Welty, James R., Wicks, Charles E. and Wilson, Robert E.; Fundamentals of Momentum and Mass Transfer. 


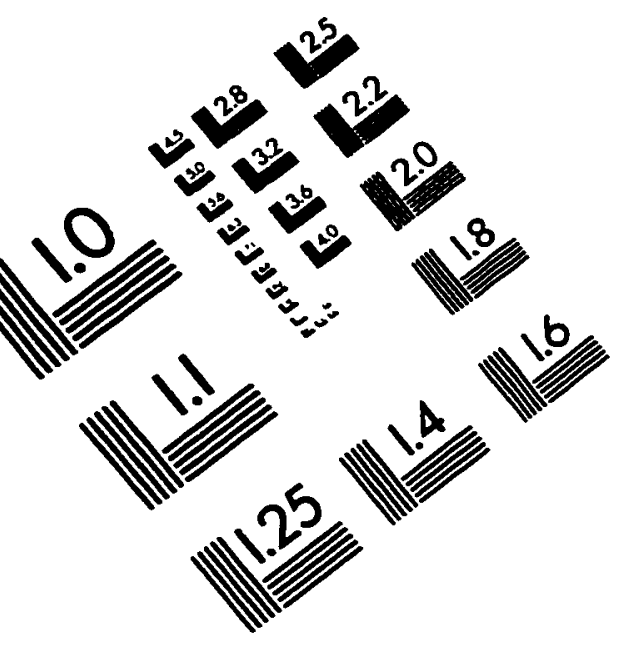

\section{IMAGE EVALUATION \\ TEST TARGET (QA-3)}
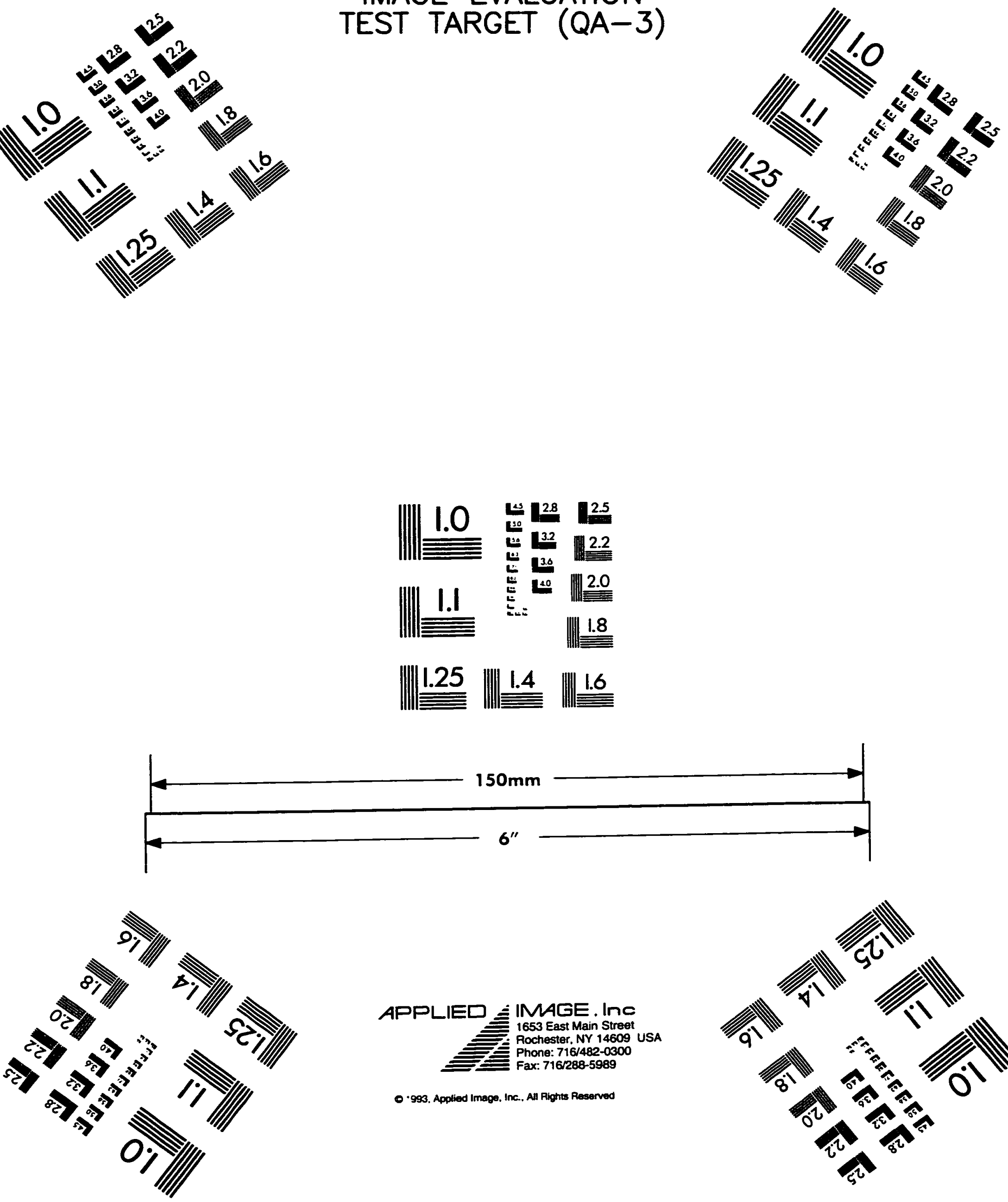

APPLIED ڤIMAGE. InC

1653 East Main Street

Rochester. NY 14609 USA

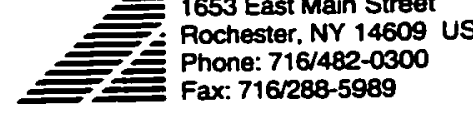

a)

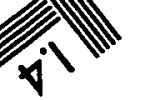

